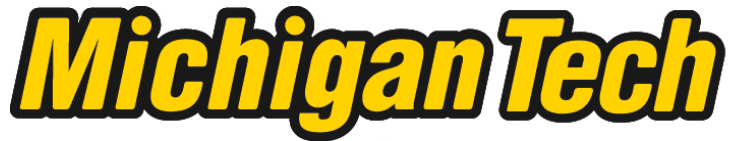 \\ Michigan Technological University Create the Future Digital Commons @ Michigan Tech
}

2015

\section{APPLICATION OF HYDRODYNAMIC MODELS IN SIMULATING THE THERMAL REGIME OF LAKE SUPERIOR}

Rasika K. Gawde

Michigan Technological University

Follow this and additional works at: https://digitalcommons.mtu.edu/etds

Part of the Environmental Engineering Commons

Copyright 2015 Rasika K. Gawde

\section{Recommended Citation}

Gawde, Rasika K., "APPLICATION OF HYDRODYNAMIC MODELS IN SIMULATING THE THERMAL REGIME OF LAKE SUPERIOR", Dissertation, Michigan Technological University, 2015.

https://doi.org/10.37099/mtu.dc.etds/1009

Follow this and additional works at: https://digitalcommons.mtu.edu/etds

3 Part of the Environmental Engineering Commons 


\title{
APPLICATION OF HYDRODYNAMIC MODELS IN SIMULATING THE THERMAL REGIME OF LAKE SUPERIOR
}

\author{
By \\ Rasika K. Gawde
}

A DISSERTATION

Submitted in partial fulfillment of the requirements for the degree of DOCTOR OF PHILOSOPHY

In Environmental Engineering

MICHIGAN TECHNOLOGICAL UNIVERSITY

2015

(C) 2015 Rasika K. Gawde 
This dissertation has been approved in partial fulfillment of the requirements for the Degree of DOCTOR OF PHILOSOPHY in Environmental Engineering.

Department of Civil and Environmental Engineering

Dissertation Advisor: Dr. Martin T. Auer

Committee Member: Dr. Nancy A. Auer

Committee Member: Dr. Noel R. Urban

Committee Member: Dr. Joseph F. Atkinson

Department Chair: Dr. David W. Hand 
To my parents,

Mr. Kishor Gawde \& Mrs. Ketki Gawde and my brother, Saurabh Gawde 


\section{Table of Contents}

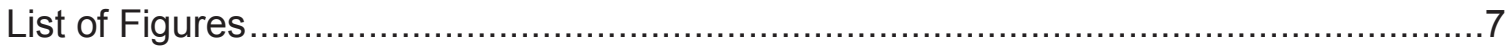

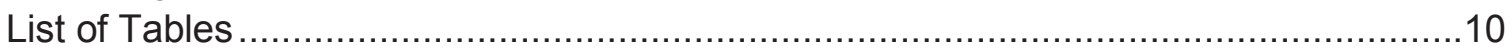

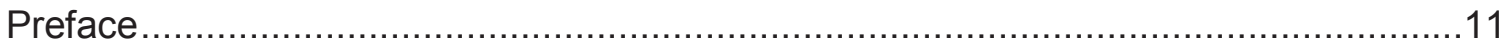

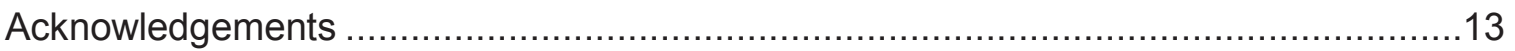

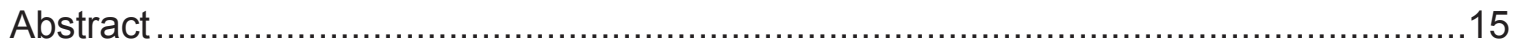

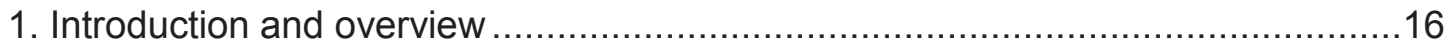

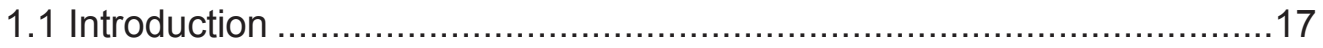

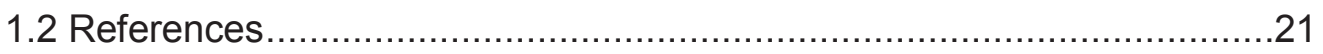

2. Calibration and confirmation of a three-dimensional hydrodynamic framework for Lake Superior: evaluating model performance using an ecologically-meaningful

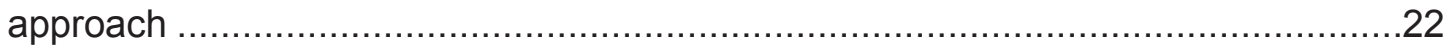

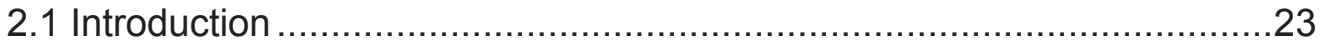

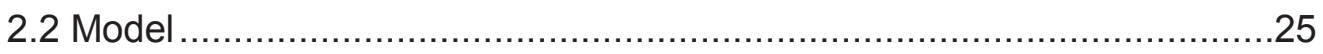

2.2.1 Hydrodynamic model configuration .......................................25

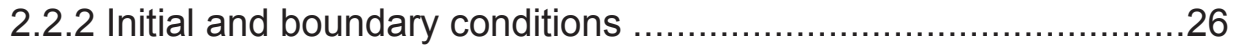

2.2.3 Meteorological forcing conditions ............................................27

2.3 Field measurements and site description ........................................29

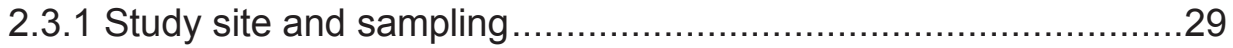

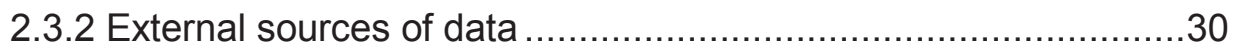

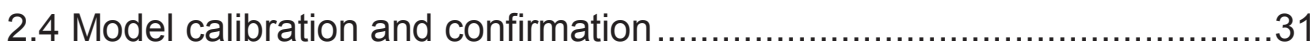

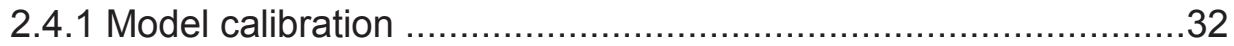

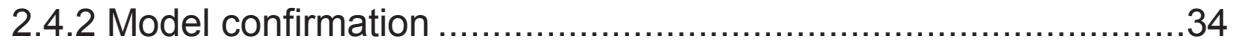

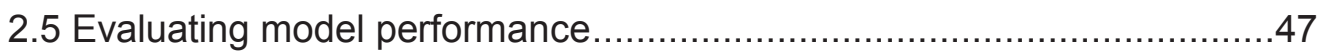

2.5.1 Performance in relation to thermal regime ................................47

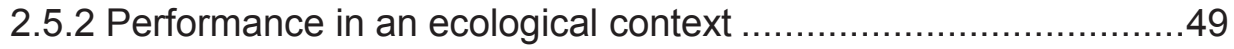

2.5.2.1 Sensitivity analysis ....................................................

2.5.2.2 Application to Lake Superior ........................................56

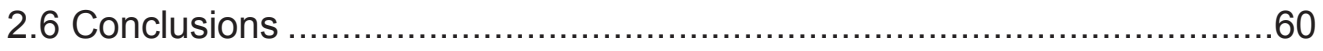

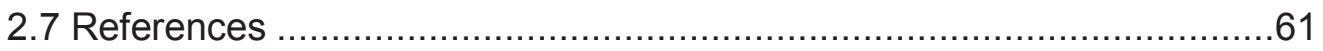

3. Introducing a mechanistic, one-dimensional n-layer hydrodynamic model with

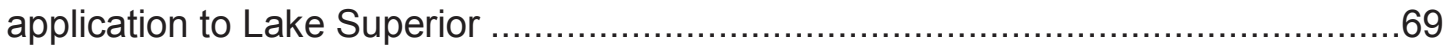

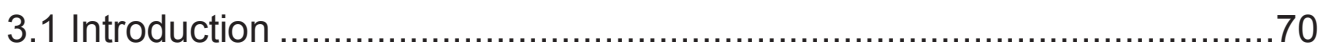

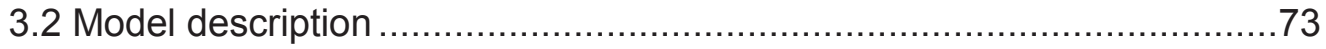

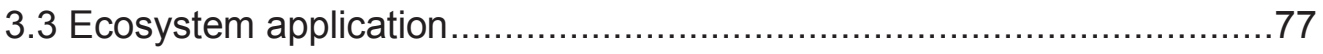

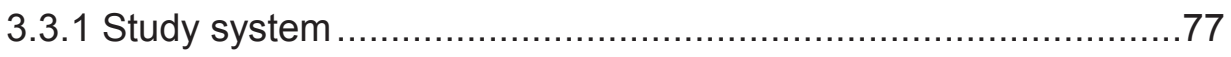




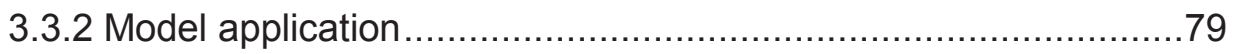

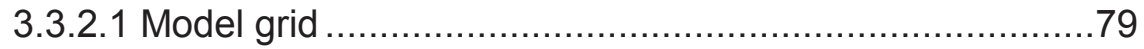

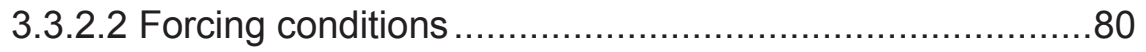

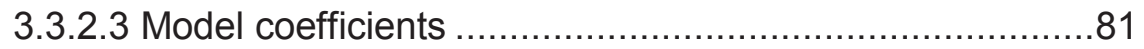

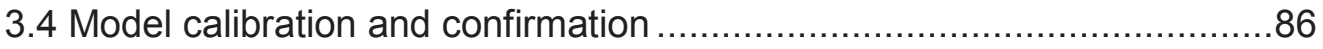

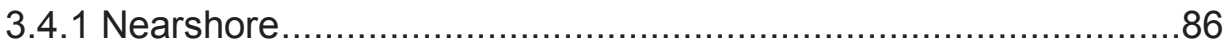

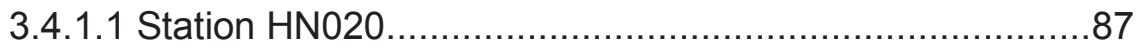

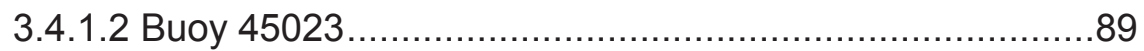

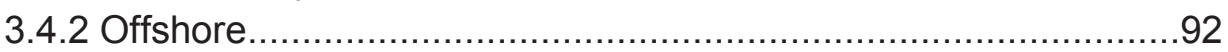

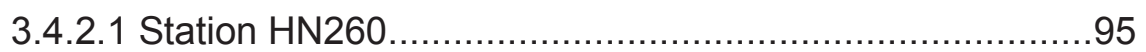

3.4.2.2 EPA stations: SU12, SU14 and SU16 …….................97

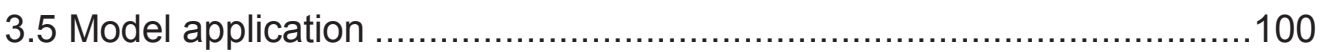

3.5.1 Comparing the predictive capacity of $1 \mathrm{D}$ and 3D models ..........100

3.5.2 Modeling vertical mixing on a temporal scale ...........................104

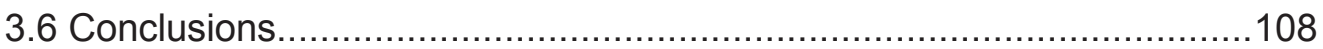

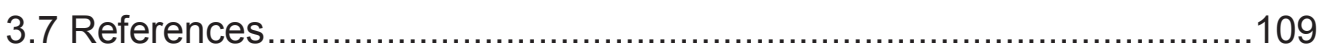

4. Modeling the impact of climatic 'bookend' years on the thermal regime of Lake

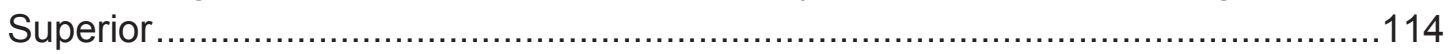

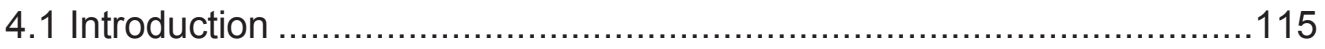

4.2 Climatic conditions and monitoring .............................................117

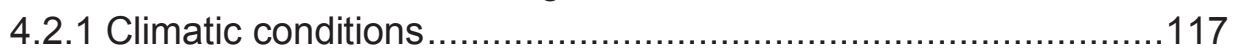

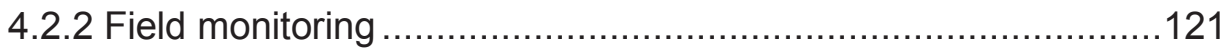

4.3 Model description, inputs and specifications ....................................123

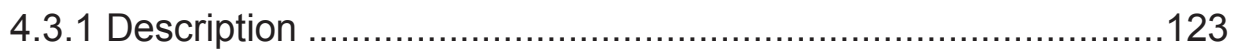

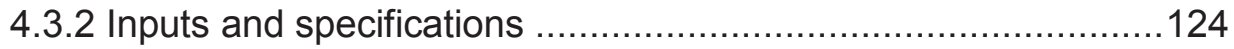

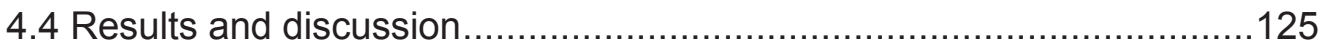

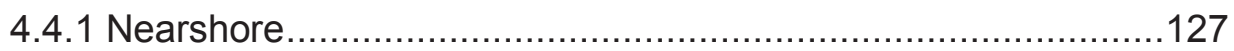

4.4.1.1 Characteristics of the thermal regime in 2011 (average

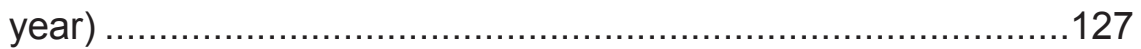

4.4.1.2 Surface water temperatures and rate of warming in 2012

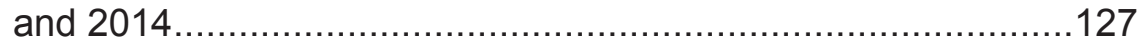

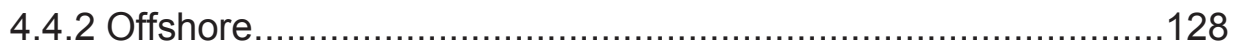

4.4.2.1 Characteristics of the thermal regime in 2011 (average

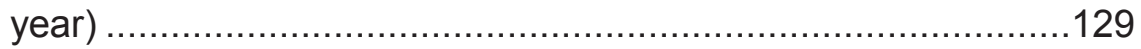

4.4.2.2 Surface water temperatures and rate of warming in 2012

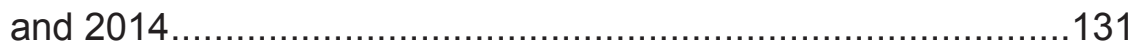

4.4.2.3 Thermal characteristics during the stratified period in 2012

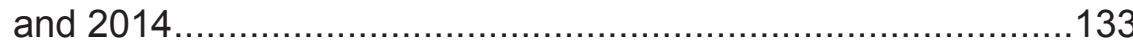

4.5 Mixing and the thermal regime in an ecological context.....................133

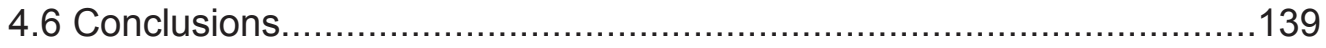

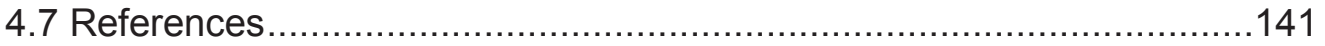




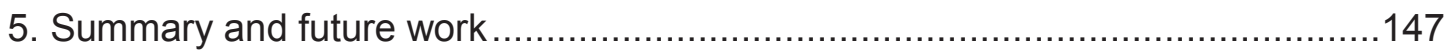

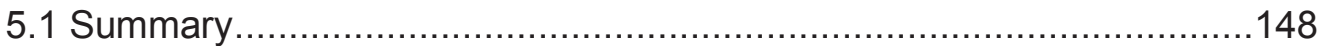

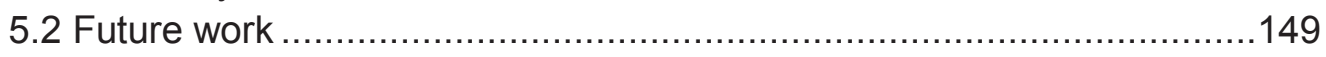

5.3 References..................................................................... 150

Appendix: Copyright Permission Documentation .............................................. 151 


\section{List of Figures}

Figure 2.1. EFDC model grid established over the western basin of Lake Superior .......28

Figure 2.2. Sampling locations in western Lake Superior 31

Figure 2.3. Comparison of surface water temperatures along the $\mathrm{HN}$ transect in Lake Superior. 37

Figure 2.4. Comparison of vertical temperature profiles at (a) HN020 (b) HN090 and (c) HN210 in Lake Superior for the May-September period of 2011 38

Figure 2.5. Time series of surface temperatures at (a) Buoy 45006 (b) Buoy 45023 and (c) Buoy 45027 in Lake Superior for the May-September period of 2011. 39

Figure 2.6. Comparison of vertical profiles of temperature at the nine EPA stations (SU11-19) in Lake Superior in (a) April and (b) August of 2011 40

Figure 2.7. Comparison of RMSE values calculated at the three HN stations, the three meteorological buoys and the EPA stations for 2011 41

Figure 2.8. Comparison of surface water temperatures along the HN transect in Lake Superior.

Figure 2.9. Comparison of vertical temperature profiles at (a) HN020 (b) HN090 and (c) HN210 in Lake Superior for the April-September period of 2012

Figure 2.10. Time series of surface temperatures at (a) Buoy 45006 (b) Buoy 45023 and (c) Buoy 45027 in Lake Superior for the April-September period of 2012

Figure 2.11. Comparison of vertical profiles of temperature at the nine EPA stations (SU11-19) in Lake Superior in (a) April and (b) August of 2012.

Figure 2.12. Comparison of RMSE values calculated at the three HN stations, the three meteorological buoys and the EPA stations for 2012.

Figure 2.13. Measured and modeled vertical temperature profiles during (a) mixed (b) transitional and (c) stratified periods

Figure 2.14. Comparing the RMSE value calculated for the synthetic temperature profiles to the corresponding percentage error obtained in areal primary production for mixed, transitional and stratified periods.

Figure 2.15. Temperature attenuation functions adopted in the primary production model

Figure 2.16. Comparison of the areal primary production, measured vs. EFDC model based temperature profiles at (a) HN040 and (b) HN260 in Lake Superior for 2011 and 2012

Figure 2.17. Comparison of measured and modeled vertical temperature profiles corresponding to the eight points that degrade the goodness-of-fit between areal primary production estimates derived from measured and modeled temperatures .59 
Figure 3.1. Western basin of Lake Superior with the Houghton North (HN) transect and the locations of three EPA sampling stations and the meteorological buoy $45023 \ldots \ldots . . .79$

Figure 3.2. Temporal trends captured in measurements at the (a) HN020 and (b) HN260 stations in Lake Superior over the May to October period of 2011

Figure 3.3. Vertical temperatures profiles serving as initial conditions at (a) HN020 (b) Buoy 45023 (c) HN260 (d) SU12 (e) SU14 and (f) SU16 study sites in Lake Superior in 2011.

Figure 3.4. Comparison of the measured and modeled temperature profiles at the

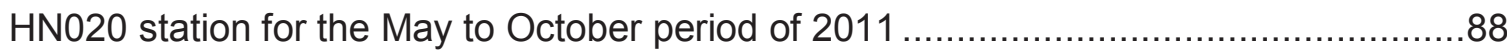

Figure 3.5. Time series of wind direction at the HN020 station ..............................90

Figure 3.6. Comparison of the measured and modeled temperature profiles at Buoy

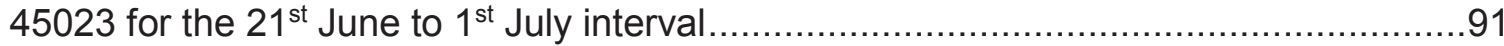

Figure 3.7. Comparison of the measured and modeled temperature profiles at Buoy 45023 for the $29^{\text {th }}$ August to $8^{\text {th }}$ September interval .93

Figure 3.8. Comparison of the measured and modeled temperature profiles at Buoy 45023 for the $9^{\text {th }}$ to $18^{\text {th }}$ September interval

Figure 3.9. Comparison of the measured and modeled temperature profiles at the HN260 station for the May to October interval ....................................................

Figure 3.10. Vertical temperature profiles at the three U.S. EPA stations .99

Figure 3.11. Comparison of the measured, UFILS4 predicted and EFDC predicted temperature profiles at station HN020 for the May to September interval of $2011 \ldots . . .103$

Figure 3.12. Comparison of the measured, UFILS4 predicted and EFDC predicted temperature profiles at station HN260 for the May to September interval of $2011 \ldots \ldots .105$

Figure 3.13. Seasonal trend in vertical mixing coefficients $\left(\mathrm{m}^{2} \cdot \mathrm{d}^{-1}\right)$ at the HN260 station for the April to October interval of 2011 107

Figure 4.1. Ice cover on Lake Superior during the winter of 2011 - 2012 and 2013 2014 118

Figure 4.2. Air temperature anomaly of March 2012 119

Figure 4.3. Deviation from decadal average in air temperature surrounding the Great Lakes basin over the December 2013 to February 2014 interval .....

Figure 4.4. The Keweenaw Peninsula with an inset identifying the 11 sampling stations along the Houghton North (HN) transect. 122

Figure 4.5. Vertical temperatures profiles serving as initial conditions at HN020 for the (a) 2012 and (b) 2014 simulations and at HN260 for the (c) 2012 and (d) 2014 simulations 126

Figure 4.6. Surface water temperatures at the HN020 station in Lake Superior. 129 
Figure 4.7. Surface water temperatures at the HN260 station in Lake Superior ...........132

Figure 4.8. Temporal trends in measured vertical temperature profiles at the HN260 station for the April to October period in (a) 2011, (b) 2012 and (c) $2014 \ldots \ldots \ldots \ldots \ldots \ldots . . . . .135$

Figure 4.9. Seasonal trend in vertical mixing coefficients $\left(\mathrm{m}^{2} \cdot \mathrm{d}^{-1}\right)$ at the HN260 station in

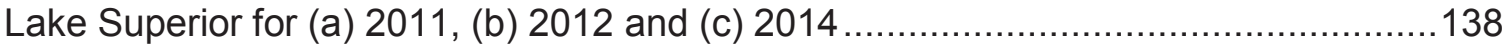




\section{List of Tables}

Table 3.1. Summary of model characteristics for all the nearshore and offshore 'model

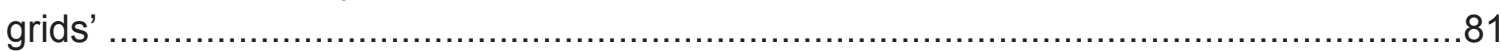

Table 3.2. Calibration coefficients determined for the nearshore and offshore region ....83

Table 4.1. Summary of the differing meteorological forcing conditions in the average year (2011) and the two 'bookend' years (2012 and 2014) ....................................121 


\section{Preface}

My doctoral research and dissertation is directed towards making a significant contribution to the field of water-quality modeling with a particular focus on application of hydrodynamic frameworks in addressing environmental concerns in freshwater systems. In this dissertation, chapters 2, 3 and 4 have been developed as independent publications for submission to the peer-reviewed literature. These represent products of collaborative research, details of which are provided below.

Chapter 2 addresses calibration and confirmation of a three-dimensional model, Environmental Fluids Dynamic Code (EFDC) that I conducted to support the hydrodynamic component of the EPA Great Lakes Research Initiative (GLRI) project (GL-00E00560/0) awarded to Drs. N.A. Auer and M.T. Auer. Temperature measurements used in Figures 2.3, 2.4, 2.8, 2.9, 2.17a and b were collected aboard the research vessel, the $R / V$ Agassiz, to support this GLRI project with the assistance of Captain Stephen Roblee and my colleague Marcel L. Dijkstra (a fellow doctoral student). The concept of a new application-oriented criterion for evaluating the performance of hydrodynamic models used in coupled frameworks, discussed by me, my advisor Dr. M.T. Auer and Marcel, was introduced in this chapter. Figures 2.14 and 2.16, added to support establishment of this criterion, were developed by me using calculations performed by Marcel with the help of his primary production model. Also, data to support Figure 2.15 was obtained from Chapter 2 of Marcel's dissertation with his approval. The entire Chapter 2 was written by me and was reviewed by Dr. M.T. Auer.

Chapter 3 introduces the application of a one-dimensional hydrodynamic model to large lake ecosystems (like Lake Superior). This model was developed by our collaborator, Emmet M. Owens, P.E., Section Chief, Water Quality Modeling at the New York City Department of Environmental Protection, Kingston, NY. Emmet also wrote 
Section 3.2 of Chapter 3 in this dissertation to describe the model formulation. In this study, I collected the meteorological forcings, formatted model inputs as per requirements, accessed temperature measurements, performed the calibration and confirmation procedures at the nearshore and offshore regions of Lake Superior and evaluated the quality of model output by comparison with a 3D hydrodynamic tool. Excepting Section 3.2, Chapter 3 was written by me. My advisor, Dr. M.T. Auer, offered feedback on the results of model calibration and confirmation, provided guidance for the comparison of model output from 1D and 3D frameworks and reviewed my writing in this chapter.

Chapter 4 focuses on identifying the differences in thermal structure in the nearshore and offshore regions resulting from the divergent meteorological forcing conditions of two 'bookend' years, 2012 and 2014. The two figures, Figure 4.2 and 4.3, obtained from published material, were referenced appropriately and used with permission (see Appendix). As mentioned earlier, the temperature dataset used for analysis in Figures 4.6, 4.7 and 4.8 was collected in support of the GLRI project on board the R/V Agassiz by Marcel with the help of Captain Stephen Roblee. The model, developed and described (in Section 3.2) by Emmet was adopted for this study too. In addition to writing the entire Chapter 4, my contribution to this chapter focused on collecting the necessary model inputs, analyzing the temperature measurements, conducting simulations using the 1D model and evaluating the inter-annual variability in mixing conditions and thermal regime for the two years. My advisor, Dr. M.T. Auer, wrote the first paragraph in Section 4.5, reviewed the results of the temperature analysis and model simulations and guided me in my writing by proof-reading this chapter. 


\section{Acknowledgements}

"Sometimes it's the journey that teaches you a lot about your destination."

This phrase, delivered by the famous Toronto hip-hop artist Drake at a high school commencement speech, reverberates within me as I look back on the greatest journey I have undertaken to date, the record of which has been documented in this dissertation. Many people have helped bring this dissertation to completion and it is and will always be a pleasure to thank each and every one of them.

First and foremost, I would like to sincerely thank Dr. Martin T. Auer, professor, mentor and dissertation advisor extraordinaire, for his help, encouragement and counsel, unstintingly given through the entire process of earning my doctorate degree. A special debt of gratitude is also owed to my dissertation committee members, Dr. Nancy A. Auer, Dr. Noel R. Urban and Dr. Joseph F. Atkinson, who have taken particular interest in my research and have provided valuable insights, feedback and guidance towards its completion.

I would like to acknowledge the Environmental Protection Agency (EPA) Great Lakes Restoration Initiative (GLRI) grant GL-00E00560/0 for funding this project. I would also like to extend my acknowledgements to the Great Lakes Observing System (GLOS) for providing financial assistance for this research. It would be very remiss of me to not mention and thank Ed Verhamme at LimnoTech Inc. for help and support with the EFDC model, Gregory Lang at NOAA GLERL for providing meteorological forcing conditions from the NCEP NARR model and Emmet M. Owens at the New York City Department of Environmental Protection for providing help with the UFILS4 model.

I also want to take this opportunity to thank Marcel L. Dijkstra, my friend and colleague, for always listening and giving me words of encouragement. My heart-felt thanks to Anika Kuczynski, Nathan Zgnilec and all of my friends at Michigan Tech who 
have helped me survive the stress from these past few years through their support and care and have kept me focused on my doctoral studies. Their friendship has made my graduate experience at Tech a memorable one that I will cherish forever.

Most importantly, this journey would not have been possible without the generous support and understanding of my family. My parents and my brother, to whom this dissertation is dedicated, have always encouraged me in my pursuit of education, dreams and happiness. Their never-ending emotional support has been my strength throughout this endeavor, inspiring me to attain greater heights of success. A debt of eternal thanks is owed to my parents and my brother, Saurabh for their continuous love, care and support. I am also extremely grateful for the encouragement and support of my extended family, Drs. Ashok \& Usha Salvi, Mr. Krishna Padwal and Mr. \& Mrs. Vijayaraghavan, and greatly appreciate their confidence in me. And last but definitely not the least, I am deeply grateful for the enthusiasm, patience and encouragement of Saagar Vijayaragavan, whose love and unfailing support have made all the difference in my life. 


\section{Abstract}

In large systems, such as the Great Lakes and coastal oceans, physical processes have a significant influence on chemical and biological phenomena. Hydrodynamic modeling assists in describing these physical characteristics and in recent years, these models have been extensively applied in the Great Lakes basin to study the response of the lake ecosystem to long-term meteorological forcing conditions. Due to its role in mediating physical, biological and chemical processes in lake environments, water temperature (and the attendant thermal regime) has been the parameter of interest in many of these mathematical modeling studies and was adopted as the primary metric for this research. Owing to its pristine waters and relatively undisturbed (lowest-urban-impact) watershed, Lake Superior, the largest, deepest and northernmost of the Great Lakes, was selected as the study site for this doctoral work.

This study first describes the calibration and confirmation procedure for a threedimensional (3D) hydrodynamic model developed for the western basin of Lake Superior, with an emphasis on evaluating model performance using a multi-criteria approach, and the introduction of a new goodness-of-fit criterion that finds applicability in an ecological context. The following segment introduces a one-dimensional (1D) hydrodynamic framework, adapted to explore spatio-temporal patterns in thermal stratification in Lake Superior (large lakes), supporting the development of coupled 1D frameworks to provide a computationally efficient and accurate approach to parameterize and test complex 3D ecosystem models. This 1D hydrodynamic model was further applied, in conjunction with field measurements of water temperature, to identify differences in the response of the thermal regime of Lake Superior in the nearshore and offshore regions to the divergent forcing conditions in the unusually warm year (2012) and the extreme cold year (2014). 


\section{Chapter 1}

\section{Introduction and Overview}




\subsection{Introduction}

As a doctoral student in environmental engineering, I have found myself attracted to the science of modeling, which offers the capacity to predict the response of a system subject to known or specified drivers in cases where determining the behavior of the system is impractical or impossible through experimentation. This interest parallels developments in the field of water-quality modeling where fate and transport of environmental constituents in freshwater and marine ecosystems are tracked by coupling two or more models. This enthusiasm for application of numerical models was nurtured and strengthened in pursuit of my doctorate at Michigan Technological University.

My doctoral research was supported by the Great Lakes Restoration Initiative (GLRI) grant (GL-00E00560/0) jointly awarded to Dr. N.A. Auer (Project Director and Principal Investigator) and Dr. M.T. Auer (Co-Principal Investigator). The overall goal of this interdisciplinary project was to develop a linked hydrodynamic-water-qualitybioenergetics model to predict the response of the Lake Superior ecosystem to changes in climate, variation in nutrient loading and alteration of the food web. My particular interest focused on the hydrodynamic component of this modeling tool.

First, I tackled a three-dimensional (3D) hydrodynamic model, Environmental Fluids Dynamics Code (EFDC), to address the requirements of the GLRI project's coupled modeling tool, and there I became interested in certain features of the calibration process. Calibration of models, as described by Chapra (1997), "consists of varying the model parameters to obtain an optimal agreement between the model calculations and the data set". The 'goodness' of this optimal fit is typically evaluated using quantitative methods including Root Mean Square Error (RMSE) and Correlation 
Coefficients (CC). Most of the hydrodynamic modeling studies in the Great Lakes adopt these quantitative criteria to establish good model performance. While these criteria are satisfactory to establish the necessary credibility and reliability in model performance, they provide arbitrary levels of acceptance and fail to accommodate model uncertainty in terms of characteristics of the system being modeled. Therefore, this approach, while appropriate for evaluating the performance of stand-alone hydrodynamic models, faces limitations when applied to coupled frameworks tracking the fate and transport of environmental constituents. Chapter 2 of this dissertation, therefore, introduces an application-oriented criterion that relates the error in the physical modeling component to a corresponding uncertainty in the ecological functions. This work supports and encourages wide-spread application of linked hydrodynamic-ecosystem modeling frameworks by providing the means for evaluating model performance using an ecologically-meaningful criterion.

In working with 3D models, certain shortfalls or challenges became apparent, most notably the resource intensive nature of these frameworks. The high computational cost (in terms of time required to complete a simulation) associated with these modeling frameworks, due to their inherent complexity, prevents a thorough calibration through iterative evaluation of model parameters. This is especially observed in working with coupled frameworks where calibration of complex 3D models describing ecosystem dynamics necessitates accurate parameterization of dozens of coefficients. It is, therefore, unrealistic and impractical to pursue an effective multi-coefficient calibration effort using the complex $3 D$ models when the computational time for completing a single simulation could require multiple days. A simple but computationally-efficient one-dimensional (1D) coupled hydrodynamic-ecosystem framework offers an expedient solution by providing a test-bed approach that allows for 
a quick, comprehensive and iterative evaluation of model coefficients that can then be extended for application in the more complex 3D tools (McDonald et al. 2012). Chapter 3 of this dissertation introduces a 1D hydrodynamic model, UFILS4, which represents the physical component of a coupled framework developed to investigate fate and transport of variables of importance in determining water-quality in large lake ecosystems. This 1D model was then calibrated and confirmed for the nearshore and offshore regions of Lake Superior using temperature measurements from field sampling supported by the EPA GLRI grant (GL-00E00560/0) and those obtained from external sources. After developing and confirming this tool, I set about comparing the capabilities of the $1 \mathrm{D}$ and 3D frameworks in modeling the thermal regime of Lake Superior. Results suggest that the two models are comparable in their ability to capture the rate of warming of the water column in the nearshore but the $1 \mathrm{D}$ model performance in resolving the vertical structure of a stratified water column in the offshore is better than that of the 3D model. Therefore, having established the credibility and reliability of the UFILS4 model for large lake application, this body of work contributes to the field of water-quality by providing a method of evaluating 3D model kinetics in large lakes using a 1D framework with the UFILS4 model applied in conjunction with an ecosystem model.

While the work supporting these two studies was proceeding, an opportunity evolved to use a modeling framework to examine and evaluate two climate anomalies that impacted the Great Lakes basin in rapid succession: the climatic 'bookend' years the unusually warm 2012 season ('Big Heat') and the extreme cold of 2014 ('Big Chill'). In Chapter 4, the 1D hydrodynamic model, UFILS4, is applied for the April to October period of 2012 and 2014, to characterize the thermal regime of Lake Superior resulting from differences in annual meteorological forcing conditions. This modeling effort is supported by a rich, comprehensive dataset of surface water temperatures and vertical 
temperature profiles collected as part of a collaborative effort supported by the EPA GLRI grant (GL-00E00560/0) in 2012 and 2014. Impacts of these extreme climatic events were observed along temporal and spatial scales of the thermal regime; e.g., an early onset (by 4 weeks) and longer duration (>136 days) of thermal stratification, elevated water surface temperatures (by $5-8^{\circ} \mathrm{C}$ ) and depth of the upper mixed layer (by $>5 \mathrm{~m}$ ) were observed in 2012 while the summer of 2014 was characterized by delayed onset of stratification (by 3 weeks), shorter length of the stratified period ( 104 days), reduced basin-wide surface temperatures (by $3-5^{\circ} \mathrm{C}$ ) and a shallower thermocline (by $<5 m$ ). Attempts to model outcomes of climatic variations in the Great Lakes basin have generated disparate projections of thermal structure and attendant responses by primary producers (Brooks and Zastrow 2002, Lehman 2002). Therefore, this characterization of the thermal regime for the two 'bookend' years, using temperature measurements and through application of a mathematical model, offers insights regarding the potential response of the lake to long-term climate.

This scholarly journey that I undertook at Michigan Tech has helped me grow, both as a researcher and an individual. It has provided me with the opportunity to contribute to the existing body of knowledge in the field of water-quality modeling and prepared me to practice my profession as a research scientist. As I begin my professional career in earnest, I will continue applying myself in the hopes that one day, I will be able to make a significant contribution to the world, knowing that Michigan Tech was instrumental in my success. 


\subsection{References}

Brooks, A. S., and Zastrow, J. C. (2002). "The potential influence of climate change on offshore primary production in Lake Michigan." Journal of Great Lakes Research, 28(4), 597-607.

Chapra, S. C. (1997). Surface water-quality modeling. McGraw-Hill New York.

Lehman, J. T. (2002). "Mixing patterns and plankton biomass of the St. Lawrence Great Lakes under climate change scenarios." Journal of Great Lakes Research, 28(4), 583-596.

McDonald, C. P., Bennington, V., Urban, N. R., and McKinley, G. A. (2012). “1-D testbed calibration of a 3-D Lake Superior biogeochemical model." Ecological Modelling, 225, 115-126. 


\section{Chapter 2}

Calibration and confirmation of a three-dimensional hydrodynamic framework for Lake Superior: evaluating model performance using an ecologically-meaningful approach 


\subsection{Introduction}

In large systems, like the Great Lakes and coastal oceans, physical processes have a significant influence on chemical and biological phenomena (Lam and Halfon 1978, Simons 1976, Boyce 1974). Distribution of heat, nutrients, toxicants and suspended solids (either offshore, parallel to shore or vertically in the water column) is regulated through advective and dispersive processes in the lake. For example, limited offshore transport, resulting from the presence of a thermal bar (Auer and Gatzke 2004, Ullman et al. 1998) is one of the causal processes associated with nutrient enrichment of the nearshore, a chemical phenomenon that has been observed and confirmed in multiple locations in the Great Lakes (Auer and Gatzke 2004, Moll et al. 1993, Spain et al. 1976). Subsequent nearshore-offshore transport of nutrients, together with appropriate depositional environments, also contributes to a peak in biomass of macrobenthos such as Diporeia i.e., the "Ring of Fire" paradigm observed in Lake Superior (Auer et al. 2013). Along-shore transport of coliform bacteria and other contaminants presents a risk to human health and is responsible for beach closings due to fecal pollution (Liu et al. 2006). Vertically, development of the deep chlorophyll maximum (DCM), a biological signal in the Great Lakes (White and Matsumoto 2012, Sterner 2010, Barbiero and Tuchman 2001) is influenced by mixing gradients.

The role of transport in mediating the fate of environmental constituents has long been recognized in the peer-reviewed literature (Scavia and Bennett 1980, Simons 1976, Boyce 1974), spurring the development and testing of tools in support of management decision-making. Over the last few decades, there has been a marked advancement in mathematical modeling, aided considerably by the evolution and availability of computer technology. This progression from simple numerical solutions to computationally advanced model frameworks has prompted researchers to integrate 
physical and biochemical processes to develop a more comprehensive approach to understanding ecosystem dynamics. In recent years, these linked models have been applied in a predictive capacity to all the Great Lakes (Lake Superior - White et al. 2012; Lake Michigan - Beletsky et al. 2007, Liu et al. 2006; Lake Erie - Bocaniov et al. 2014, Leon et al. 2011, Schwab et al. 2009; Lake Ontario - Leon et al. 2012). In these coupled frameworks, hydrodynamic modeling assists in characterizing physical processes, specifically diffusive transport and circulation patterns, and their impact on the ecosystem.

The step-wise procedure inherent to the modeling process calls for calibration and confirmation of the model prior to its application. The output derived from hydrodynamic models includes components amenable to direct measurement (water temperature - Beletsky et al. 2013, Atkinson et al. 2012, Rao et al. 2009; current magnitude and direction - Bai et al. 2013, Zhao et al. 2012, Chen et al. 2001; lake levels - Nyugen et al. 2014, Gronewold et al. 2011) and others that are derived and not measurable (horizontal and vertical mixing coefficients). However, it should be recognized that the verifiable phenomena, including the thermal regime and current patterns in the lake, are dictated by these unmeasurable mixing coefficients. Therefore, the mixing parameters are verified, albeit in a secondary context, through a direct [observed - predicted] comparison of the measurable components.

However, while calibration and confirmation establish confidence in a model, the procedures involved in accomplishing these tasks raise questions about model credibility. Foremost among these questions is the stringency of criteria extended to the calibration process. Traditionally, quantitative methods (e.g. Root Mean Square Error, RMSE; Maximum Error; Correlation Coefficient, CC) have been deemed appropriate to determine the quality of output from a hydrodynamic model (Nyugen et al. 2014, Liu et 
al. 2008, Schwab and Beletsky 1998). Unfortunately, this approach has turned into a battleground to satisfy the demand for increasingly precise calibration without establishing a clear basis for adopting a particular criterion. In the case of linked models, the quality of performance for the hydrodynamic model is appropriately reflected in its endpoint application. It might, for example, be useful to consider how uncertainty associated with hydrodynamic model output cascades through a linked hydrodynamicwater quality model, so that the ecosystem response, measured and modeled, provides a more meaningful indication of model robustness.

This paper describes calibration and confirmation for a hydrodynamic model developed for the western basin of Lake Superior, with particular attention to the goodness-of-fit concept, and the establishment of an appropriate degree of model credibility and reliability set within an environmentally meaningful management context.

\subsection{Model}

\subsubsection{Hydrodynamic model configuration}

A public domain, open source, three-dimensional hydrodynamic model, Environmental Fluid Dynamics Code (EFDC) (Hamrick 1992), is adopted to support this modeling effort. The mathematical formulation for EFDC is derived from the extensive literature available for ocean circulation models (Semtner 1974, Bryan 1969) and numerical frameworks for lakes, estuaries and coastal oceans (Blumberg and Mellor 1987, Liu and Leenderste 1978, Simons 1974). Continued development and maintenance of EFDC at Tetra Tech, Inc. has included a comprehensive validation incorporating analytical solutions, laboratory experiments and field measurements through wide-spread application to rivers, lakes, estuaries, wetlands, reservoirs and 
coastal ocean regions (Camacho et al. 2015, Liu et al. 2008, Ji et al. 2007, Zou et al. 2006, Wool et al. 2003, Hamrick and Mills 2000).

In this application of EFDC, a graphical user-interface (GUI) based MATLAB program, Seagrid, is used to establish a horizontal model grid over the western basin of Lake Superior. The spatial extent of the model domain is defined by 4153 active cells per layer using curvilinear, orthogonal coordinates. Thirty-one Generalized Vertical Coordinate (GVC) layers delineate vertical partitioning of Lake Superior's bathymetry. Dimensions of grid cells range from $1.8 \mathrm{~km}$ to $8.5 \mathrm{~km}$ in width and $1.2 \mathrm{~km}$ to $3.5 \mathrm{~km}$ length; the finer resolution of the grid is utilized along the Keweenaw Peninsula (Figure 2.1). The model uses a finite volume method to solve three dimensional, time dependent hydrostatic primitive equations (continuity equation, conservation of momentum and conservation of energy) for each grid cell. Vertical mixing coefficients are calculated in EFDC with the level 2.5 turbulence closure scheme developed by Mellor and Yamada (1982) and modified by Galperin et al. (1988).

\subsubsection{Initial and boundary conditions}

The simulations are conducted for the April - September interval for two consecutive years, 2011 and 2012, with defined initial conditions. The model is initialized with water temperature measurements at the start of the ice-free period (1 April) of each year. Boundary conditions quantifying flow rate and temperature, required only for the open eastern edge of the model grid (Figure 2.1), were obtained from the National Oceanic and Atmospheric Administration (NOAA) Great Lakes Coastal Forecasting System (GLCFS) Nowcast model for 2011 and 2012. To account for the difference in horizontal resolution between the GLCFS and EFDC grids, the EFDC grid (with finer resolution) was overlain by the $10 \times 10 \mathrm{~km}$ GLCFS grid to generate averaged flow rates across each of the eastern edge boundary grid cells. GLCFS temperatures 
were similarly distributed along the eastern boundary and applied uniformly to each vertical layer.

\subsubsection{Meteorological forcing conditions}

Forcing conditions applied to the model were obtained from NOAA GLCFS, NOAA National Climatic Data Center (NCDC), National Centers for Environmental Prediction (NCEP) National American Regional Reanalysis (NARR) and U.S. Geological Survey (USGS) databases. Source selection was primarily driven by the availability of site-specific, temporally uninterrupted and spatially consistent meteorological forcing conditions over the ice-free periods of the two years, 2011 and 2012.

Downward shortwave radiation flux and cloud cover, required by EFDC as atmospheric forcing conditions, are obtained from the NCEP NARR (Mesinger et al. 2006) at a single location in Lake Superior $\left(46.4078^{\circ} \mathrm{N}, 87.1093^{\circ} \mathrm{W}\right)$ over the April to September period of 2011 and 2012 in 3-hourly intervals. Taking into consideration the spatial resolution of the NCEP NARR (32 km, Mesinger et al. 2006) and the negligible variation in downward solar flux over the range of latitudes involved, horizontal uniformity was assumed for the two parameters over the grid surface. Air temperature and relative humidity are retrieved from the NOAA NCDC database for station 14858 (Houghton County Airport) and incorporated into the model's atmospheric forcing input file, with the other two parameters, on a 3 hourly basis.

In the initial phase of this research, the model was forced using a single time series of wind speed and wind direction measured at the 45006 buoy (western basin) from the NOAA National Data Buoy Center (NDBC). However, results of a sensitivity analysis pointed to the need for additional wind series to accurately map the effect of wind-induced transport over the model domain. Accordingly, time series of wind speed and direction, obtained from NOAA GLCFS at seven grid cell locations (black filled 
circles in Figure 2.1), were interpolated over the spatial extent of the grid to generate a composite wind map that was applied to subsequent simulations. Further increasing the number of sites for which wind series were developed did not contribute significantly to the result.

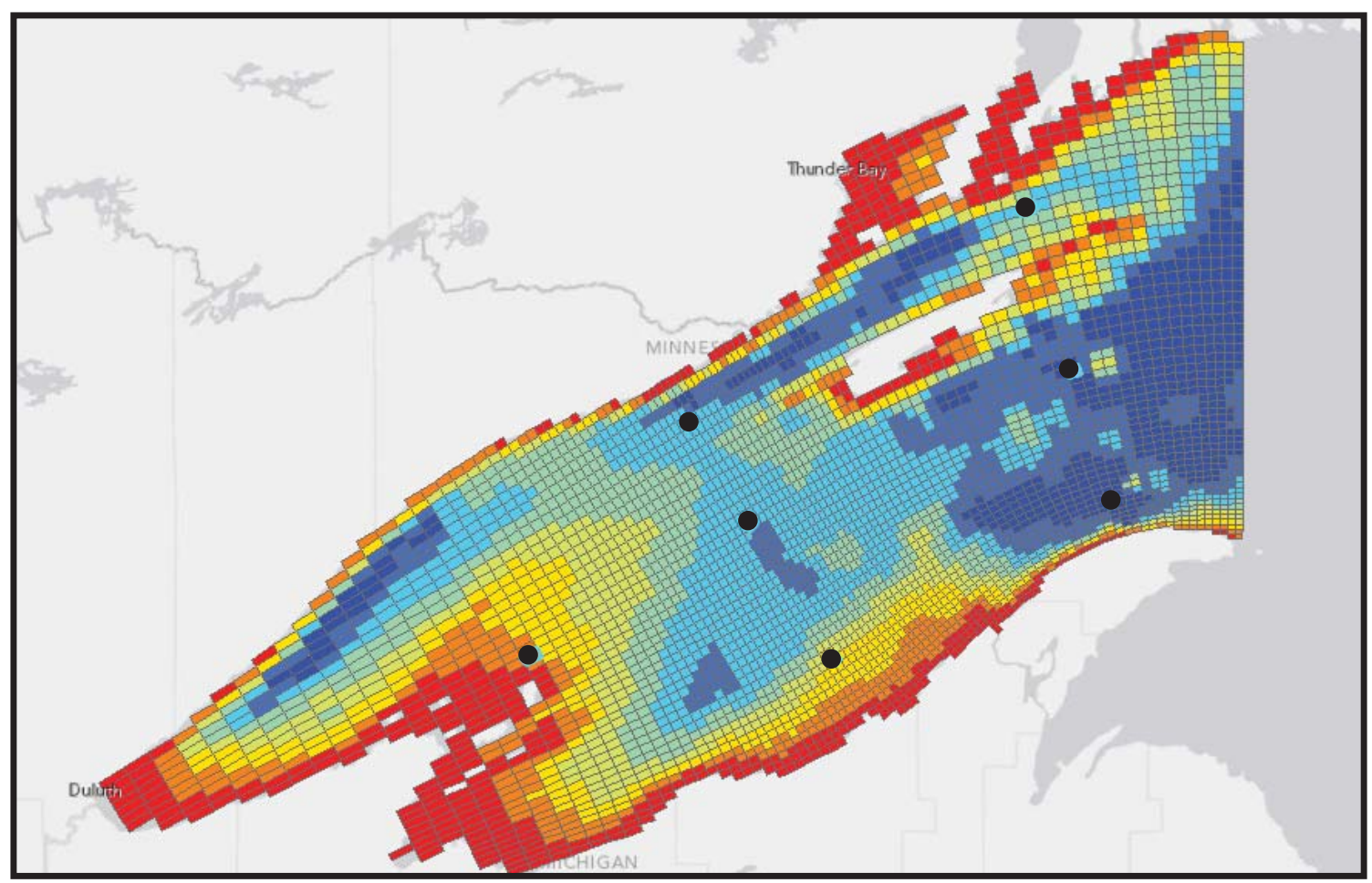

Figure 2.1. EFDC model grid established over the western basin of Lake Superior. The colors represent bathymetry, outlining depths between 0-300 m divided into eight contours (shallow nearshore regions in red and the deepest offshore areas in dark blue). The seven black dots identify the wind series locations.

The EFDC model is configured to include input flows from the Portage Canal (Keweenaw Waterway) and the two largest (as characterized by turbidity and nutrient load) U.S. tributaries, the Ontonagon River, MI and the St. Louis River, MN. While the USGS database provides daily flow rate measurements for the two tributaries for 2011 and 2012, estimating the flow patterns for the North Entry of Portage Canal poses more 
of a challenge (i.e. fluctuations are driven primarily by water levels). Flow rates and water temperature, determined for the Portage Canal at 3 hour intervals over the two years, were therefore retrieved from NOAA GLCFS.

\subsection{Field measurements and site description}

\subsubsection{Study site and sampling}

For this study, sampling efforts focused on the Houghton North (HN) transect (Auer and Kahn 2004) located adjacent to the North Entry of the Keweenaw Waterway on the southern shore of western Lake Superior (Figure 2.2). Extending lakeward, this transect increases in depth from $10 \mathrm{~m}$ at $1 \mathrm{~km}$ off shore to a depth of $183 \mathrm{~m}$ at $26 \mathrm{~km}$ off shore. Eleven stations were selected along this transect, 1, 2, 3, 4, 5, 7, 9, 11, 13, 17, 21 and $26 \mathrm{~km}$ off shore, to encompass the shelf, slope and profundal regions of the lake. In accordance with the bounds established by Auer and Kahn (2004), stations with depths up to $30 \mathrm{~m}$ were included in the shelf region (HN010, HN020, HN030), those with depths ranging between 30 and $110 \mathrm{~m}$ were assigned to the slope region (HN040, HN050, HN070, HN090) and those with depths exceeding $110 \mathrm{~m}$ were considered profundal in nature (HN130, HN170, HN210, HN260). Though these stations were originally categorized based on particle distribution in their respective depositional environments (shelf - sand size particles, slope - mix of sand and silt/clay particles, profundal - sand and sand/silt mixes; Auer et al. 2013), the nature of the three zones resonates with the ecological characteristics addressed in this study. The shallow shelf region, dominated by nearly isothermal profiles through the entire ice-free period, undergoes warming early in the season and is first to attain its maximum surface water temperature. In the profundal region, the water column is slow to warm, experiences a period of stratification and has a lower maximum surface water temperature, reached at 
a date later than that of the slope. The slope represents the transitional area between the other two regions, as it warms rapidly (as at shelf sites), but undergoes thermal stratification (as at profundal sites).

At the $\mathrm{HN}$ transect, a spatio-temporally rigorous field sampling program was conducted over the April to October interval of two years, 2011 and 2012 aboard the $R / V$ Agassiz. This program was designed to capture hydrodynamic features such as thermal bar development, establishment of vertical stratification and dissipation of the stratified system. Accordingly, surface temperatures and vertical temperature profiles were measured at the eleven stations at 2-week intervals over the ice-free period of 2011 and 2012. Vertical temperature profiles were measured using a Conductivity/Temperature/Depth (CTD) profiler (Seabird25 CTD), the depth and temperature probes of which were calibrated by the manufacturer.

\subsubsection{External sources of data}

Additional temperature data were obtained from external sources to augment the data set developed along the $\mathrm{HN}$ transect. Hourly surface temperature data were retrieved from the NOAA NDBC database at the 45027 (near Duluth, MN), 45006 (western basin) and 45023 (Michigan Tech, Portage Canal) buoys (yellow circles, Figure 2.2), for the 2011 and 2012 summer periods. Vertical temperature profiles recorded by the Environmental Protection Agency (EPA) at nine U.S. open-lake stations (SU11, SU12, SU13, SU14, SU15, SU16, SU17M, SU18 and SU19, Figure 2.2) in April and August of the two years were also incorporated in this study. These additional data sources enhance the temporal and spatial variability of the temperature data set and support a more robust calibration and confirmation. 


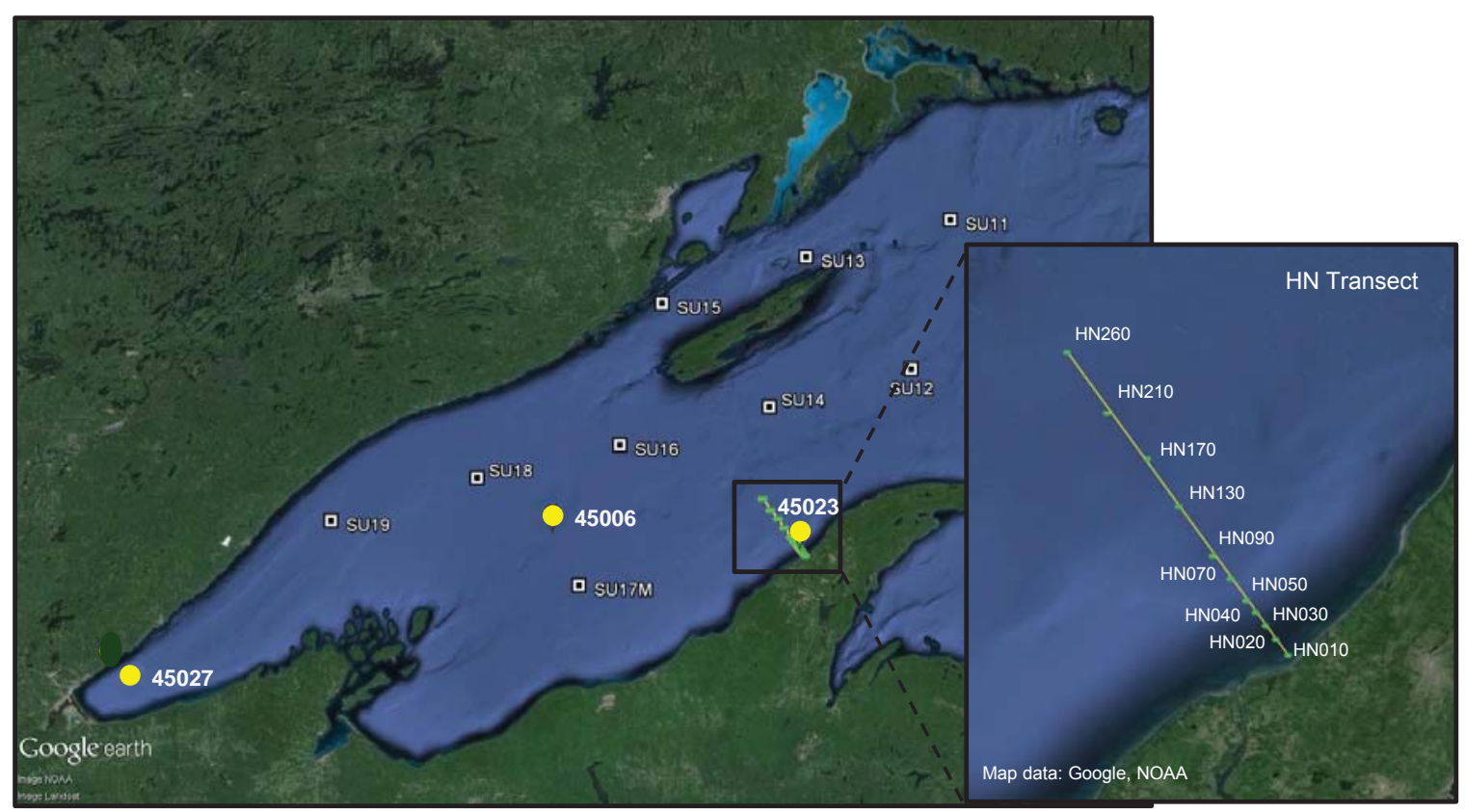

Figure 2.2. Sampling locations in western Lake Superior. The inset shows the Houghton North $(\mathrm{HN})$ transect in detail. The yellow circles show locations of the three surface buoys, two operated by NOAA and one by Michigan Technological University. The white squares outside the inset represent the nine EPA sampling stations. Map data: Google, NOAA, USGS/NASA Landsat Program. (C) 2015 Google Inc, used with permission. Google and the Google logo are registered trademarks of Google Inc.

\subsection{Model calibration and confirmation}

Water temperature, the primary regulator of most chemical and biological processes in lake ecosystems, was used as an indicator throughout this study to track transport of water and energy in the lake. Accordingly, the EFDC hydrodynamic model was calibrated (2011) and confirmed (2012) on a spatial and temporal basis using water temperature as a quantitative index. Root mean square error (RMSE), extensively used in evaluating model performance, is used here as a quantitative metric. Performance of the model was therefore evaluated by comparing RMSE values with those reported in the peer-reviewed literature for the Great Lakes basin $\left(1.69{ }^{\circ} \mathrm{C}\right.$ at buoy $45006,2.12{ }^{\circ} \mathrm{C}$ at buoy 45004 and $1.77{ }^{\circ} \mathrm{C}$ at buoy 45001 (25-year averaged RMSE) in Lake Superior, 
White et al. $2012 ; 3.2^{\circ} \mathrm{C}$ at buoy $45006,3.0^{\circ} \mathrm{C}$ at buoy 45004 and $3.4{ }^{\circ} \mathrm{C}$ at buoy 45001 (28-year averaged RMSE) in Lake Superior, Bennington et al. 2010; $0.95-1.43{ }^{\circ} \mathrm{C}$ in Lake Ontario, Huang et al. $2010 ; 1.039^{\circ} \mathrm{C}$ in Lake Erie, Wang et al. $2010 ; 0.7-2.5^{\circ} \mathrm{C}$ in Lake Michigan, Beletsky and Schwab 2001). An average RMSE value of $1.98{ }^{\circ} \mathrm{C}$ with $95 \%$ confidence intervals of upper and lower bounds of $2.54{ }^{\circ} \mathrm{C}$ and $1.42{ }^{\circ} \mathrm{C}$, respectively, was calculated from these sources as a frame of reference for calibration and confirmation. These metrics form the basis for qualitative characterization (e.g. excellent, good, fair, etc.) of model performance.

\subsubsection{Model calibration}

In calibration, model predictions of water temperatures from the AprilSeptember period of the 2011 simulation run were compared with temperature measurements from the $\mathrm{HN}$ transect field sampling program, buoy measurements and EPA GLENDA stations. Surface temperatures and vertical profiles, obtained on a biweekly basis along the 11-station $\mathrm{HN}$ transect (Figure 2.2), were matched with predicted values at corresponding locations on the model grid. The model performance is good as it satisfactorily captures the warming of the surface waters along this longitudinal profile (extending from the nearshore to the offshore) as the season progresses (Figure 2.3), but does not track the nearshore warming trend observed early in the period (Figure $2.3 \mathrm{a}, \mathrm{b}, \mathrm{c}, \mathrm{d}$ ). Also, comparing the modeled and measured vertical profiles for three sample stations along the HN transect, HN020 (shelf), HN090 (slope) and HN210 (profundal) demonstrates the excellent performance of the model in capturing the rate of warming at the shelf station and the progression from an isothermal water column to a stratified system at the other two zones (Figure 2.4). The thermocline in the measured profile is more sharply defined than the modeled profile, a concern noted in other hydrodynamic modeling studies (White et al. 2012, Huang et al. 2010, Hu 
and Wang 2010, Bennington et al. 2010, Beletsky and Schwab 2001). Along the HN transect, in 2011 , the average RMSE value for surface temperature was $1.38{ }^{\circ} \mathrm{C}$ and ranged between $1.1-2.0{ }^{\circ} \mathrm{C}$ for the vertical profiles $\left(1.1,1.6\right.$ and $1.3{ }^{\circ} \mathrm{C}$ for $\mathrm{HN} 020$, HN090 and HN210 respectively).

The calibration process continues with comparison of modeled surface temperatures with measured hourly temperature data from buoys 45006,45023 and 45027 (Figure 2.2). The EFDC model is able to capture the temporal variability in surface temperatures at the three buoys reasonably well (Figure 2.5), supporting good model performance. At two of the buoys, 45006 and 45027, model temperatures are warmer than those observed early in the season but provide a better fit in the stratified and cooling periods (Figure 2.5a and c), suggesting mis-specification of initial conditions since the error decreases as the season progresses. For the 45027 buoy, its location in the western most region of the model grid reduces the likelihood that conditions there are well represented by (interpolated) western basin meteorological forcings, thereby adding to the uncertainty in model output and yielding a fair performance at that location. The RMSE values at buoys 45006, 45023 and 45027, over the 2011 sampling season, were $2.6,1.6$ and $5.8^{\circ} \mathrm{C}$ respectively.

Model predicted vertical profiles of temperature were also compared to those measured by EPA at nine sampling stations (SU11-19, Figure 2.2), once in April 2011 documenting near-isothermal conditions and later in August 2011 to capture the stratified water column. In April 2011, modeled water temperatures at seven EPA stations (SU17M and SU19 were not sampled) were isothermal and slightly warmer than those measured over the entire water column (Figure 2.6a), potentially an impact of the specified initial conditions. This bias in modeled temperatures decreased over time and the model was able to satisfactorily match the stratified water column August 
temperature profile at all EPA stations (Figure 2.6b), signifying good model performance at these offshore stations. The RMSE values noted for these April and August water column profiles for the nine EPA stations range between $1.3-3.9^{\circ} \mathrm{C}$.

Spatially, the model output temperatures matched the horizontal and vertical thermal structure. Temporal patterns in the water column thermal structure were also reproduced by the model. The RMSE values calculated for the three HN transect stations (circles), the three buoys (diamonds) and the EPA stations (triangles) are evaluated using the average RMSE and 95\% confidence intervals (determined from peer-reviewed Great Lakes literature) as the criteria for good model performance (Figure 2.7). With the exception of Buoy 45027 (westernmost location), the RMSE values determined for this simulation were comparable to or better than those reported in the literature (Figure 2.7) and the EFDC model was deemed calibrated for 2011.

\subsubsection{Model confirmation}

Confirmation of the model proceeded in a similar fashion, i.e. comparing model predicted temperatures from the 2012 simulation with those obtained from the three data sources mentioned in the earlier section for this second year of model application. In keeping with the spirit of confirmation, this 2012 modeling effort is driven by meteorological forcing conditions which are markedly different than those used for calibration. Characterized by the unusually warm winter of 2011-2012 (maximum ice cover $8.5 \%$, NOAA Great Lakes Environmental Research Laboratory (GLERL) Great Lakes Ice Cover data) and an isolated, positive anomaly observed in local air temperature measurements in March (a deviation of $\sim 15{ }^{\circ} \mathrm{C}$ from decadal average extending over the Great Lakes for a period of 2 weeks, Dole et al. 2014), the summer of 2012 presents a particularly appropriate temperature dataset to confirm the EFDC model for Lake Superior. 
Confirmation of the performance of the EFDC model along the $\mathrm{HN}$ transect (Figure 2.2) focused first on surface temperatures. Warming of the surface waters through the summer period at the 11 stations located $1,2,3,4,5,7,9,13,17,21$ and 26 $\mathrm{km}$ offshore was successfully captured by the EFDC framework (Figure 2.8), supporting excellent model performance for this application in Lake Superior. The model tracked the rate of warming in the shelf (HN020, vertical profiles) and the temporal transition from an isothermal water column to an established stratified system at the HN090 and HN210 (Figure 2.9). As mentioned earlier, the modeled thermocline is not as marked as the measured one, a common issue with most 3D hydrodynamic models. Towards the end of the stratified period, the modeled epilimnion (upper mixed layer) temperatures at the HN090 station were slightly lower than those observed resulting in a fair performance of the EFDC model. In 2012, the RMSE value for the HN transect surface temperature was $1.87^{\circ} \mathrm{C}$ and ranged between $1.4-2.5^{\circ} \mathrm{C}$ for the vertical profiles $(2.3$, 1.4 and $2.2^{\circ} \mathrm{C}$ for $\mathrm{HN} 020, \mathrm{HN} 090$ and HN210 respectively).

Next, on a temporal scale, the performance of the EFDC model was good as model-generated surface temperatures compared favorably with hourly measurements recorded by the three NOAA buoys 45006, 45023 and 45027 (Figure 2.10). The fit between modeled and measured temperatures is excellent in the 45006 and 45023 buoy time series plots excepting the slightly warmer surface temperature measurements late in the stratified season (Figure 2.10a and b). The RMSE value at buoys 45006, 45023 and 45027 for 2012 were $2.0,2.2$ and $3.8^{\circ} \mathrm{C}$ respectively.

Vertical profiles of temperature measured in April and August 2012 at the nine EPA stations located in western Lake Superior (SU11-19, Figure 2.2) were also analyzed as part of model confirmation. The model yielded a good performance here as it was successfully able to capture the near isothermal conditions in April at all nine 
stations (Figure 2.11a). In August, the modeled vertical temperature structure matched the stratified water column measurements at each of the EPA stations with some tendency toward slightly lower surface temperatures (Figure 2.11b), representing an overall good performance by the EFDC model. RMSE, calculated at each of the nine stations, ranged between $0.9-2.5^{\circ} \mathrm{C}$.

On a spatial and temporal scale, the EFDC model was able to reproduce transitions in both the shape (vertical structure) and magnitude (warming of the surface waters) of the thermal regime of Lake Superior through the April to September period of 2012. Maintaining the standards for model confirmation identical to those outlined for calibration, the 2012 RMSE values for the three HN stations (circles), the three meteorological buoys (diamonds) and the EPA stations (triangles) compare favorably to the average RMSE values (Figure 2.12) derived from the literature. All the RMSE values, with the exception of Buoy 45027 (westernmost location), were in agreement with the reference value (Figure 2.12) and the EFDC model was therefore confirmed for the 2012 application. 


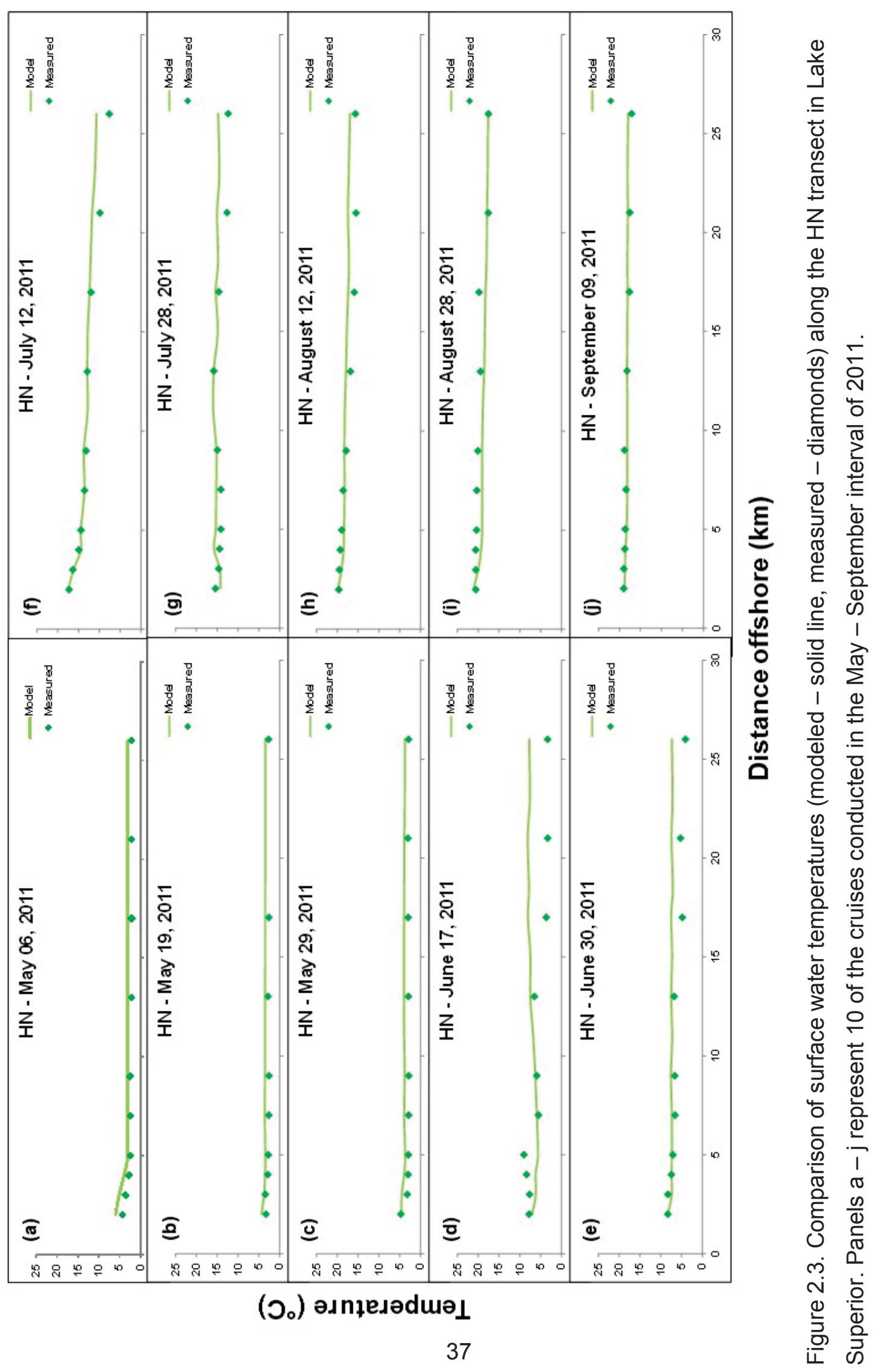




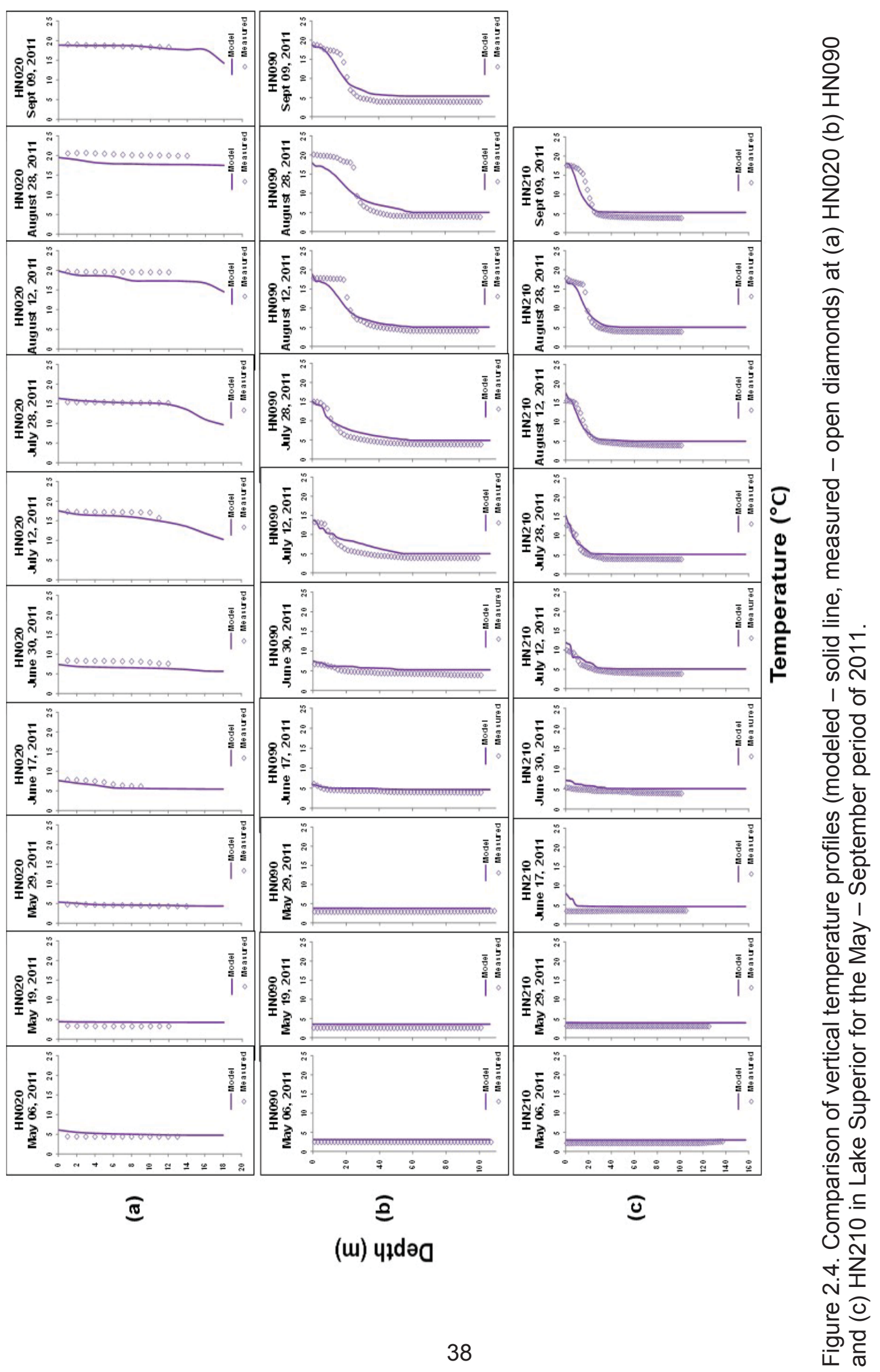



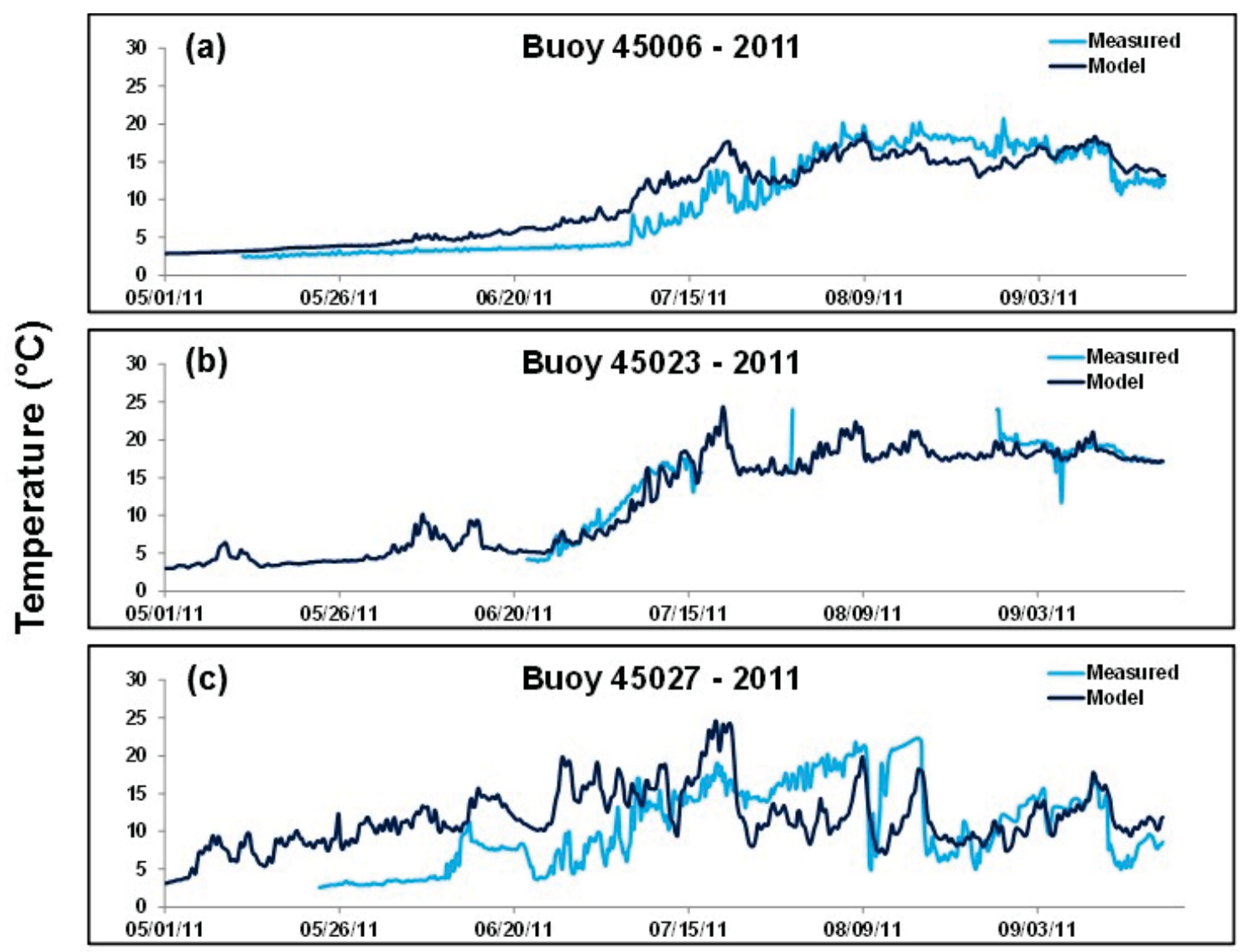

\section{Date Time}

Figure 2.5. Time series of surface temperatures (modeled - dark line, measured - light blue line) at (a) Buoy 45006 (b) Buoy 45023 and (c) Buoy 45027 in Lake Superior for the May - September period of 2011. 


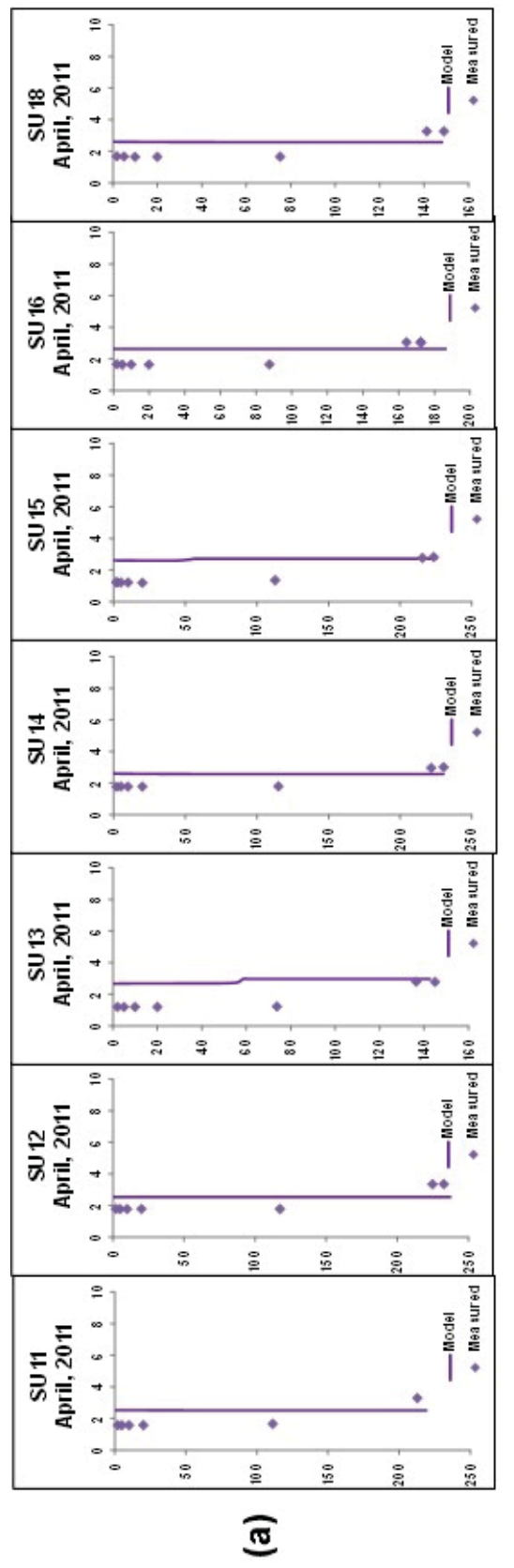

(ui) पวdəa

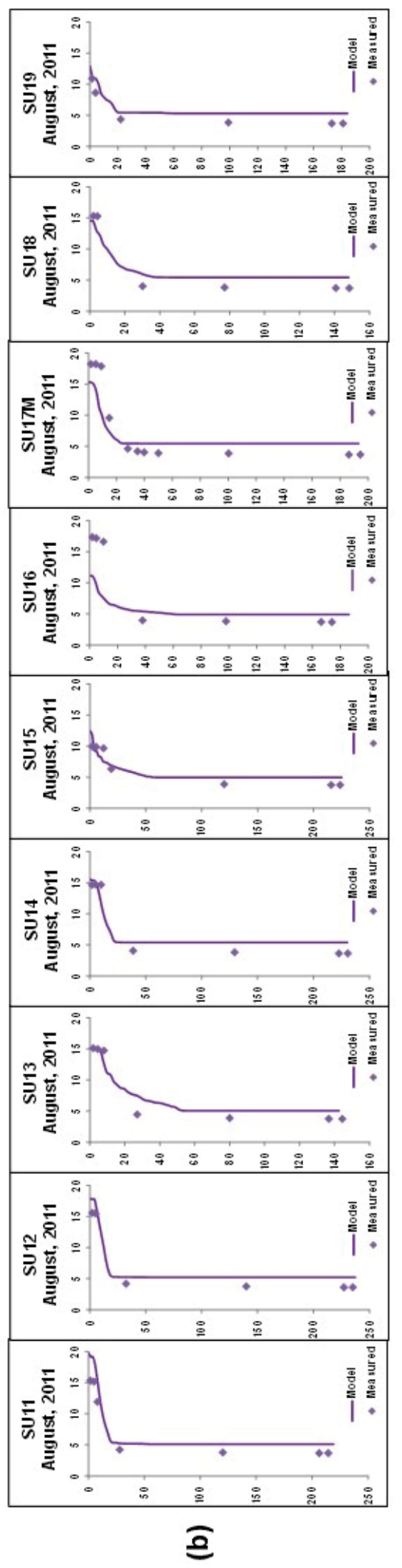

40

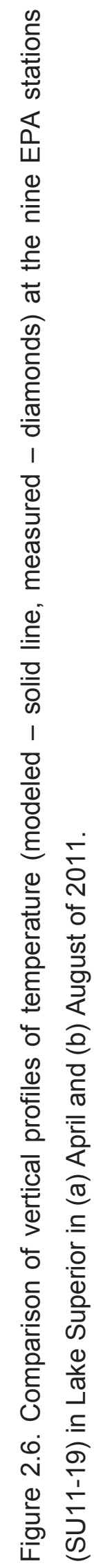




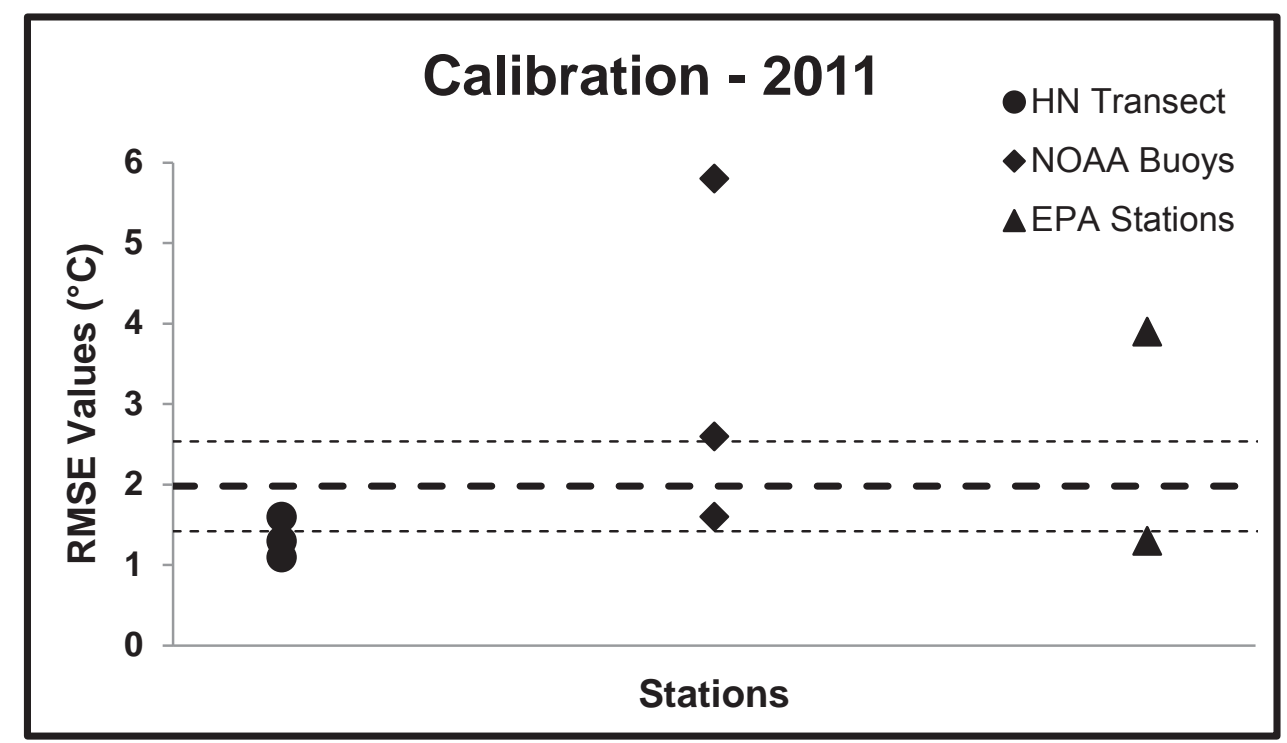

Figure 2.7. Comparison of RMSE values calculated at the three HN stations (circles), the three meteorological buoys (diamonds) and the EPA stations (triangles) for 2011. The dark dashed line represents the average RMSE $\left(1.98{ }^{\circ} \mathrm{C}\right)$ while the lighter dashed lines represent the upper $\left(2.54{ }^{\circ} \mathrm{C}\right)$ and lower $\left(1.42{ }^{\circ} \mathrm{C}\right)$ bounds of the $95 \%$ confidence interval. 


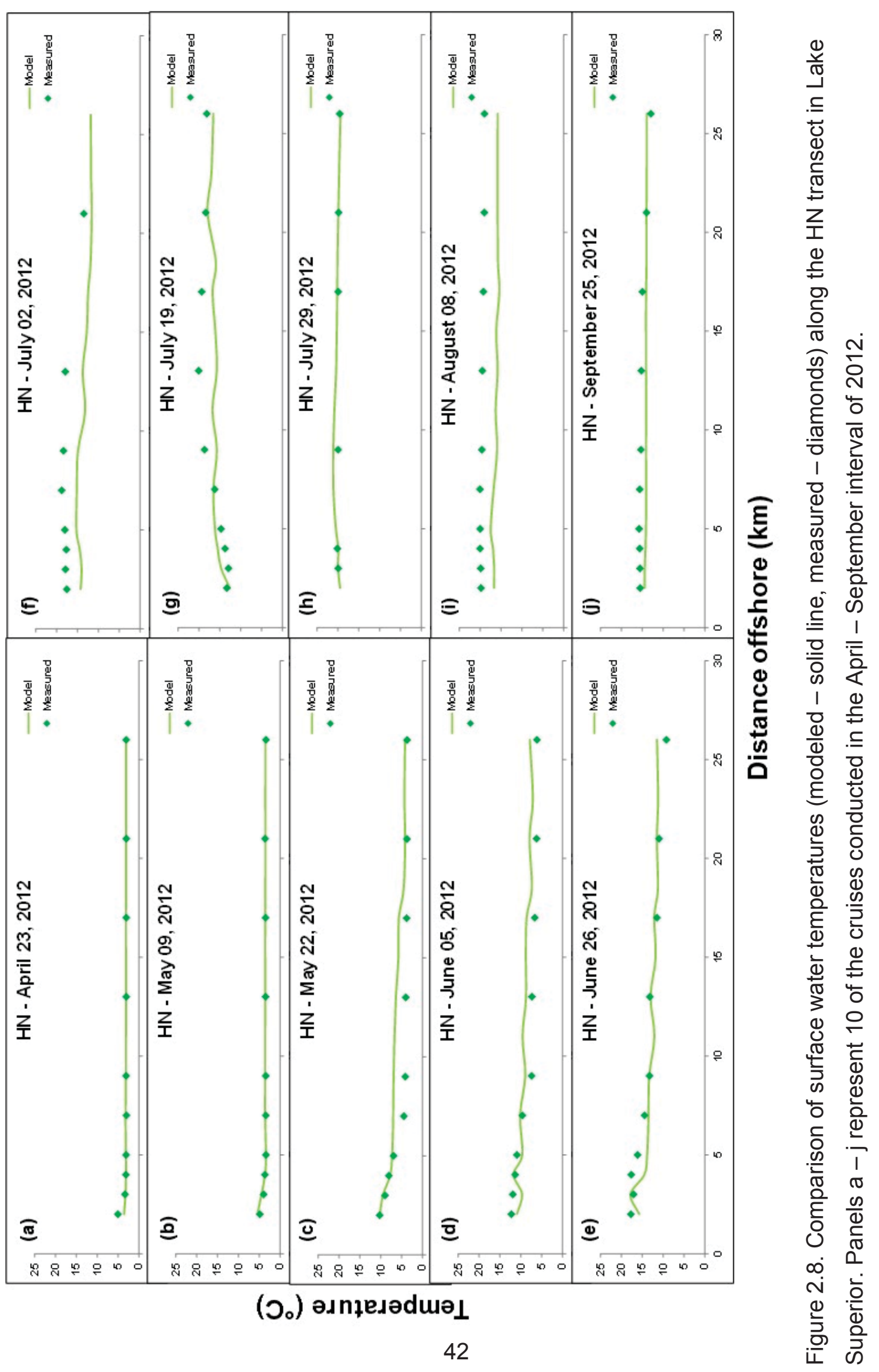




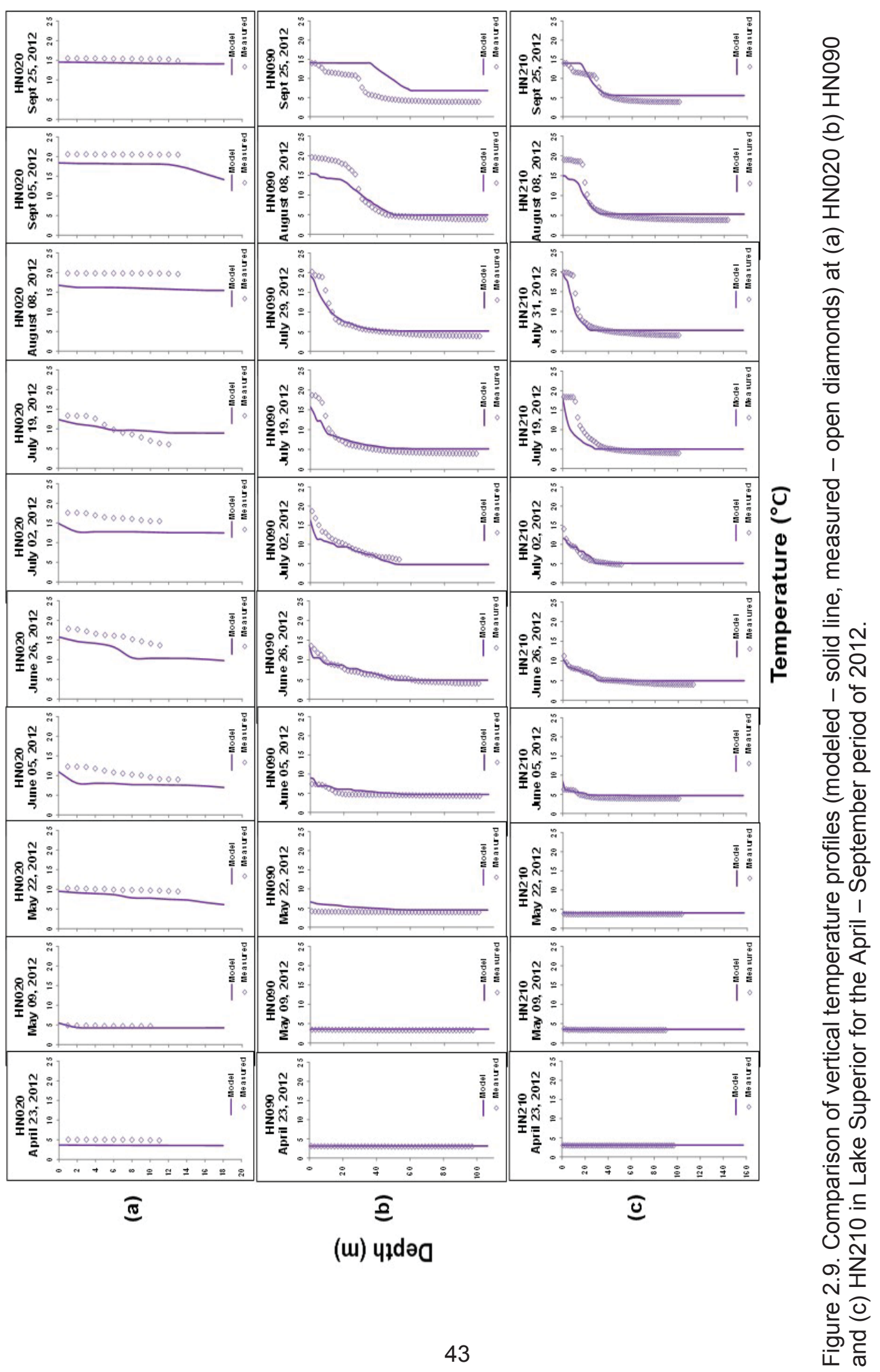




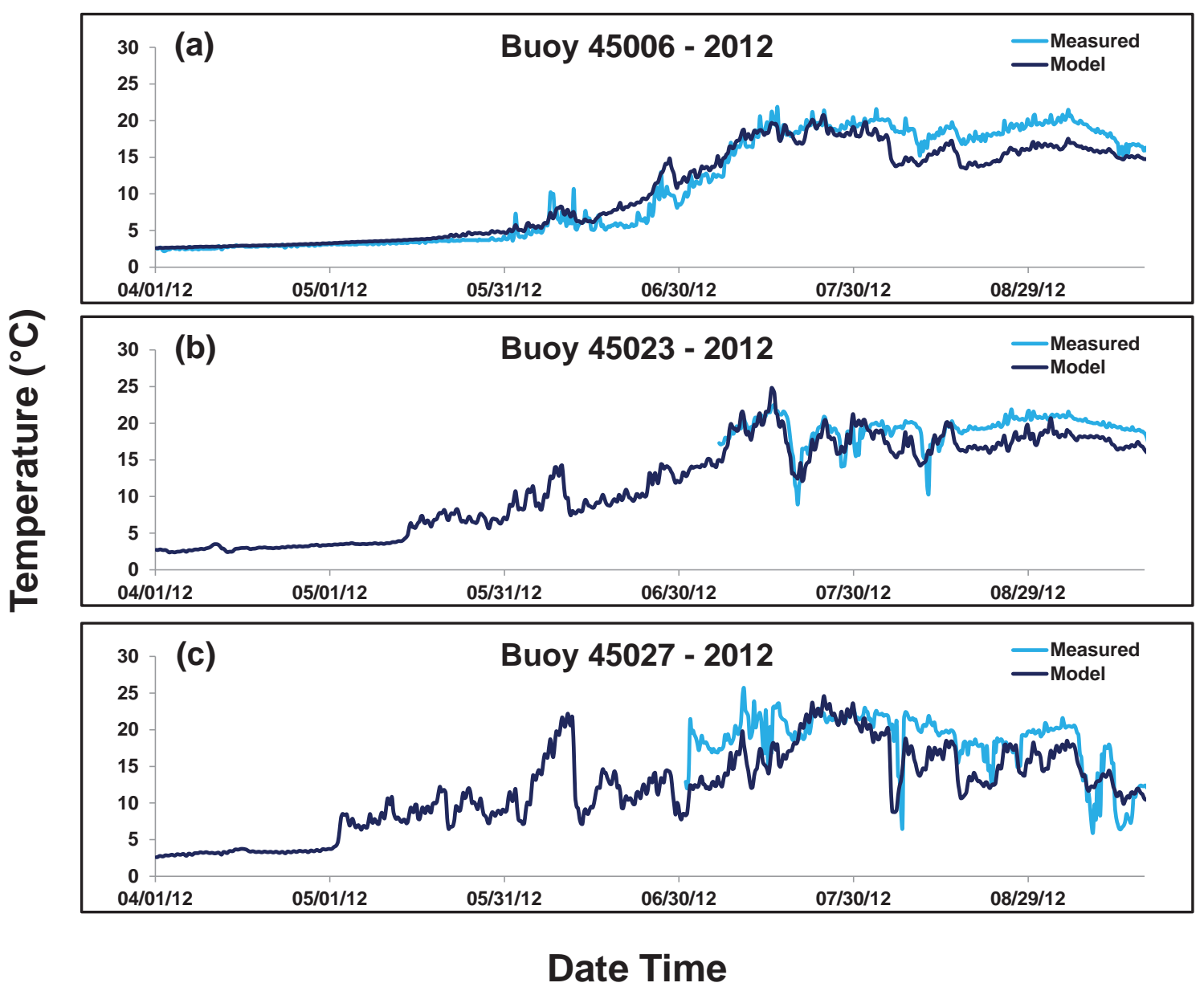

Figure 2.10. Time series of surface temperatures (modeled - dark line, measured - light blue line) at (a) Buoy 45006 (b) Buoy 45023 and (c) Buoy 45027 in Lake Superior for the April - September period of 2012. 


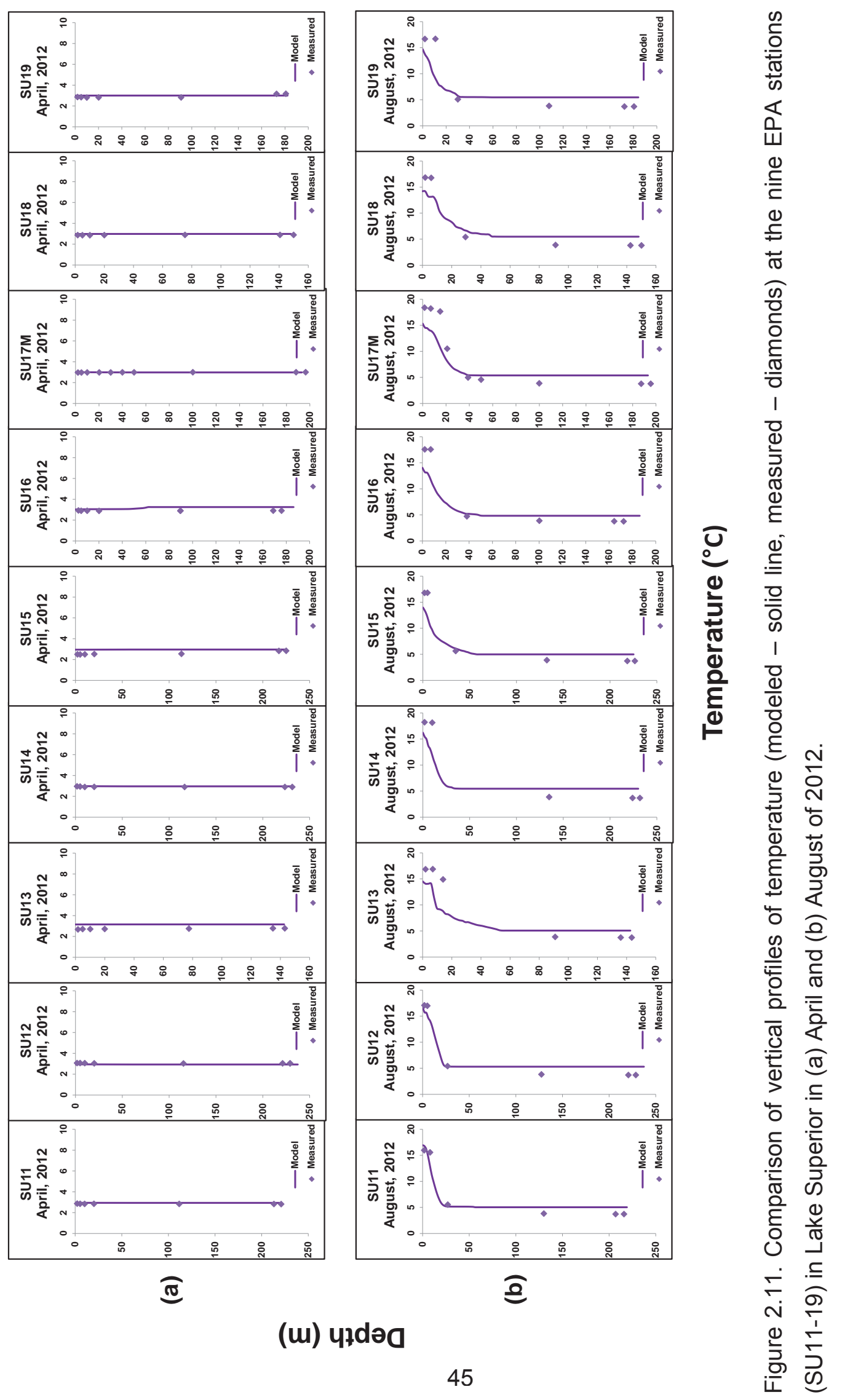




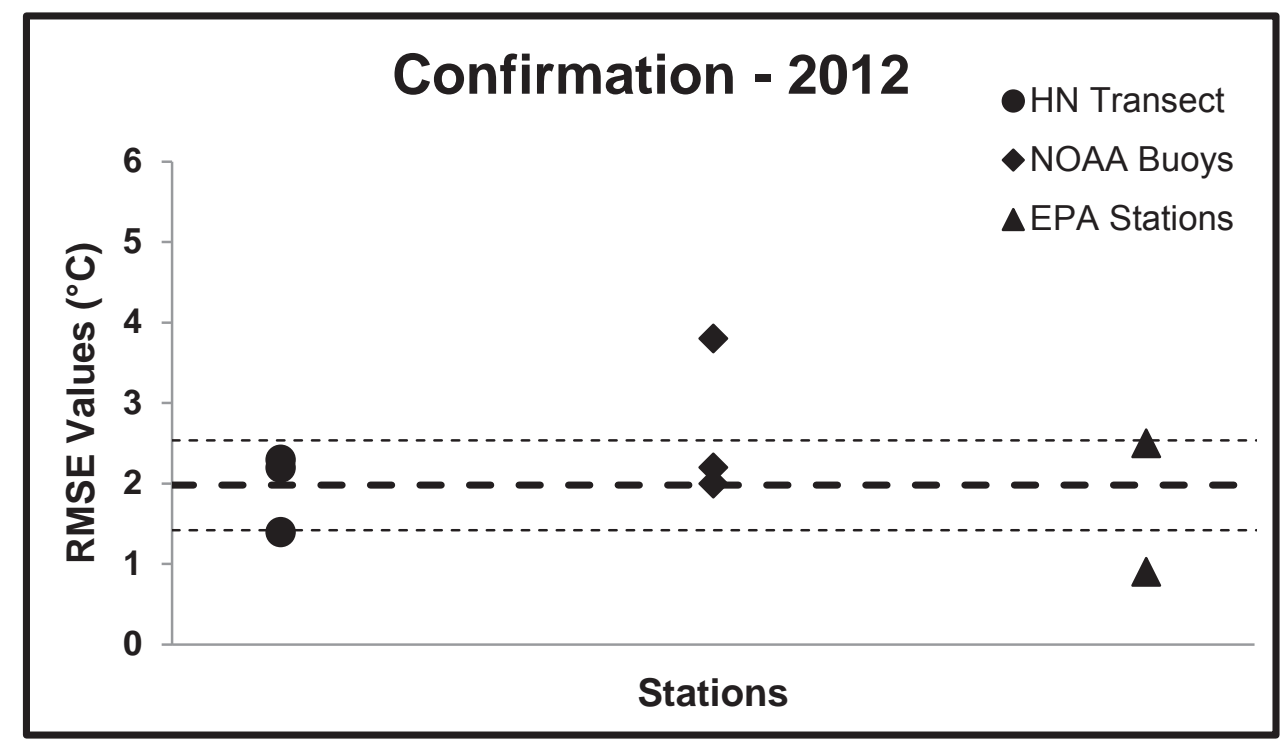

Figure 2.12. Comparison of RMSE values calculated at the three HN stations (circles), the three meteorological buoys (diamonds) and the EPA stations (triangles) for 2012. The dark dashed line represents the average RMSE $\left(1.98^{\circ} \mathrm{C}\right)$ while the lighter dashed lines represent the upper $\left(2.54{ }^{\circ} \mathrm{C}\right)$ and lower $\left(1.42{ }^{\circ} \mathrm{C}\right)$ bounds of the $95 \%$ confidence interval. 


\subsection{Evaluating Model Performance}

This modeling effort was supported by a robust temperature dataset consisting of surface water measurements and water column profiles collected at twenty-three sites (eleven $\mathrm{HN}$ transect stations, three surface buoys, nine EPA stations) in western Lake Superior in 2011 and 2012. These data were used to calibrate the model and confirm its ability to capture spatial and temporal variability in the lake's thermal regime. The quality of calibration and confirmation were determined using a quantitative metric (RMSE values). Criteria for acceptance of calibration and confirmation were based on evaluations of model performance for other Great Lakes hydrodynamic models (Figures 2.7 and 2.12). Except for a single station in extreme western Lake Superior, performance of the EFDC model equaled or exceeded that of these reference works and the model is judged to be calibrated and confirmed for 2011 and 2012.

\subsubsection{Performance in Relation to the Thermal Regime}

While these quantitative methods are appropriate and even necessary to establish confidence in model performance, they represent arbitrary criteria for acceptance in linked model applications unless viewed from an ecosystem perspective. The quantitative approach is limited in its ability to express the error associated with model output in terms of the characteristic features and processes of the lake. The thermal regime, as one of the defining phenomena in physical limnology, accommodates this concern and has been widely applied as a supplemental criterion for the calibration and confirmation of hydrodynamic models (Beletsky and Schwab 2001, McCormick 1990). Here, the model's ability to qualitatively describe a set of characteristics defining the lake's thermal regime, e.g. (thermal bar development, vertical thermal structure during well-mixed and stratified periods) is used as the criterion. 
Lake Superior is completely mixed vertically in April and early May, the spring turnover period. This feature of the annual thermal regime is reflected in vertical temperature profiles at HN020 (Figure 2.4a and 2.9a), HN090 (Figure 2.4b and 2.9b), HN210 (Figure 2.4c and 2.9c) and all the EPA stations (Figure 2.6a and 2.11a) and is well described by the model. As the season progresses, the water column in the shallow nearshore region warms to $4^{\circ} \mathrm{C}$ (shelf station HN020: June $17^{\text {th }} 2011$, Figure $2.4 \mathrm{a}$; May $22^{\text {nd }} 2012$, Figure $2.9 a$ ), thereby setting up a thermal front (or bar) separating the warm, well-mixed waters of the nearshore (shelf) from the deeper, colder areas of the lake (slope, profundal). This thermal front gradually moves lakeward, reaching the center in late June - early July and ultimately resulting in stratification lake-wide. In some cases, the model tracks the vertical structure of the profiles well, in others it does not (compare $12^{\text {th }}$ and $28^{\text {th }}$ August 2011 [Figure 2.4c] and $2^{\text {nd }}$ and $19^{\text {th }}$ July 2012 [Figure 2.9c]). The shortfall here is the inability to accurately capture the observed slope of the profiles and depth of the thermocline as the modeled profiles remain less strongly developed through most of the stratified period. This challenge, facing those working with threedimensional hydrodynamic models, has been recognized and noted (White et al. 2012, Bennington et al. 2010, Huang et al. 2010, Wang et al. 2010, Beletsky et al. 2006, Beletsky and Schwab 2001). The model is, however, able to reproduce deepening of the thermocline (and therefore thickening of the epilimnion) over the stratified interval (Figures $2.4 \mathrm{~b}$ and $2.4 \mathrm{c}$ and $2.9 \mathrm{~b}$ and $2.9 \mathrm{c}$ ), a phenomenon impacting net water column primary production (Dijkstra and Auer, pending submission). Seasonality and nearshore - offshore trends in surface water temperatures along the HN transect (Figures 2.3, 2.8) are also well tracked by the model, as are seasonal progressions in surface water temperature at the three EPA buoys (Figures 2.5, 2.10). Thus, the model is able to capture features of the thermal regime, i.e. the timing of stratification, duration of the 
stratified period, depth of the thermocline and spatio-temporal trends in surface water temperature, for these two years and the application of EFDC in modeling the thermal regime of Lake Superior may be considered calibrated and confirmed.

\subsubsection{Performance in an Ecological Context}

Two criteria for calibration, one quantitative (RMSE values) and the second qualitative (characteristics of the thermal regime), have been successfully utilized in calibrating and confirming EFDC for application to Lake Superior. Both approaches point to good model performance for a stand-alone hydrodynamic model. However, more and more often hydrodynamic models are finding acceptance and application in coupled frameworks investigating the influence of transport phenomena on characteristics of ecosystem function. In these fate and transport applications, it is important to quantify the extent to which the ability to simulate biochemical processes is influenced by the errors associated with the physical model. Modeling studies interfacing hydrodynamic and ecological models must recognize the need to accurately represent the physical characteristics prior to conducting water quality simulations and seek to minimize the uncertainty and enhance reliability in model predictions (Camacho et al. 2015, Atkinson et al. 2012). However, criteria for assessing the performance of physical models that are meaningful in an ecosystem sense have yet to be established.

With an annual average temperature of $3.64{ }^{\circ} \mathrm{C}$ (Bennett 1978), Lake Superior may be characterized as a deep, cold, oligotropic system. As in all lakes, food web dynamics in Lake Superior are driven by primary production in the photic zone, a thin layer accounting for less than $18 \%$ of the lake's volume (based on compensation depth estimates of 25-30 m, Schertzer et al. [1978] and $28 \mathrm{~m}$, Attila et al. [2011]). The dimensions of the layers hosting the photic zone (i.e. the epilimnion and metalimnion) and the seasonal time course of temperature therein, vary markedly as the lake's 
thermal regime is influenced by interannual differences in meteorological forcing conditions (Gawde et al., pending submission). This linkage between hydrodynamics and water quality suggests that annual rates of primary production may provide an ecologically meaningful metric for evaluating performance of the hydrodynamic model. Here, a mechanistic, one-dimensional primary production model, developed for Lake Superior by Dijkstra and Auer (pending submission), is adopted to facilitate an application-oriented approach for evaluating the performance of the hydrodynamic model.

This model framework, developed specifically for Lake Superior and described in its entirety by Dijkstra and Auer (pending submission), consists of a suite of algorithms and attendant coefficients (e.g. maximum C:P ratio, maximum specific rate of net primary production) that are used to calculate rates of primary production as a function of light (photosynthetically active radiation, PAR), temperature and primary producer nutrient content (C:P ratio). The model calculates primary production as the product of algal biomass (particulate organic carbon) and the maximum specific rate of net primary production $\left(\mu_{\max }\right)$, accommodating three algorithms that attenuate the maximum rate in accordance with environmental forcing conditions. Model runs are driven by environmental forcing conditions (light, temperature and nutrient content) derived specifically for Lake Superior. The model of Dijkstra and Auer (pending submission) was calibrated using measurements of primary production performed on water from Lake Superior incubated over a gradient of light and temperature conditions (Auer et al. 2010) and successfully confirmed using in situ measurements made for Lake Superior by Sterner (2010). 


\subsubsection{Sensitivity Analysis}

In its ecosystem application, the hydrodynamic model will be used to quantify the temperature conditions that serve as a driving force for the primary production model. Here, the models are applied in examining the sensitivity of calculated rates of areal primary production to model over- and under-prediction of temperature at various stages in the evolving thermal regime. Accordingly, temperature profiles representing mixed, transitional and stratified conditions are selected from the 2011 temperature database (solid lines, Figure 2.13). A series of synthetic temperature profiles are then created reproducing the shape of the respective measured curves, but representing various degrees of inaccuracy (over- and under-prediction) in modeled temperatures (dashed lines, Figure 2.13). Daily areal primary production $\left(\mathrm{mgC} \cdot \mathrm{m}^{-2} \cdot \mathrm{d}^{-1}\right)$ is calculated over a depth of $30 \mathrm{~m}$ (encompassing the entire productive zone) for the measured temperature profile and for each of the synthetic temperature profiles with all other conditions held constant (e.g. epilimnion and metalimnion size and position) or optimum (incident light, vertical light attenuation and nutrient status). Differences in model-calculated primary production between the measured and synthetic temperature profiles are calculated and expressed as a percent error (\%). The sensitivity of modeled primary production model to inaccuracies in modeled predictions of temperature is then evaluated by plotting that error against the temperature RMSE $\left({ }^{\circ} \mathrm{C}\right)$ for measured versus synthetic profiles (Figure 2.14). While there are no standards established for guiding application of a productionbased evaluation of model performance, analytical procedures typically recognize an error of $10 \%$ as acceptable.

It is evident from the sensitivity analysis (Figure 2.14) that, in the transitional and stratified periods, calculation of areal production is less sensitive to variation in modelcalculated temperature profiles for the range of temperature RMSE values typically 


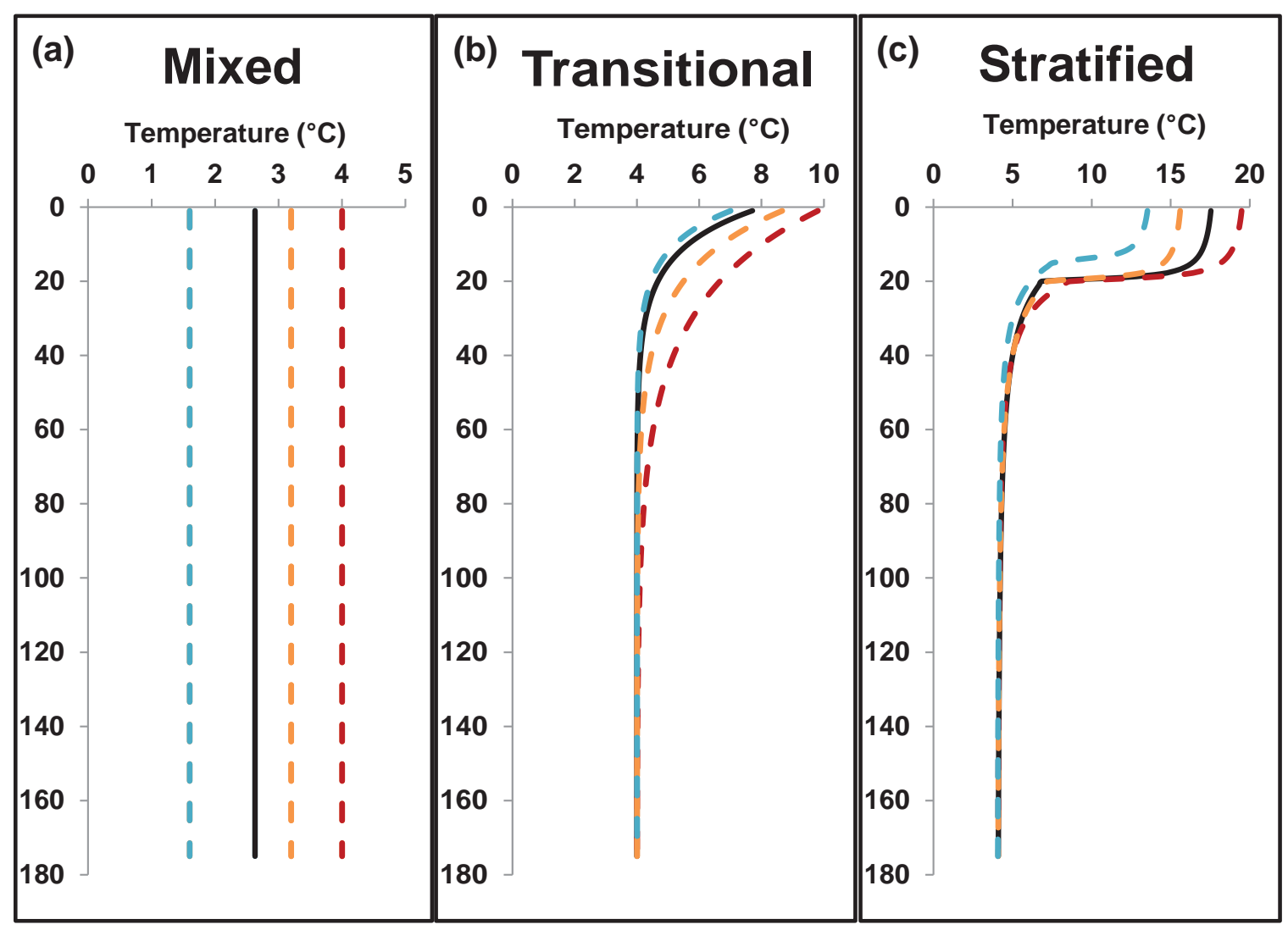

Figure 2.13. Measured and modeled vertical temperature profiles during (a) mixed (b) transitional and (c) stratified periods. The solid lines indicate representative measured temperature profiles from the 2011 sampling season while the dotted lines depict synthesized (modeled) warm (red), average (yellow) and cold (blue) water temperature conditions for each mixing period. 
deemed acceptable in hydrodynamic modeling of the Great Lakes (Figure 2.7 and 2.12). Here, RMSE values of $0.3{ }^{\circ} \mathrm{C}$ to $1.6{ }^{\circ} \mathrm{C}$ (transitional period) and $0.6{ }^{\circ} \mathrm{C}$ to $3.2{ }^{\circ} \mathrm{C}$ (stratified period) lead to errors in predicted areal primary production of $4-14 \%$ and 6$9 \%$, respectively, and average $7.8 \pm 3.2 \%$, an acceptable level of uncertainty. A temperature attenuation algorithm specific to a warm water phytoplankton assemblage is adopted in the production model for the stratified period (Figure 2.15a; Dijkstra and Auer, pending submission). The sensitivity of the production model to temperature is dictated by the shape of that algorithm and the position of the model-generated values on that response curve. During the stratified period, the maximum rate of production is observed at the metalimnion (at $\sim 20 \mathrm{~m}$ depth, Dijkstra and Auer, pending submission), and temperatures corresponding to this depth range are derived from the synthetic profiles. These synthetic temperatures range from $10-15^{\circ} \mathrm{C}$, a relatively flat region on the temperature response curve and result in a narrow range $(0.80-0.95)$ of variation in the normalized rate of primary production (Figure 2.15a). In the transitional period (spring conditions, Figure 2.15b), an algorithm specific to a cold water phytoplankton assemblage is utilized (Dijkstra and Auer, pending submission). Synthetic profile temperatures within the photic zone range between $5-10^{\circ} \mathrm{C}$ in this period, also yielding a limited variability in the normalized rate of primary production $(0.8-0.95$; Figure $2.15 b)$. The sensitivity of the primary production model to variations in temperatures is therefore more subdued in the transitional and stratified periods.

A strong contrast in sensitivity is observed for the early spring interval where the water column is well mixed (Figure 2.13). Here, despite excellent performance in simulating temperature (RMSE ranging from $0.6{ }^{\circ} \mathrm{C}$ to $1.4^{\circ} \mathrm{C}$ ), the error in simulated areal primary production ranged from $31 \%$ to $72 \%$, an unacceptable level of performance (circles, Figure 2.14). This less than satisfactory model performance is 
strongly related to the wide range in normalized rates of primary production $(0.1-0.7$, Figure $2.15 \mathrm{~b})$ corresponding to the range of temperatures $\left(1.7-4^{\circ} \mathrm{C}\right)$ represented by the synthetic temperature profiles in the mixed period. Therefore, a small error in capturing the rate of warming in the early spring has a magnified impact on simulated productivity.

This sensitivity analysis, conducted on well-mixed, transitional and stratified conditions, demonstrates the impact of period-specific temperature patterns on phytoplankton dynamics and highlights the interplay of modeled temperature response algorithms in governing the sensitivity of the primary production model. These findings offer guidance to other modelers seeking to identify and address the temperaturesensitive periods in their simulations.

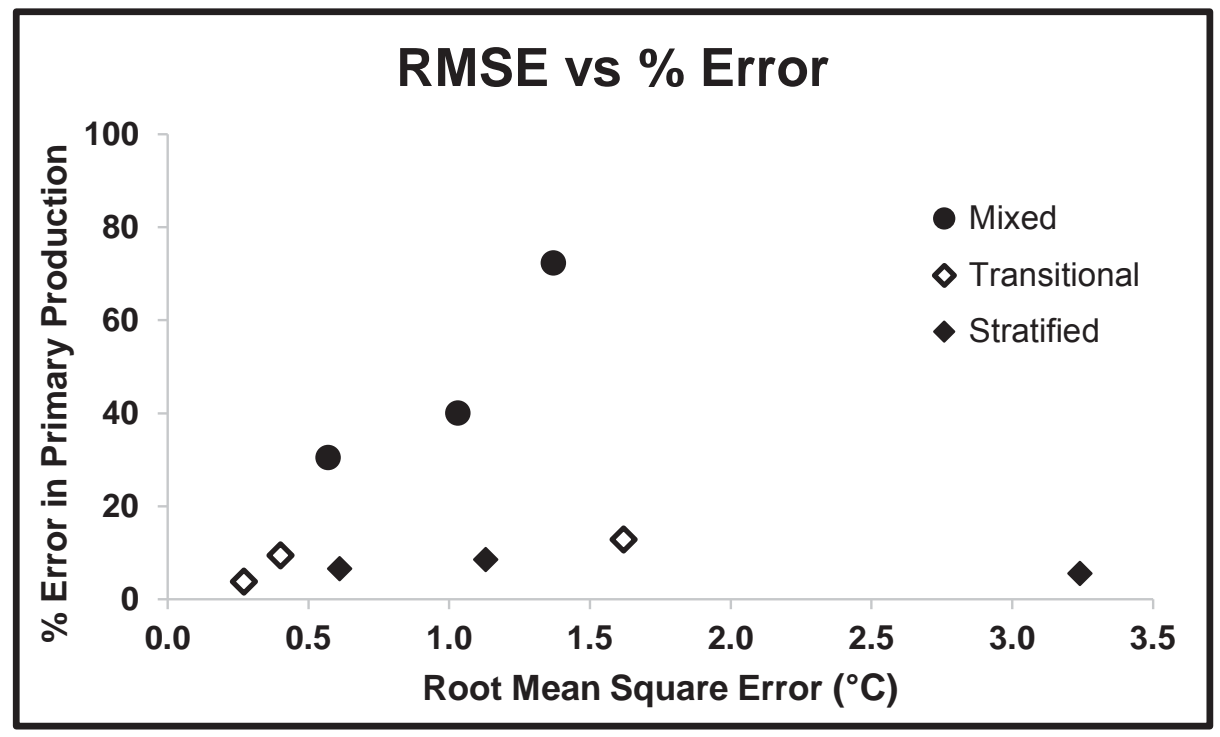

Figure 2.14. Comparing the RMSE value calculated for the synthetic temperature profiles to the corresponding percentage error obtained in areal primary production for mixed (circles), transitional (open diamonds) and stratified (filled diamonds) periods. 


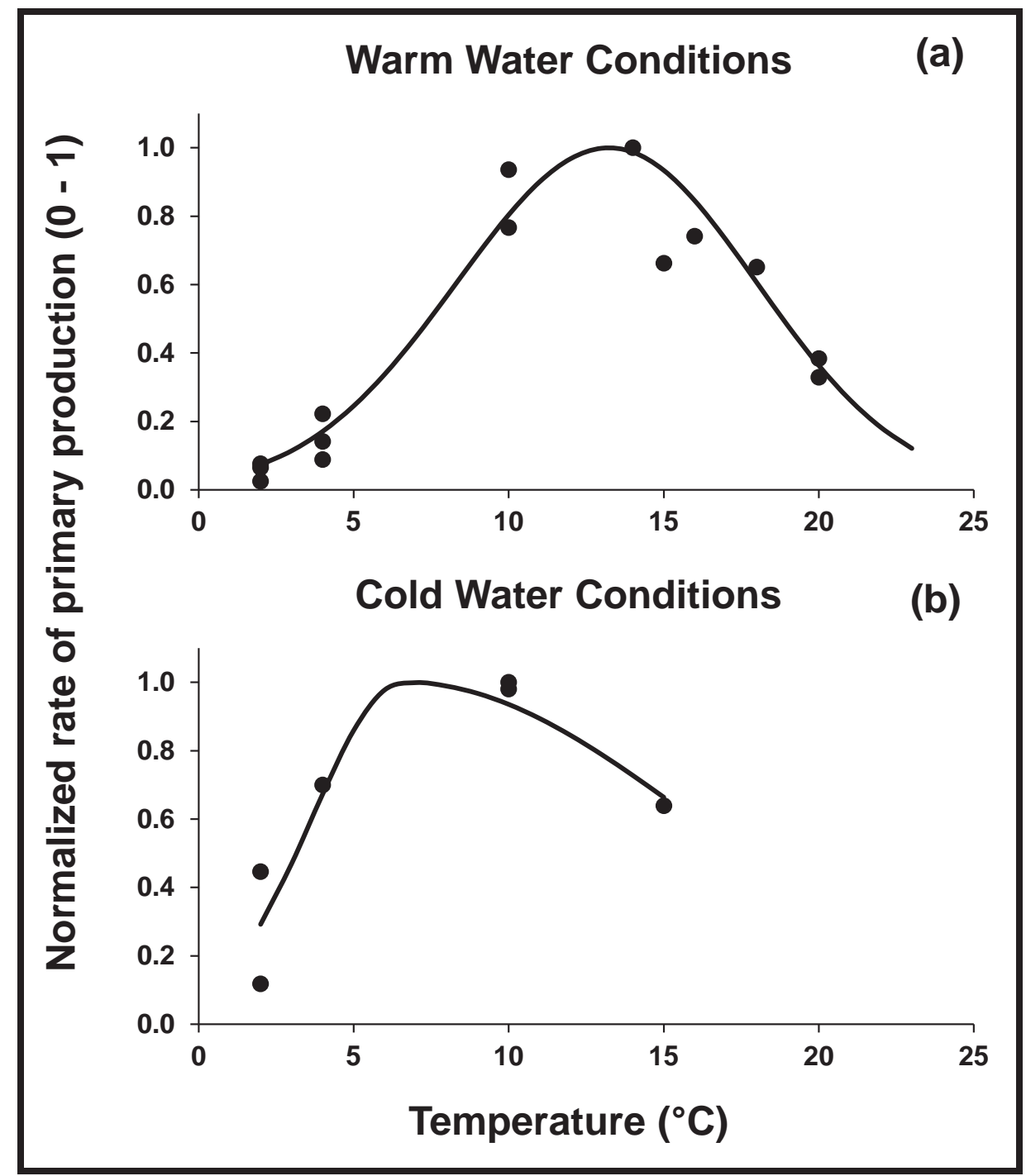

Figure 2.15. Temperature attenuation functions adopted in the primary production model. Normalized to range between zero and one for algal assemblages adapted to (a) warm water conditions and (b) cold water conditions, these functions are represented by the solid line. The normalized specific rates of primary production measured over the given range of temperatures are represented by the circles. 


\subsubsection{Application to Lake Superior}

Proceeding from the sensitivity analysis, the primary production model is further applied to introduce an ecologically-meaningful criterion in evaluating the performance of the hydrodynamic model. Data from two stations along the HN transect, one nearshore (HN040) and the other offshore (HN260), are utilized for this purpose. Daily areal primary production rates, driven by EFDC model-generated and measured temperature profiles, are calculated and compared at each of the two sites (HN040, Figure 2.16a; HN260, Figure 2.16b). Regression analysis applied to evaluate this comparison yields a good agreement (high $\mathrm{R}^{2}$ values) between rates of areal primary production based on measured and modeled temperatures (HN040, $\left.R^{2}=0.94 ; H N 260, R^{2}=0.96\right)$. The quality performance of these linked temperature - production calculations is reflected in two examples for the isothermal and stratified periods. At the offshore station (HN260), for instance, a vertically isothermal temperature profile measured in early spring (May $\left.9^{\text {th }}\right)$ of 2012 generates an areal net rate of primary production of $123 \mathrm{mgC} \cdot \mathrm{m}^{-2} \cdot \mathrm{d}^{-1}$ while the corresponding model-predicted temperature profile yields a value of $126 \mathrm{mgC} \cdot \mathrm{m}^{-2} \cdot \mathrm{d}^{-}$ 1. This completely mixed temperature profile had an RMSE value of $0.3^{\circ} \mathrm{C}$ and yielded an error of $2 \%$ in primary production calculations. Similarly, a temperature profile with a deep thermocline measured late in the 2012 sampling season (September $25^{\text {th }}$ ), yields an RMSE value of $1.7^{\circ} \mathrm{C}$ with $6 \%$ error in areal primary production. 

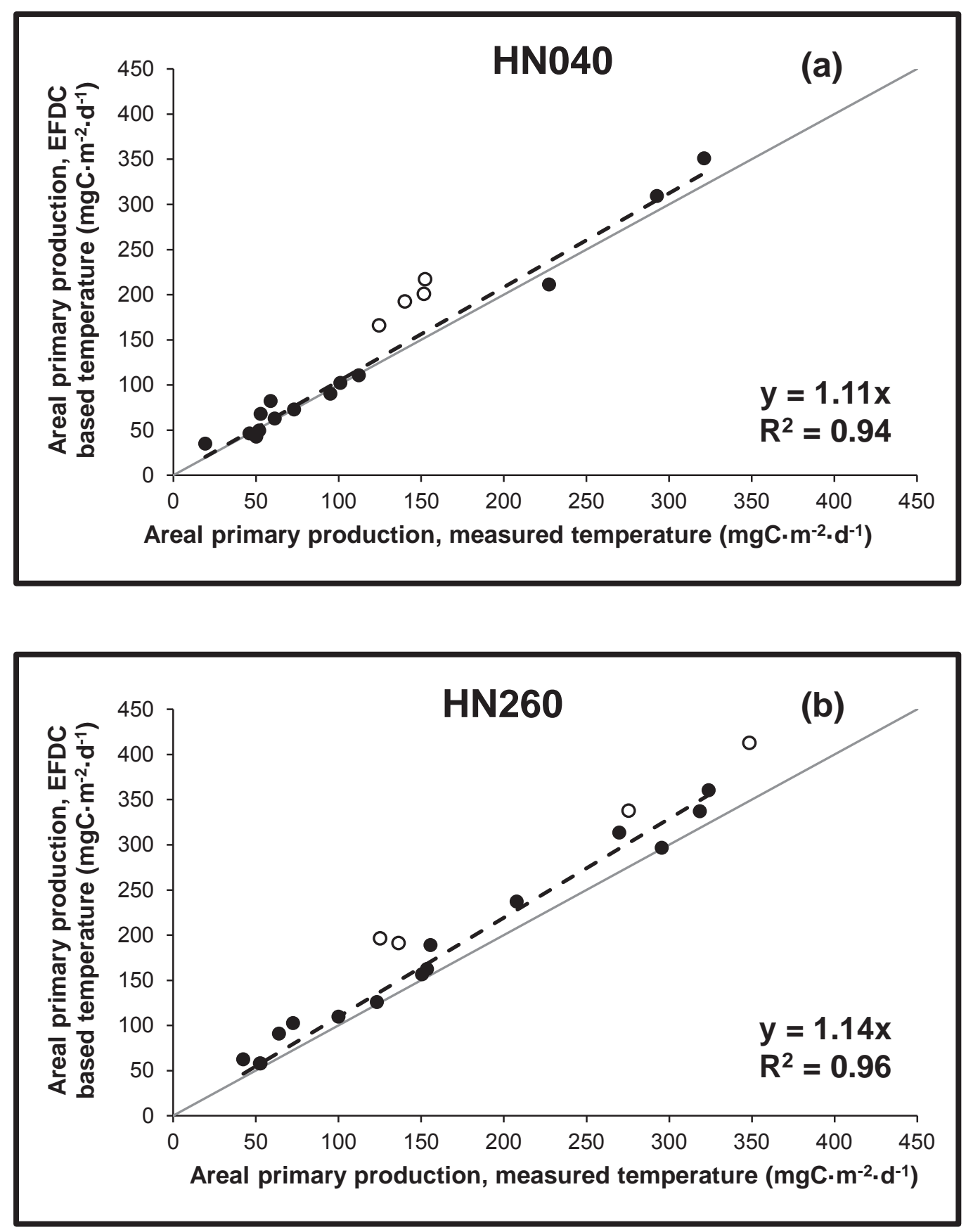

Figure 2.16. Comparison of the areal primary production, measured vs. EFDC model based temperature profiles at (a) HN040 (nearshore station) and (b) HN260 (offshore station) in Lake Superior for 2011 and 2012. The 1:1 relationship, used as a reference to determine an optimal fit between measured and modeled values, is represented by the dark gray line. The open circles in panels $a-b$ indicate the eight points that cause the comparison in the nearshore and offshore regions to deviate from the 1:1 line. 
As described earlier, analytical procedures typically accept an error of $10 \%$ to represent a satisfactory fit and that was adopted in this study to determine good model performance in the absence of established standards for this ecologically-meaningful criterion. Production model simulations for 2011 and 2012 performed for the nearshore (HN040) and offshore (HN260) yielded an over-prediction of measured temperaturedriven values by $11 \%$ and $14 \%$, respectively. This result is largely consistent with the $10 \%$ criterion adopted here. However, inspection of the data along the $1: 1$ line in the two graphical representations identifies eight points (four in each, open circles in Figure 2.16a and b) that serve to degrade the quality of the comparison. In the nearshore data set (HN040), three of the highlighted points correspond to isothermal profiles recorded in early spring (May $6^{\text {th }}$, May $19^{\text {th }}$ and May $29^{\text {th }}$, Figure $2.17 \mathrm{a}$ ) where the rate of warming was over-predicted by the hydrodynamic model. Also, the hydrodynamic model predicts a warmer than observed water column on four dates in the transitional/stratified water column on four dates (Figure 2.17b). Re-fitting Figure 2.16, excluding these eight points, improves the quality of performance to $4 \%$ and $10 \%$ at the HN040 and HN260 stations, respectively, both within the accepted criterion. Insight gained from this visual and quantitative comparison of measured and modeled temperature driven estimates of areal primary production and an appreciation for the algorithm incorporated in the model described by Dijkstra and Auer (pending submission), therefore, recommends revisiting and improving model calibration for these two regions.

An ecologically meaningful criterion has, therefore, been introduced to evaluate the performance of hydrodynamic models used in the context of coupled frameworks applied to simulate ecosystem response. This criterion establishes a relationship between the error in the physical model (RMSE value) and the corresponding degree of uncertainty in primary production (\% error), offering an application-oriented quantification 


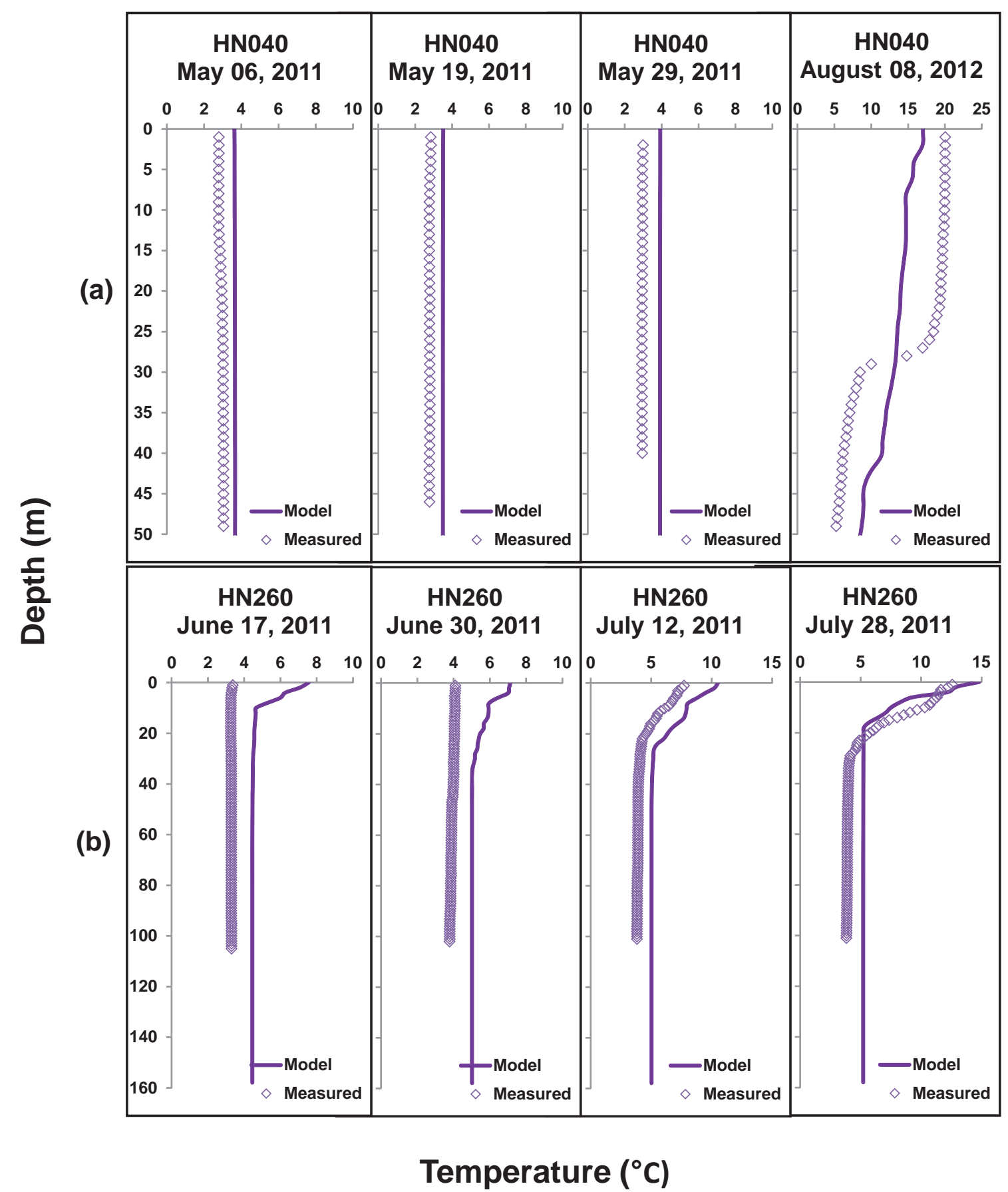

Figure 2.17. Comparison of measured (open diamonds) and modeled (solid line) vertical temperature profiles corresponding to the eight points (open circles in Figure 2.16) that degrade the goodness-of-fit between areal primary production estimates derived from measured and modeled temperatures; (a) four at the nearshore station HNO40 and (b) four at the offshore station HN260 in Lake Superior. 
and interpretation of the inaccuracy associated with the output from a hydrodynamic model.

\subsection{Conclusions}

In this study, a three-dimensional hydrodynamic model EFDC has been successfully established over the western basin of Lake Superior to investigate the thermal regime of the lake. Results from the EFDC model, for 2011 and 2012, were then evaluated through quantitative and qualitative criteria to ascertain the goodness-offit as compared to the temperature data set. Quantitatively, the EFDC model was calibrated (2011) and confirmed (2012) on a spatial and temporal basis. Spatially, model output matched both vertical and horizontal temperature measurements. Time series of modeled temperatures were also compared against buoy data. RMSE values for 2011 and 2012 matched those reported in the literature and this application of EFDC was deemed calibrated and validated. Qualitatively, graphical representations were evaluated to identify characteristics of the thermal regime. The EFDC model satisfactorily tracked spring mixing, onset of stratification, duration of the stratified period and dissipation of stratification at shelf, slope and profundal zones in 2011 and 2012 and model performance was concluded to be in agreement with the criterion. The modeled thermoclines, however, were less defined in comparison to the observed ones, possibly due to inadequate vertical resolution or the lack of a wave sub-model in this simulation.

This paper introduced a new criterion for evaluating model performance of hydrodynamic modeling systems. The motivation driving the establishment of this ecologically-meaningful method lies in the extensive application and use of coupled physical and ecological model frameworks. This application-oriented approach used a mechanistic one dimensional primary production model, developed for Lake Superior by 
Dijkstra and Auer (pending submission), to generate estimates of areal primary productivity based on modeled and measured sets of temperature profiles. This criterion, therefore, relates inaccuracy in the thermal structure, as determined through analytical procedures (RMSE), to a corresponding uncertainty (\% error) in primary phytoplankton production in the water column and was successfully applied to the nearshore and offshore regions in this modeling exercise. A sensitivity analysis, conducted on well-mixed, transitional and stratified conditions, offers insights about the influence of timing and distribution of temperature patterns on biochemical processes in Lake Superior. This criterion, therefore, finds wide application in assessing model performance and determining suitability and reliability of the physical model for pursuing management alternatives.

\subsection{References}

Atilla, N., McKinley, G. A., Bennington, V., Baehr, M., Urban, N.R., DeGrandpre, M., Desai, A. R., and Wu, C. (2011). "Observed variability of Lake Superior pCO2." Limnology and Oceanography, 56(3), 775-786.

Atkinson, J. F., Edwards, W. J., and Feng, Y. (2012). "Physical measurements and nearshore nested hydrodynamic modeling for Lake Ontario nearshore nutrient study." Journal of Great Lakes Research, 38, 184-193.

Auer, M. T., Auer, N. A., Urban, N. R., and Auer, T. (2013). "Distribution of the amphipod Diporeia in Lake Superior: The Ring of Fire." Journal of Great Lakes Research, 39(1), 33-46.

Auer, M. T., Bub, L. A., Auer, N. A., and Urban, N. R. (2010). "Primary production, carbon flux, and the distribution of Diporeia in Lake Superior." Verhandlungen der 
Internationalen Vereinigung fur Theoretische und Angewandte Limnologie, 30(10), 1499-1505.

Auer, M. T., and Gatzke, T. L. (2004). "The spring runoff event, thermal bar formation, and cross margin transport in lake Superior." Journal of Great Lakes Research, 30, 64-81.

Auer, N. A., and Kahn, J. E. (2004). "Abundance and distribution of benthic invertebrates, with emphasis on Diporeia, along the Keweenaw Peninsula, Lake Superior." Journal of Great Lakes Research, 30, 340-359.

Austin, J. A., and Allen, J. (2011). "Sensitivity of summer Lake Superior thermal structure to meteorological forcing." Limnology and Oceanography, 56(3), 1141-1154.

Bai, X., Wang, J., Schwab, D. J., Yang, Y., Luo, L., Leshkevich, G. A., and Liu, S. (2013). "Modeling 1993-2008 climatology of seasonal general circulation and thermal structure in the Great Lakes using FVCOM." Ocean Modelling, 65, 40-63.

Barbiero, R. P., and Tuchman, M. L. (2001). "Results from the US EPA's biological open water surveillance program of the Laurentian Great Lakes: I. Introduction and phytoplankton results." Journal of Great Lakes Research, 27(2), 134-154.

Beletsky, D., Hawley, N., and Rao, Y. R. (2013). "Modeling summer circulation and thermal structure of Lake Erie." Journal of Geophysical Research: Oceans, 118(11), 6238-6252.

Beletsky, D., Mason, D. M., Schwab, D. J., Rutherford, E. S., Janssen, J., Clapp, D. F., and Dettmers, J. M. (2007). "Biophysical Model of Larval Yellow Perch Advection and Settlement in Lake Michigan." Journal of Great Lakes Research, 33(4), 842866. 
Beletsky, D., and Schwab, D. J. (2001). "Modeling circulation and thermal structure in Lake Michigan: Annual cycle and interannual variability." Journal of Geophysical Research, 106(C9), 19-745.

Beletsky, D., Schwab, D., and McCormick, M. (2006). "Modeling the 1998-2003 summer circulation and thermal structure in Lake Michigan." Journal of Geophysical Research: Oceans, 111(C10), C10010.

Bennett, E. B. (1978). "Characteristics of the thermal regime of Lake Superior." Journal of Great Lakes Research, 4(3), 310-319.

Bennington, V., McKinley, G. A., Kimura, N., and Wu, C. H. (2010). "General circulation of Lake Superior: Mean, variability, and trends from 1979 to 2006." Journal of Geophysical Research, 115, C12015.

Blumberg, A. F., and Mellor, G. L. (1987). "A description of a three-dimensional coastal ocean circulation model." Three-dimensional Coastal Ocean Models, 4, 1-16.

Bocaniov, S. A., Smith, R. E. H., Spillman, C. M., Hipsey, M. R., and Leon, L. F. (2014). "The nearshore shunt and the decline of the phytoplankton spring bloom in the Laurentian Great Lakes: insights from a three-dimensional lake model." Hydrobiologia, 731(1), 151-172.

Boyce, F. M. (1974). "Some aspects of Great Lakes physics of importance to biological and chemical processes." Journal of the Fisheries Board of Canada, 31(5), 689730.

Bryan, K. (1969). "A numerical method for the study of the circulation of the world ocean." Journal of Computational Physics, 4(3), 347-376.

Camacho, R. A., Martin, J. L., Watson, B., Paul, M. J., Zheng, L., and Stribling, J. B. (2015). "Modeling the factors controlling phytoplankton in the St. Louis Bay 
Estuary, Mississippi and evaluating estuarine responses to nutrient load modifications." Journal of Environmental Engineering, 141(3).

Chen, C., Zhu, J., Ralph, E., Green, S. A., Budd, J. W., and Zhang, F. Y. (2001). "Prognostic modeling studies of the Keweenaw current in Lake Superior. Part I: Formation and evolution." Journal of Physical Oceanography, 31(2), 379-395.

Dijkstra, M.L., and Auer, M.T. "Development and application of a site-specific primary production model for Lake Superior and its utility to satellite based production estimates." Pending submission.

Dole, R., Hoerling, M., Kumar, A., Eischeid, J., Perlwitz, J., Quan, X.-W., Kiladis, G., Webb, R., Murray, D., Chen, M., and others. (2014). "The making of an extreme event: putting the pieces together." Bulletin of the American Meteorological Society, 95(3), 427-440.

Galperin, B., Kantha, L. H., Hassid, S., and Rosati, A. (1988). "A quasi-equilibrium turbulent energy model for geophysical flows." Journal of the Atmospheric Sciences, 45(1), 55-62.

Gawde, R.K., Auer, M.T, and Owens, E.M. "Modeling the impact of climatic 'bookend' years on the thermal regime of Lake Superior." Pending submission.

Gronewold, A. D., Clites, A. H., Hunter, T. S., and Stow, C. A. (2011). "An appraisal of the Great Lakes advanced hydrologic prediction system." Journal of Great Lakes Research, 37(3), 577-583.

Hamrick, J. M. (1992). “A three-dimensional environmental fluid dynamics computer code: theoretical and computational aspects." PhD. Thesis, Virginia Institute of Marine Science, College of William and Mary. 
Hamrick, J. M., and Mills, W. B. (2000). "Analysis of water temperatures in Conowingo Pond as influenced by the Peach Bottom atomic power plant thermal discharge." Environmental Science and Policy, 3, 197-209.

Huang, A., Rao, Y. R., and Lu, Y. (2010). "Evaluation of a 3-D hydrodynamic model and atmospheric forecast forcing using observations in Lake Ontario." Journal of Geophysical Research, 115(C2), C02004.

Hu, H., and Wang, J. (2010). "Modeling effects of tidal and wave mixing on circulation and thermohaline structures in the Bering Sea: Process studies." Journal of Geophysical Research: Oceans (1978-2012), 115(C1).

Ji, Z. G., Hu, G., Shen, J., and Wan, Y. (2007). "Three-dimensional modeling of hydrodynamic processes in the St. Lucie Estuary." Estuarine, Coastal and Shelf Science, 73(1-2), 188-200.

Lam, D. C. L., and Halfon, E. (1978). "Model of primary production, including circulation influences, in Lake Superior." Applied Mathematical Modelling, 2(1), 30-40.

Leon, L. F., Smith, R. E. ., Hipsey, M. R., Bocaniov, S. A., Higgins, S. N., Hecky, R. E., Antenucci, J. P., Imberger, J. A., and Guildford, S. J. (2011). "Application of a 3D hydrodynamic-biological model for seasonal and spatial dynamics of water quality and phytoplankton in Lake Erie." Journal of Great Lakes Research.

Leon, L. F., Smith, R. E. H., Malkin, S. Y., Depew, D., Hipsey, M. R., Antenucci, J. P., Higgins, S. N., Hecky, R. E., and Rao, R. Y. (2012). "Nested 3D modeling of the spatial dynamics of nutrients and phytoplankton in a Lake Ontario nearshore zone." Journal of Great Lakes Research, 38, Supplement 4, 171-183.

Liu, L., Phanikumar, M. S., Molloy, S. L., Whitman, R. L., Shively, D. A., Nevers, M. B., Schwab, D. J., and Rose, J. B. (2006). "Modeling the transport and inactivation of 
E. coli and enterococci in the near-shore region of Lake Michigan." Environmental Science and Technology, 40(16), 5022-5028.

Liu, S. K., and Leendertse, J. J. (1978). "Multidimensional numerical modeling of estuaries and coastal seas." Advances in Hydroscience, 11, 95-164.

Liu, Z., Hashim, N. B., Kingery, W. L., Huddleston, D. H., and Xia, M. (2008). "Hydrodynamic modeling of St. Louis Bay estuary and watershed using EFDC and HSPF." Journal of Coastal Research, 107-116.

McCormick, M. J. (1990). "Potential changes in thermal structure and cycle of Lake Michigan due to global warming." Transactions of the American Fisheries Society, 119(2), 183-194.

Mellor, G. L., and Yamada, T. (1982). "Development of a turbulence closure model for geophysical fluid problems." Reviews of Geophysics and Space Physics, 20(4), 851-875.

Mesinger, F., DiMego, G., Kalnay, E., Mitchell, K., Shafran, P. C., Ebisuzaki, W., Jović, D., Woollen, J., Rogers, E., and Berbery, E. H., others. (2006). "North American regional reanalysis." Bulletin of the American Meteorological Society, 87(3).

Moll, R. A., Bratkovich, A., Chang, W. Y., and Pu, P. (1993). "Physical, chemical, and biological conditions associated with the early stages of the Lake Michigan vernal thermal front." Estuaries, 16(1), 92-103.

Nguyen, T. D., Thupaki, P., Anderson, E. J., and Phanikumar, M. S. (2014). "Summer circulation and exchange in the Saginaw Bay-Lake Huron system." Journal of Geophysical Research: Oceans, 119(4), 2713-2734.

Rao, Y. R., Marvin, C. H., and Zhao, J. (2009). "Application of a numerical model for circulation, temperature and pollutant distribution in Hamilton Harbour." Journal of Great Lakes Research, 35(1), 61-73. 
Scavia, D., and Bennett, J. R. (1980). "Spring transition period in Lake Ontario - A numerical study of the causes of the large biological and chemical gradients." Canadian Journal of Fisheries and Aquatic Sciences, 37(5), 823-833.

Schertzer, W. M., Elder, F. C., and Jerome, J. (1978). "Water transparency of Lake Superior in 1973." Journal of Great Lakes Research, 4(3-4), 350-358.

Schwab, D. J., and Beletsky, D. (1998). Lake Michigan mass balance study: Hydrodynamic modeling project. NOAA Technical Memorandum, Great Lakes Environmental Research Laboratory, Ann Arbor, MI.

Schwab, D. J., Beletsky, D., DePinto, J., and Dolan, D. M. (2009). "A hydrodynamic approach to modeling phosphorus distribution in Lake Erie." Journal of Great Lakes Research, 35(1), 50-60.

Semtner, A. J. (1974). An oceanic general circulation model with bottom topography. Department of Meteorology, University of California.

Simons, T. J. (1974). "Verification of numerical models of Lake Ontario: Part I. Circulation in spring and early summer." Journal of Physical Oceanography, 4(4), 507-523.

Simons, T. J. (1976). "Analysis and simulation of spatial variations of physical and biochemical processes in Lake Ontario." Journal of Great Lakes Research, 2(2), 215-233.

Spain, J. D., Wernert, G. M., and Hubbard, D. W. (1976). "The structure of the spring thermal bar in Lake Superior, II." Journal of Great Lakes Research, 2(2), 296-306.

Sterner, R. W. (2010). "In situ-measured primary production in Lake Superior.” Journal of Great Lakes Research, 36(1), 139-149.

Ullman, D., Brown, J., Cornillon, P., and Mavor, T. (1998). "Surface temperature fronts in the Great Lakes." Journal of Great Lakes Research, 24(4), 753-775. 
Wang, J., Hu, H., Schwab, D., Leshkevich, G., Beletsky, D., Hawley, N., and Clites, A. (2010). "Development of the Great Lakes Ice-circulation Model (GLIM): Application to Lake Erie in 2003-2004." Journal of Great Lakes Research, 36(3), 425-436.

White, B., Austin, J., and Matsumoto, K. (2012). "A three-dimensional model of Lake Superior with ice and biogeochemistry." Journal of Great Lakes Research, 38, 6171.

White, B., and Matsumoto, K. (2012). "Causal mechanisms of the deep chlorophyll maximum in Lake Superior: A numerical modeling investigation." Journal of Great Lakes Research, 38(3), 504-513.

Wool, T. A., Davie, S. R., and Rodriguez, H. N. (2003). "Development of threedimensional hydrodynamic and water quality models to support total maximum daily load decision process for the Neuse River estuary, North Carolina." Journal of Water Resources Planning and Management, 129, 295-306.

Zhao, J., Rao, Y. R., and Wassenaar, L. I. (2012). "Numerical modeling of hydrodynamics and tracer dispersion during ice-free period in Lake Winnipeg." Journal of Great Lakes Research, 38, Supplement 3(0), 147-157.

Zou, R., Carter, S., Shoemaker, L., Parker, A., and Henry, T. (2006). "Integrated hydrodynamic and water quality modeling system to support nutrient total maximum daily load development for Wissahickon Creek, Pennsylvania." Journal of Environmental Engineering, 132, 555. 


\section{Chapter 3}

Introducing a mechanistic, one-dimensional n-layer hydrodynamic model with application to Lake Superior 


\subsection{Introduction}

Mathematical modeling provides a powerful computational tool to enhance our understanding of surface water systems through determination of the "response of a physical system to changes in external stimuli" (Chapra 1997) and in developing management alternatives to address attendant concerns. These time-dependent, numerical modeling frameworks have matured from simplified lumped system models to complex tools capable of accommodating a high degree of spatial segmentation and kinetic resolution (Chapra 1997). Spatially, these models are categorized as zero-, one-, two- and three-dimensional (Ji 2008). A zero-dimensional or lumped system model is therefore an extremely simple representation of a water body, assuming homogeneity in the state variables along all three dimensions. The complexity increases from onedimensional to three-dimensional, such that a one-dimensional model is capable of simulating one of the lateral, horizontal or vertical dimensions, while a three-dimensional model can reproduce gradients along all three simultaneously.

Selecting the degree of spatial resolution necessary to address a specific problem is always an integral part of model development (Chapra 1997, Brooks and Tobias 1996). Modeling hydrodynamic processes in the Great Lakes basin has, however, relied largely on three-dimensional frameworks based on a general tendency to assume that a higher dimensionality necessarily improves the accuracy of predictions. A suite of three-dimensional hydrodynamic models and General Circulation Models (GCM's) have found wide applicability in the Great Lakes basin to simulate water temperature (Beletsky et al. 2013, Atkinson et al. 2012, Rao et al. 2009), current magnitude and direction (Bai et al. 2013, Zhao et al. 2012, Chen et al. 2001) and additional variables of physical limnology, often in conjunction with ecological models (Bocaniov et al. 2014, Leon et al. 2012, White et al. 2012, Beletsky et al. 2007). These 
complex hydrodynamic and ecological models certainly have merit in addressing coastal dynamics and three-dimensional phenomena such as upwelling, internal waves and nearshore-offshore nutrient transport in large lake environments. However, the resource intensive computational time associated with their application is the primary obstacle limiting their capacity for iterative testing in the development and calibration phases of the modeling process. This property is especially critical while conducting a comprehensive evaluation of the many coefficients associated with ecological frameworks. Even a single model simulation, conducted using high performance computing clusters, can span several days of computational time and therefore an attempt to thoroughly calibrate all the components of such a complex three-dimensional model would require an unreasonable period of time. In hydrodynamic models, computational time is dependent on the spatial extent of the model domain (dimensions and bathymetry) and the spatio-temporal resolution dictated by the grid itself. Since the physical characteristics of the system cannot be altered, the time required to execute the model can only be reduced by introducing a coarser grid resolution in time and space which in turn may have a negative impact on the quality of model output. Lack of fine spatial resolution along the vertical dimension is one of the primary reasons why these models have faced challenges in defining the structure of a stratified water column in large, deep lakes (White et al. 2012, Bennington et al. 2010, Huang et al. 2010, Wang et al. 2010, Beletsky and Schwab 2001).

Alternatively, adopting a one-dimensional approach offers a simple and computationally-efficient method of investigating ecosystem response to meteorological drivers. In studies that are not limited by the loss of lateral and horizontal resolution (i.e. not primarily influenced by three-dimensional phenomena such as upwelling and horizontal transport), application of a vertically-segmented hydrodynamic model is 
sufficient to reproduce the characteristics of mixing and heat distribution in the water column. In addition, the one-dimensional framework allows for quick iterative simulations to fine tune coefficients as required for development and calibration of coupled hydrodynamic-ecological models. A one-dimensional modeling framework that couples a hydrodynamic model to an ecosystem model permits rapid, iterative evaluation of the dozens of variables associated with chemical and biological processes. Evaluating results from this 1D, test-bed approach provides guidance on parameter selection and quantification in more complex three-dimensional ecological models (McDonald et al. 2012). Accordingly, a mechanistic, one-dimensional hydrodynamic model, UFILS4 was modified to support the hydrodynamic component of such a test-bed coupled physical-ecological framework. This model is parsimonious in its demand for inputs and provides estimates of physical characteristics including water temperature, depth of the thermocline and vertical mixing coefficients as required by the coupled onedimensional water-quality framework.

This UFILS4 model has been successfully applied to multiple systems including Cannonsville Reservoir (Owens 1998) and Onondaga Lake (Owens and Effler 1996, Owens and Effler 1989) in New York. In addition, a comprehensive validation of the model was performed, simulating temperature and salinity over a 19 year period in dimictic, hyposaline Onondaga Lake (O'Donnell et al. 2010). This validation demonstrated that the model could perform well over differing temporal scales (vertical profiles, seasonal trends and inter-annual differences). While the performance of this modeling tool has been tested and established, UFILS4 has focused only on smaller waterbodies supporting the assumption of horizontal homogeneity. This paper introduces the adaptation of the 1D UFILS4 model framework for application to large lakes, exploring spatial and temporal patterns in thermal stratification in Lake Superior. 
This study, therefore, describes the introductory step required in developing, testing and establishing a one-dimensional approach of coupling physical and ecological models to support parameterization and effective application of complex three-dimensional frameworks.

\subsection{Model Description}

UFILS4 is a one-dimensional hydrothermal model that simulates the vertical distribution of temperature, solar radiation, vertical turbulent diffusivity, and turbulent diffusion of heat over the entire water column from the water surface to the lake bottom. This model is based on the conservation equation for heat that considers,

$$
\frac{\partial T}{\partial t}=\frac{\partial}{\partial z}\left[K \frac{\partial T}{\partial z}\right]+\frac{1}{\rho c} \frac{\partial}{\partial z}\left(\phi_{S}\right)
$$

where $\mathbf{T}$ is water temperature, $\mathbf{t}$ is time, $\mathbf{z}$ is the vertical position (positive upward), $\mathbf{K}$ is the turbulent diffusivity for heat, $\boldsymbol{\rho}$ and $\mathbf{c}$ are the density and specific heat of water, and $\boldsymbol{\phi}_{S}$ is the flux of solar radiation in the water column. In this application of UFILS4 to Lake Superior, it is assumed that the water column has a constant area from the surface to the lake bottom, and that water column temperature is not affected by inflows to or outflow from the lake, nor by heat exchange with the shallow or deep sediments. Below the water surface, the only processes affecting temperature are: heating by absorption of solar radiation, and heating or cooling by vertical turbulent diffusion. By analogy with Fourier's Law, the vertical turbulent flux of heat $\boldsymbol{\phi}$ within the water column is given by

$$
\phi=-\rho c K \frac{\partial T}{\partial z}
$$


where $\mathbf{K}$ has dimensions of [energy/area/time]. The boundary condition for Eq. (2) at the lake bottom $(\mathbf{z}=0)$ assumes that heat exchange with the sediments is negligibly small, so that

$-\rho c K \frac{\partial T}{\partial z}=0$

The boundary condition for Eq. (2) at the water surface $\mathbf{z}=\mathbf{z}_{\mathbf{s}}$ is

$-\rho c K \frac{\partial T}{\partial z}=\beta \phi_{S N}+\phi_{A}+\phi_{B}+\phi_{E}+\phi_{C}$

where $\boldsymbol{\beta}$ is the fraction of the net (incident less reflected) solar radiation immediately below the water surface (defined as $\phi_{S N}$ ), and $\phi_{A}, \phi_{B}, \phi_{E}$, and $\phi_{C}$ are the net atmospheric, back longwave, evaporative, and conductive components of heat flux at the water surface, respectively.

In this application, the incident solar radiation is directly measured; reflected solar radiation is estimated using an empirical relation dependent on solar angle, and the net solar radiation $\boldsymbol{\phi}_{S N}$ is equal to incident less reflected radiation. The general relationship for atmospheric radiation $\boldsymbol{\phi}_{\boldsymbol{A}}$ is given by $\varepsilon \sigma T_{a}^{4}$, where $\boldsymbol{\varepsilon}$ is the emissivity of the atmosphere, $\boldsymbol{\sigma}$ is the Stefan-Boltzmann constant, and $\mathbf{T}_{\mathbf{a}}$ is the absolute air temperature. The empirical expression for the emissivity given by Swinbank (1963) is used, where $\boldsymbol{\varepsilon}$ is a function of air temperature and cloud cover represented as,

$$
\varepsilon=9.07 \times 10^{-6} T_{a}^{2}\left(1+0.17 C^{2}\right)
$$

where $\mathbf{C}$ is the cloud cover fraction. For back radiation,

$\phi_{B}=\varepsilon \sigma T_{a s}^{4}$

where $\mathbf{T}_{\mathbf{a}}$ is the absolute temperature of the water surface, and the water surface is assumed to have a constant emissivity $\varepsilon=0.97$ (a nearly perfect blackbody). The evaporative heat loss is given by, 
$\phi_{E}=\frac{L}{R T_{a}}(a+b W)\left(e_{S}-e_{A}\right)$

where $\mathbf{L}$ is the latent heat of vaporization, $\mathbf{R}$ is the gas constant, $\mathbf{T}_{\mathbf{a}}$ is the absolute air temperature, $\mathbf{e}_{\mathbf{S}}$ is the saturated vapor pressure of the air, and $\mathbf{e}_{\mathbf{A}}$ is the actual vapor pressure of the air, and $\mathbf{a}$ and $\mathbf{b}$ are empirical coefficients. The saturated vapor pressure is a function of air temperature, while the actual vapor pressure is a function of the air temperature and some measure of atmospheric moisture content, such as relative humidity or dew point temperature. The conductive heat transfer is computed by,

$\phi_{C}=\rho c(a+b W)\left(T_{S}-T_{A}\right)$

where $\mathbf{T}_{\mathbf{s}}$ is the water surface temperature. In the expressions for evaporative and conductive heat exchange, the term $(a+b W)$ represents a mass or heat transfer coefficient, with dimensions of [length/time]. This expression assumes that a portion of the transfer is dependent on wind, while a portion is independent of wind.

The flux of solar radiation in the water column below the water surface is given by,

$\phi_{S}=(1-\beta) \phi_{S N} e^{-k_{D}\left(z_{S}-z\right)}$

where $\mathbf{k}_{\mathbf{D}}$ is the extinction coefficient for solar radiation in the water column.

This model uses a mixed layer approach in calculating mixing in the surface layer, or epilimnion, of the lake. It is assumed that a well-mixed layer of depth $\mathbf{h}$ exists at the lake surface. The depth and temperature of this layer are determined by conservation equations for turbulent kinetic energy (TKE) and temperature that have been integrated vertically over the depth $\mathbf{h}$ of this layer. A velocity scale $\boldsymbol{\sigma}$ that quantifies the TKE is given by, 
$\sigma^{3}=\eta^{3} u_{*}^{3}+w_{*}^{3}$

where $u_{*}=\sqrt{\tau / \rho}$ is the shear velocity associated with the wind-induced shear stress at the water surface $(\boldsymbol{\tau}), \mathbf{w} *$ is a velocity scale associated with the production of turbulence by buoyancy effects (cooling of the water surface which produces unstable vertical density gradients), and $\boldsymbol{\eta}$ is a dimensionless empirical coefficient. When the water surface is cooling (due to back radiation, evaporation, and/or conduction), penetrative convection generates TKE and $\mathbf{w} *>0$. Conversely, if the solar and atmospheric radiation warm the water surface, $\mathbf{w} *<0$ and turbulence generated by the wind is dampened. If the net effect of wind mixing and buoyancy effects produces TKE, then $\boldsymbol{\sigma}$ $>0$ and excess TKE is available to deepen the mixed layer (increase $\mathbf{h}$ ). This deepening is described by,

$\frac{d h}{d t}=\frac{C_{F} \sigma}{C_{T}+R i}$

where $\mathbf{C}_{\mathbf{F}}$ and $\mathbf{C}_{\mathbf{T}}$ are dimensionless empirical coefficients, and the bulk Richardson number $\mathbf{R i}$ for the mixed layer is defined by,

$$
R i=\frac{\sigma^{2}}{\Delta \rho g h}
$$

where $\Delta \boldsymbol{\rho}$ is the increase in density at the base of the mixed layer, and $\mathbf{g}$ is the acceleration of gravity. This equation states that in the case where $\boldsymbol{\sigma}>0$, the mixed layer depth $\mathbf{h}$ decreases. This depth is determined by solving for $\boldsymbol{\sigma}=0$, which indicates that there is a balance between the TKE input from the wind $\left(\eta^{3} u_{*}^{3}\right)$ and the dampening effect of surface heating $\left(w_{*}^{3}\right)$.

An empirical relationship is used to compute the vertical diffusivity $\mathbf{K}$ in the water column below the mixed layer. This relationship is defined as, 
$K=C_{H} \frac{u_{*}^{3}}{h_{T} N^{r}}$

where $\mathbf{C}_{\mathbf{H}}$ and $\mathbf{r}$ are empirical coefficients, and $\mathbf{N}$ is the local buoyancy frequency in the water column (varies with vertical position $\mathbf{z}$ ) and is given by

$$
N=\sqrt{-\left(\frac{g}{\rho}\right)\left(\frac{\partial \rho}{\partial z}\right)}
$$

As a result, $\mathbf{K}$ is a function of depth, $\mathbf{z}$, and time, $\mathbf{t}$. An implicit finite difference solution is used to compute the temperature of discrete model layers of thickness, $\Delta \mathbf{z}$. All calculations are done over a daily time step, so that daily averaged values of meteorological variables are used as model input. Diurnal variations in temperature are not considered by this model. For those discrete layers in the water column that fall within the mixed layer of depth $\mathbf{h}$, a constant value of the turbulent diffusivity $\mathbf{K}=5$ $\mathrm{m}^{2}$. hour ${ }^{-1}$ is used. For the segment of the water column below the mixed layer, $\mathbf{K}$ is determined using Eq. (13).

\subsection{Ecosystem Application}

\subsubsection{Study system}

Lake Superior, the largest, deepest and least anthropogenically disturbed of the Great Lakes, was selected as the study site for this modeling effort. Among the Great Lakes, Lake Superior is distinguished by the longest duration of spring mixing, the shortest period of summer stratification and the lowest maximum surface water temperature (Bennett 1978). The spring thermal bar develops latest (with respect to the

other Great Lakes) and temperature gradients between the shallow nearshore and deeper offshore are evident through the summer season (Ullman et al. 1998). 
This study focuses on the western basin of Lake Superior adjacent to the Keweenaw Peninsula. Sampling was conducted along the 11 station Houghton North (HN) transect, located just north of the North Entry to the Keweenaw Waterway, where depths increase gradually from $10 \mathrm{~m}$ at $1 \mathrm{~km}$ offshore to $183 \mathrm{~m}$ at a distance of $26 \mathrm{~km}$ (Figure 3.1). Two stations were selected for this study as offering a marked difference in thermal regime and mixing conditions: one in the nearshore (HN020, depth: $18 \mathrm{~m}$ ), located $2 \mathrm{~km}$ from shore, and one in the offshore (HN260, depth: $183 \mathrm{~m}$ ). Temporally intensive sampling was conducted at these two stations on board the $R / V$ Agassiz over the April to October period of 2011. A Seabird Electronics Conductivity/Temperature/Depth profiler (SBE-25 CTD) was used to measure vertical temperature profiles at each station. These data are used in model calibration.

In addition, at depth temperature data were obtained from two external sources, one representing the nearshore and one representing the offshore, to support the measurements recorded along the $\mathrm{HN}$ transect. Daily temperature profiles for the nearshore, representing 24-hour averages for eight vertically distributed thermistors located at MTU/U-GLOS Station 45023, were retrieved from the Upper Great Lakes Observing System (U-GLOS) Great Lakes Buoys database for the June-September interval of 2011. Temperature profiles for the offshore were recorded by the U.S. Environmental Protection Agency (EPA) during shipboard CTD deployments at three open-lake stations (SU12, SU14 and SU16) in April and August of 2011. These external sources of temperature data (nearshore buoy measurements and offshore EPA station profiles) represent independent information for use in model confirmation. 


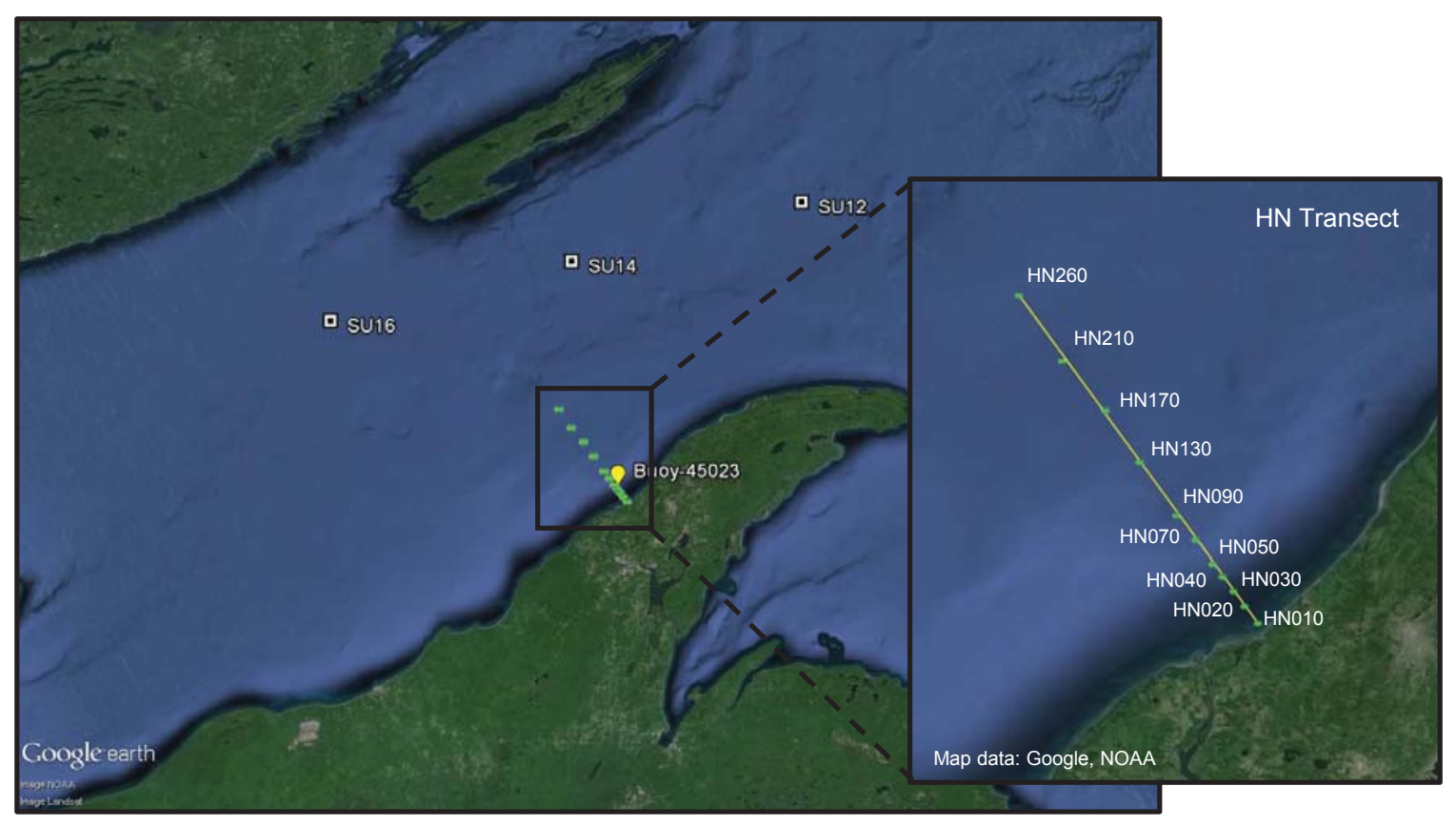

Figure 3.1. Western basin of Lake Superior with the Houghton North (HN) transect and the locations of the three EPA sampling stations (white squares) and the meteorological buoy 45023 (yellow circle). Details of the eleven stations in the HN transect are highlighted in the inset. Map data: Google, NOAA, USGS/NASA Landsat Program. (c) 2015 Google Inc, used with permission. Google and the Google logo are registered trademarks of Google Inc.

\subsubsection{Model application}

In adopting the one-dimensional UFILS4 model for this large lake application, bathymetric data, meteorological forcing conditions and model coefficients were determined on a site-specific basis.

\subsubsection{Model grid}

A vertical column with a uniform cross-sectional area of $1 \mathrm{~m}^{2}$ was established for each station (HN020, HN260, Buoy 45023 and the three EPA stations, SU12, SU14, SU16) to represent the system under consideration. The depth (and volume) of each vertical columnar grid, determined from bathymetry data obtained from the National Oceanic and Atmospheric Administration (NOAA) National Centers for Environmental 
Information (NCEI) database (Table 3.1), was further divided into multiple layers of $1 \mathrm{~m}$ thickness. Note that each multi-layer vertical column represents a unique, independent, one-dimensional 'model grid' characterizing physical specifications at a single station.

\subsubsection{Forcing conditions}

Site-specific meteorological forcing conditions, including dew point and air temperatures, incident solar radiation and wind speed, were acquired for each of the six 'model grids' presented in Table 3.1. Buoy 45023 is the only station where all of the meteorological parameters required by the model are available. For the remaining five stations, three-hour interval measurements of three meteorological variables (downward solar radiation flux, attendant cloud cover and atmospheric pressure) were retrieved for the western basin of Lake Superior over the April - September period of 2011 from the National Centers for Environmental Prediction (NCEP) National American Regional Reanalysis (NARR) database (Mesinger et al. 2006). Daily averaged values of these three parameters were calculated and assumed to be uniform over the entire study area. This assumption is supported in part by the $32 \mathrm{~km}$ horizontal resolution of NCEP NARR (Mesinger et al. 2006) but primarily by the limited variability in these atmospheric forcing conditions over the range of latitudes represented in this study. However, the other three meteorological variables, wind speed, air and dew point temperatures, reflect a greater variability over the area comprising the six stations, predominantly between the nearshore and offshore regions. Accordingly, hourly data for this second set of meteorological forcing conditions were accessed from the NOAA Great Lakes Coastal Forecasting System (GLCFS) at the HN020 (nearshore) and HN260 (offshore) stations using the Point Query Tool and converted to daily average values. Only the scalar component of wind, i.e. the wind speed, was included in this one-dimensional modeling exercise since the movement of water in the horizontal and lateral dimensions, as 
dictated by the vector attribute (i.e. the direction), is not relevant to the modeling objective of this study. Also, daily values of the light extinction coefficient $\mathbf{k}_{\mathbf{d}}$, were interpolated from biweekly field sampling conducted at the HN020 and HN260 stations in 2011 (Dijkstra and Auer, pending submission) and formatted to satisfy model requirements.

Table 3.1 Summary of model characteristics for all the nearshore and offshore 'model grids'.

\begin{tabular}{|c|c|c|c|}
\hline Station ID & Depth $(\mathrm{m})$ & Simulation Dates & Simulation Period \\
\hline \multirow{2}{*}{ HN020 } & \multirow{2}{*}{18} & May $19^{\text {th }}-$ July $11^{\text {th }}$ & Spring (rapid warming) \\
\hline & & July $12^{\text {th }}-$ October $25^{\text {th }}$ & Summer (slow warming) \\
\hline \multirow{3}{*}{ Buoy 45023} & \multirow{3}{*}{22} & June $21^{\text {st }}-$ July $1^{\text {st }}$ & \multirow{3}{*}{ Summer (slow warming) } \\
\hline & & August $28^{\text {th }}-$ September $8^{\text {th }}$ & \\
\hline & & September $9^{\text {th }}-$ September $18^{\text {th }}$ & \\
\hline \multirow{2}{*}{ HN260 } & \multirow{2}{*}{187} & April $25^{\text {th }}-$ July $11^{\text {th }}$ & Unstratified \\
\hline & & July $12^{\text {th }}-$ October $25^{\text {th }}$ & Stratified \\
\hline \multirow{2}{*}{ SU12 } & \multirow{2}{*}{239} & April $24^{\text {th }}-$ July $16^{\text {th }}$ & Unstratified \\
\hline & & July $17^{\text {th }}-$ August $20^{\text {th }}$ & Stratified \\
\hline \multirow{2}{*}{ SU14 } & \multirow{2}{*}{232} & April $24^{\text {th }}-$ July $18^{\text {th }}$ & Unstratified \\
\hline & & July $19^{\text {th }}-$ August $21^{\text {st }}$ & Stratified \\
\hline \multirow{2}{*}{ SU16 } & \multirow{2}{*}{188} & April $23^{\text {rd }}-$ July $10^{\text {th }}$ & Unstratified \\
\hline & & July $11^{\text {th }}-$ August $21^{\text {st }}$ & Stratified \\
\hline
\end{tabular}

\subsubsection{Model coefficients}

A suite of five coefficients is applied together with the forcing conditions described above in calculating heat transfer and the energy that drives mixing. Two of these coefficients, the evaporation constant $\mathbf{a}$, and the evaporation multiplier $\mathbf{b}$ from Eq. (7), accommodate the effect of evaporation on surface warming by regulating the rate of cooling associated with the latent heat of vaporization. The first of the two, a, influences 
the rate of evaporation independent of the wind speed while the latter increases the effect of wind on the rate of evaporation. The other three coefficients guide the mixing calculations in the model. The wind mixing coefficient $\boldsymbol{\eta}$, determines the effect of wind on vertical mixing throughout the water column. The remaining two coefficients, $\mathbf{C}_{\mathbf{H}}$ and $\mathbf{r}$, only influence the thermal structure below the thermocline. As with $\boldsymbol{\eta}, \mathbf{C}_{\mathbf{H}}$ enhances the effect of wind on mixing but only below the epilimnion while $\mathbf{r}$ accentuates the effect of local stratification on dampening the vertical diffusion coefficients. This modeling study focuses on adjusting two of these coefficients, $\mathbf{b}$ and $\boldsymbol{\eta}$, to reproduce observed temperature profiles using the UFILS4 model. For calibration, the evaporation multiplier, b was adjusted to obtain an accurate prediction of surface temperatures, while the wind mixing coefficient, $\boldsymbol{\eta}$ was modified to fit the depth of the epilimnion and thermocline.

The heat transfer and mixing characteristics in the nearshore region are, however, inherently different from those in the offshore. The two nearshore stations, HN020 and Buoy 45023, are shallow and are characterized by essentially linear vertical isotherms through the entire ice-free period (HN020, Figure 3.2a). Transitory stratification and short-term upwelling events (detailed in the next section) provide the exceptions to this vertical homogeneity. Thus this dynamic nearshore region, subjected to substantial wind-induced vertical mixing, does not undergo stratification. However, it does exhibit two differing rates of surface heating in spring and summer, calling for two sets of calibration coefficients (b and $\boldsymbol{\eta}$ ) to represent the spring and summer thermal regimes in the nearshore. The deep offshore stations, HN260, SU12, SU14 and SU16, are characterized by a nearly isothermal water column in spring but exhibit a stably stratified condition later in the summer (HN260, Figure 3.2b). Similar to the nearshore, two sets of coefficients are adopted here to drive the heat budget and mixing calculations necessary to capture these differing periods of offshore thermal dynamics. 
Calibration, with spring and summer coefficients, is only conducted at HN020 andHN260. Simulations at the buoy 45023 and SU12, SU14 and SU16, performed for confirmation of the model, use the same period-specific set of calibration coefficients from HN020 and HN260, respectively, (Table 3.2) over the simulation dates (period) described in Table 3.1. In this approach, the model is initialized with water temperature measurements at the start of each simulation period, as detailed in Figure 3.3.

Table 3.2 Calibration coefficients determined for the nearshore and offshore region. Two periods are identified at each region based on existing thermal dynamics, spring and summer in the nearshore and stratified and unstratified in the offshore.

\begin{tabular}{||c|c|c|c|}
\hline \multirow{2}{*}{ Region } & \multirow{2}{*}{ Simulation Period } & \multicolumn{2}{l|}{ Calibration Coefficients } \\
\cline { 3 - 4 } & & $\boldsymbol{b}$ & $\boldsymbol{\eta}$ \\
\hline \multirow{2}{*}{ Nearshore } & Spring (rapid warming) & 0.0380 & 2.5 \\
\cline { 2 - 4 } & Summer (slow warming) & 0.0028 & 1.88 \\
\hline \multicolumn{3}{|c|}{} \\
\hline \multirow{2}{*}{ Offshore } & Unstratified & 0.0013 & 1.8 \\
\cline { 2 - 4 } & Stratified & 0.0006 & 1.88 \\
\hline
\end{tabular}




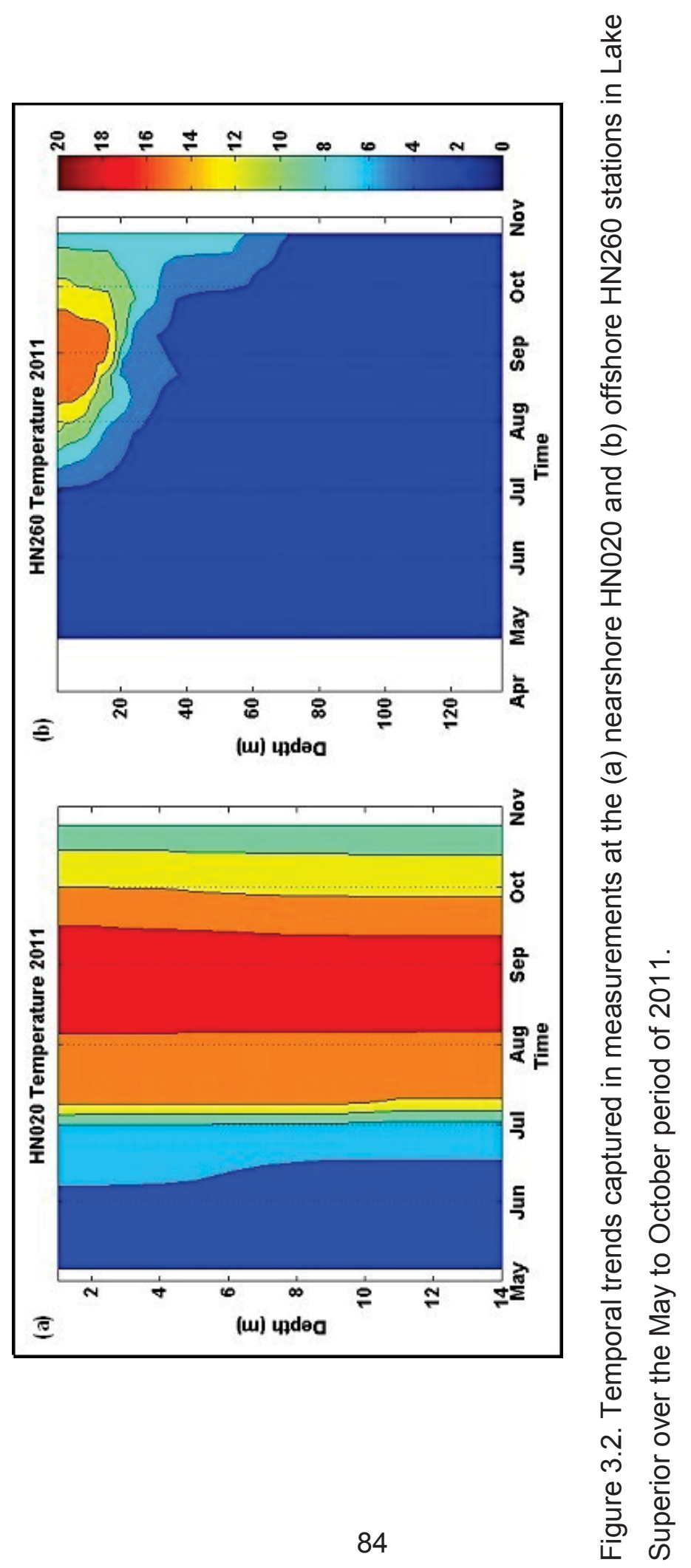




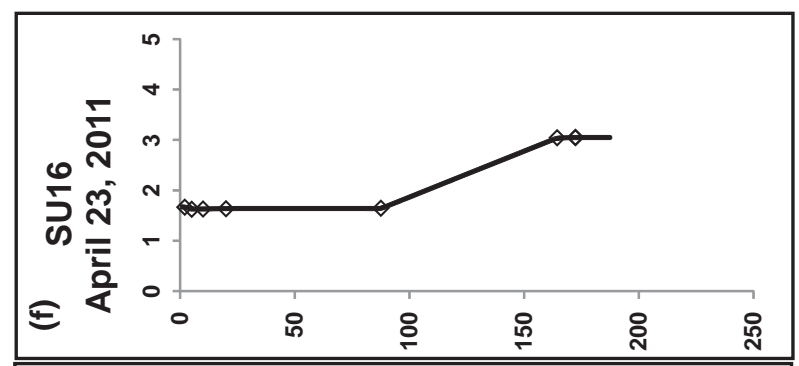

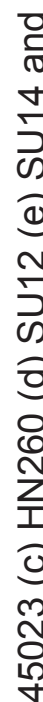
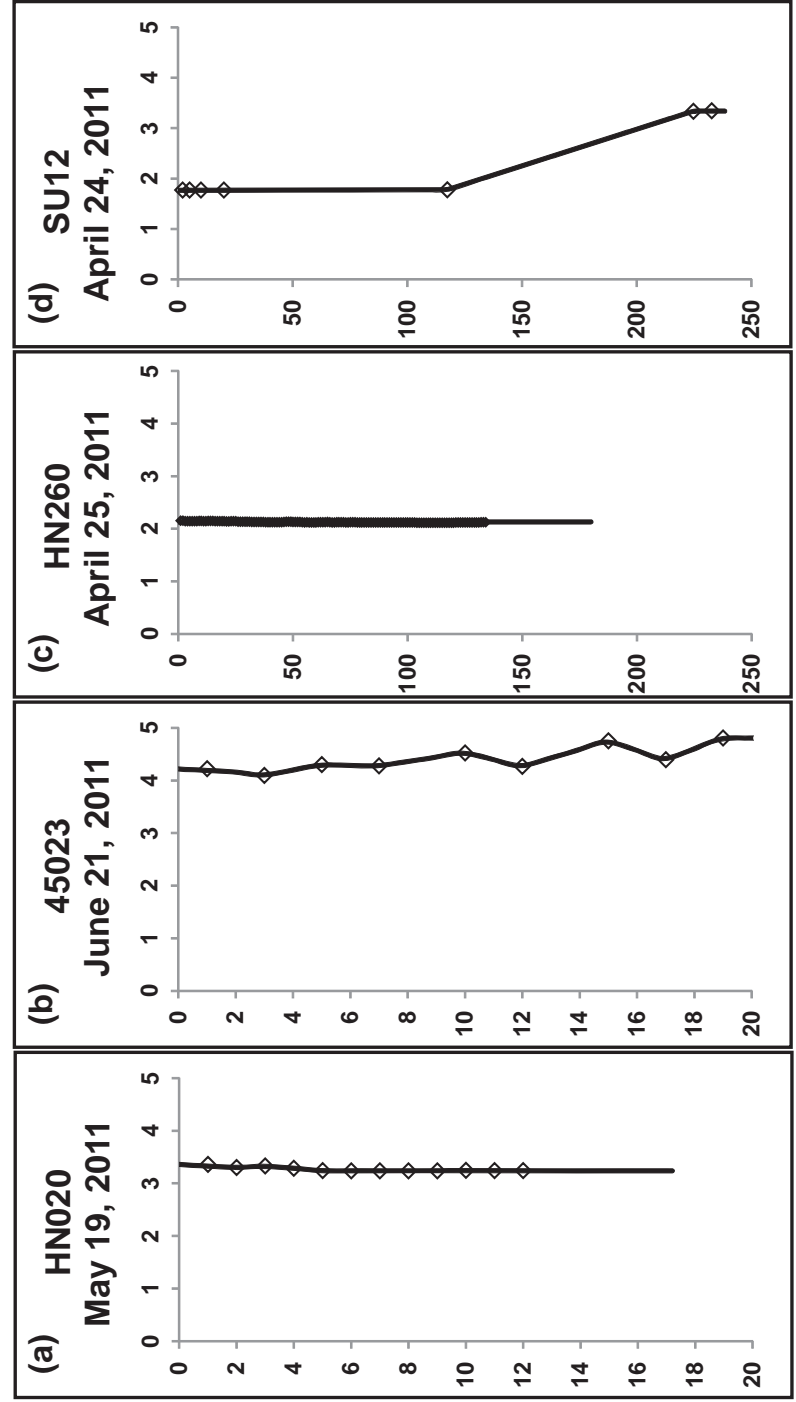

(u) पıdəa

음

으

오 을

(ำ 


\subsection{Model Calibration and Confirmation}

Calibration and confirmation of the UFILS4 model is conducted along spatial and temporal scales using water temperature as the metric for simulating the transport and distribution of heat in the lake. The performance of UFILS4 is evaluated using quantitative and qualitative criteria. A comparison of model-predictions to observations for individual vertical temperature profiles forms the primary basis for this evaluation. Quantitatively, the quality of the calibration is determined using Root Mean Square Error (RMSE) analysis, calculated as

$R M S E=\sqrt{\frac{\sum_{i=1}^{n}(x-y)^{2}}{n}}$

where $\mathbf{x}$ and $\mathbf{y}$ are modeled and measured values and $\mathbf{n}$ is the number of measurements. The goodness-of-fit for this analysis was evaluated by comparison with a reference RMSE of $1.98{ }^{\circ} \mathrm{C}$ (established in Gawde et al., pending submission), derived as the average (with $95 \%$ confidence intervals, $2.54{ }^{\circ} \mathrm{C}$ and $1.42{ }^{\circ} \mathrm{C}$ ) of the values determined for hydrodynamic modeling exercises listed in Great Lakes peer-reviewed publications. Qualitatively, visual inspection of the temperature profiles is employed to track and compare characteristic features of the thermal structure, including surface water temperatures, depth of the epilimnion, hypolimnetic temperatures and the general shape of the vertical profile.

\subsubsection{Nearshore}

Seasonal trends in the thermal regime in the nearshore region of Lake Superior were simulated at two study sites, HN020 and Buoy 45023. Calibration efforts focused on the HN020 station while Buoy 45023 measurements provided an external, independent data set to confirm the UFILS4 model for this large lake application. 


\subsubsection{Station HNO2O}

A vertical temperature profile, recorded at the start of the 2011 sampling season at HNO20 (May 19 , Figure 3.3a), depicts a cold, completely mixed water column. This profile was applied as an initial condition for the HN020 model simulation. Values of 0.038 and 2.5 were determined for the model coefficients $\mathbf{b}$ and $\boldsymbol{\eta}$ through calibration (Table 3.2).

During the period of spring turnover, the model tracks the warming of the shallow water column successfully, preserving a vertically isothermal structure (Figure 3.4a, b). However, the ephemeral stratification observed in the June $17^{\text {th }}$ measured temperature profile (Figure 3.4b) presents a challenge to the model due to the transient nature of the phenomenon; a 1D framework is not suited to capturing such transience. Also, a onedimensional model is limited in its ability to reproduce the three-dimensional phenomena observed in large lake ecosystems. For example, it is unable to capture the upwelling of cold offshore water, resulting from lateral, wind-induced displacement of surface waters $\left(18^{\text {th }}\right.$ to $23^{\text {rd }}$ June, Figure 3.5$)$, and the attendant drop in nearshore water column temperatures. As a result, the model predicts warmer temperatures than measured at HN020 on June $30^{\text {th }}$ (Figure 3.4c).

The upwelling phenomenon observed here is accommodated in the 1D framework by re-initializing the model using the vertical profile measured on July $12^{\text {th }}$ (as highlighted in Figure 3.4d). Additionally, values for the calibration coefficients $\mathbf{b}$ and $\boldsymbol{\eta}$ are adjusted at this point to better represent thermal dynamics in the summer (see Table 3.2 and Section 3.3.2.3). During this simulation period, the model accurately captures the rate of warming of the water column, as documented by the good agreement between simulated and measured vertical profiles shown in Figure 3.4f, g. Autumnal cooling of the vertically 


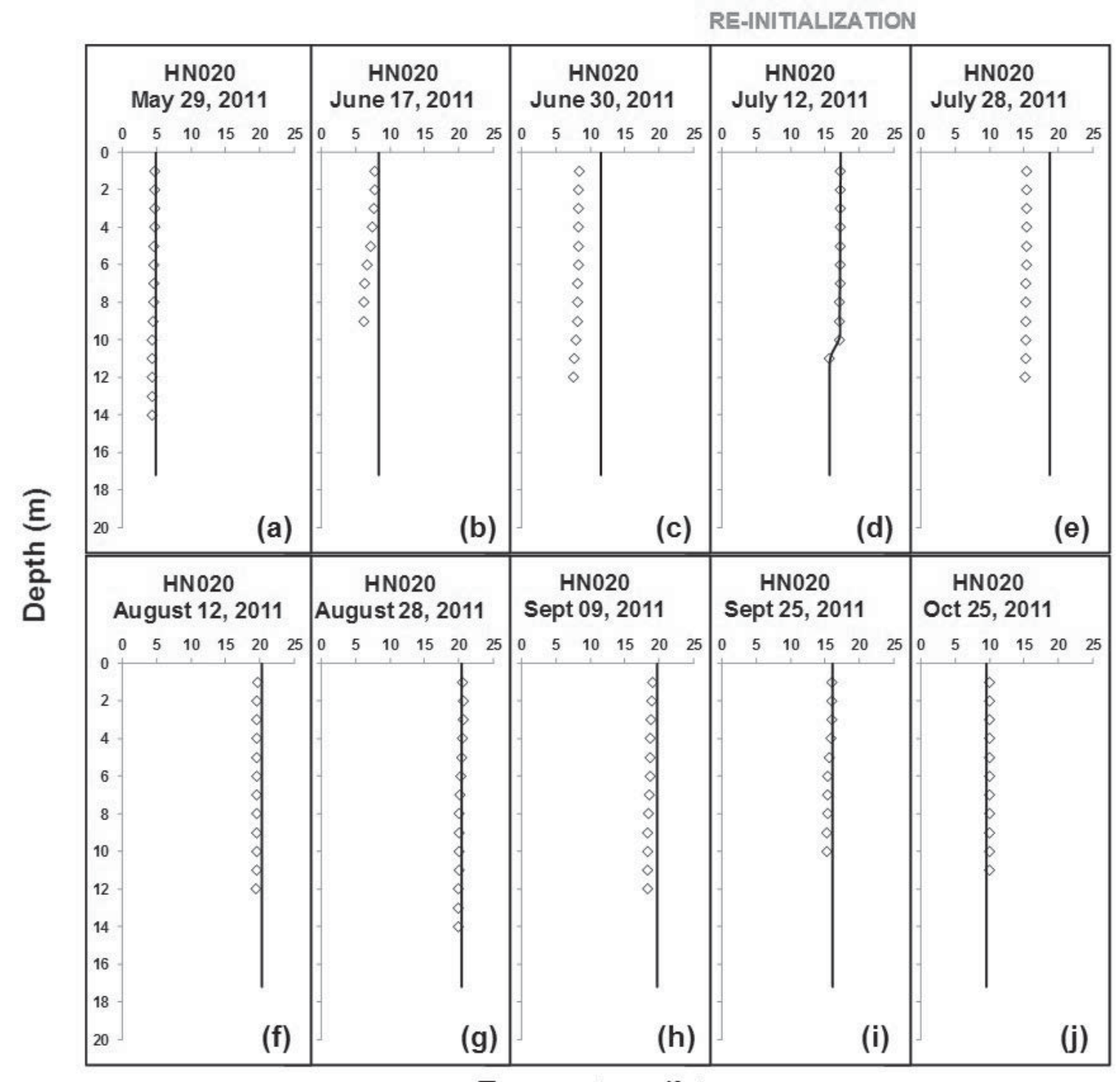

Temperature $\left({ }^{\circ} \mathrm{C}\right)$

Figure 3.4. Comparison of the measured (open diamonds) and modeled (solid line) temperature profiles at the HN020 station for the May to October period of 2011. The measured profile from July $12^{\text {th }}$ (d) serves as re-initialization for the model. 
homogeneous water column in September and October was also well tracked by the simulated temperature profiles, as observed in Figure 3.4h, i, j.

Over the entire May to October period, the HN020 modeled temperature profiles generated an RMSE of between $0.3^{\circ} \mathrm{C}$ and $3.5^{\circ} \mathrm{C}$, yielding an average RMSE of $1.3 \pm$ $1.2{ }^{\circ} \mathrm{C}$. In accordance with the established quantitative criterion, the UFILS4 model has therefore been calibrated using the measured temperature data at the HN020 station and is next subjected to confirmation using Buoy 45023 measurements.

\subsubsection{Buoy 45023}

Buoy 45023, initially deployed on $21^{\text {st }}$ June in 2011 , yielded data reflecting a vertically-homogenous thermal profile with a temperature of $\sim 4{ }^{\circ} \mathrm{C}$ (Figure $3.3 \mathrm{~b}$ ). This measurement serves here to initialize the model simulation. For the confirmation run, the model coefficients employed in calibrating for the summer period at HNO20 (Table 3.2) are adopted and are held constant over the entire period of simulation. This approach appropriately accommodates the timing of buoy deployment (late June). As observed in Figure $3.6 a-h$, the model is able to reproduce the measured vertical profiles (RMSE values ranging between $0.4{ }^{\circ} \mathrm{C}$ and $1.3^{\circ} \mathrm{C}$ ), and therefore the rate of warming, with accuracy. The vertically isothermal water column warms past $4{ }^{\circ} \mathrm{C}$ to a gently sloped profile with surface and bottom water temperatures on July 1 st of $12{ }^{\circ} \mathrm{C}$ and $8{ }^{\circ} \mathrm{C}$, respectively. However, in the summer of 2011, this buoy detached from its mooring, creating a gap in the temperature measurements. The meteorological forcing time series was thus also interrupted for this duration and the simulation period had to be divided to accommodate this event. Model simulation was restarted when the buoy was re-deployed on August $29^{\text {th }}$ (Figure 3.7a).

An upwelling event was observed in the measured temperature profiles between

September $4^{\text {th }}$ and8 ${ }^{\text {th }}$ (Figure $3.7 d-h$ ). During the upwelling, modeled 


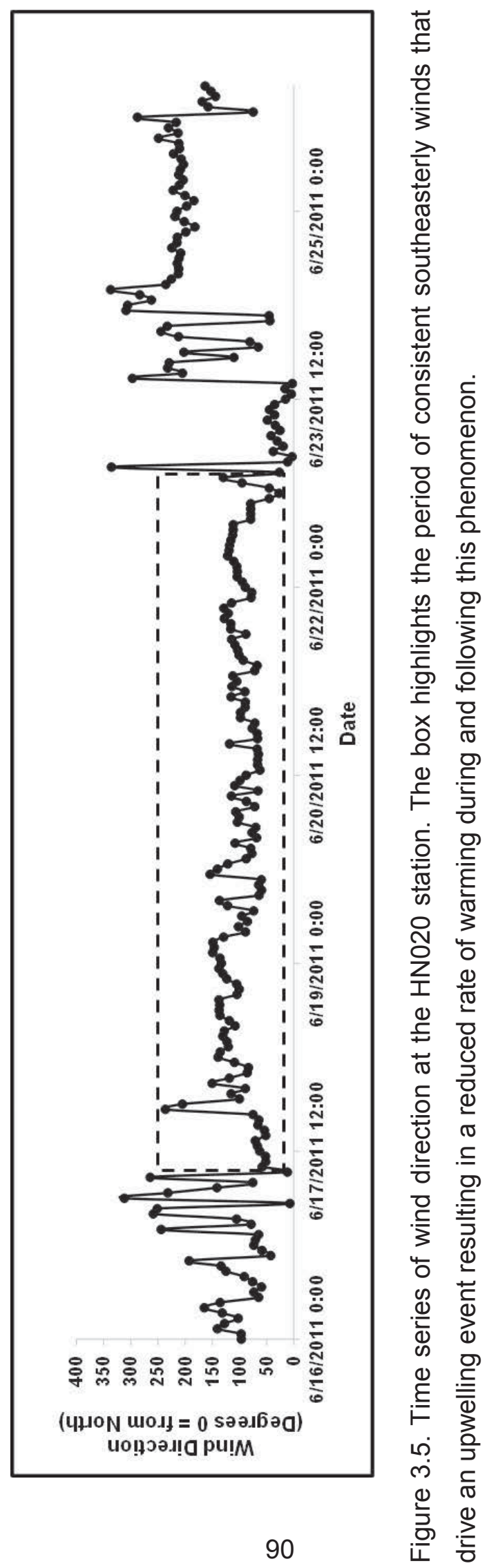




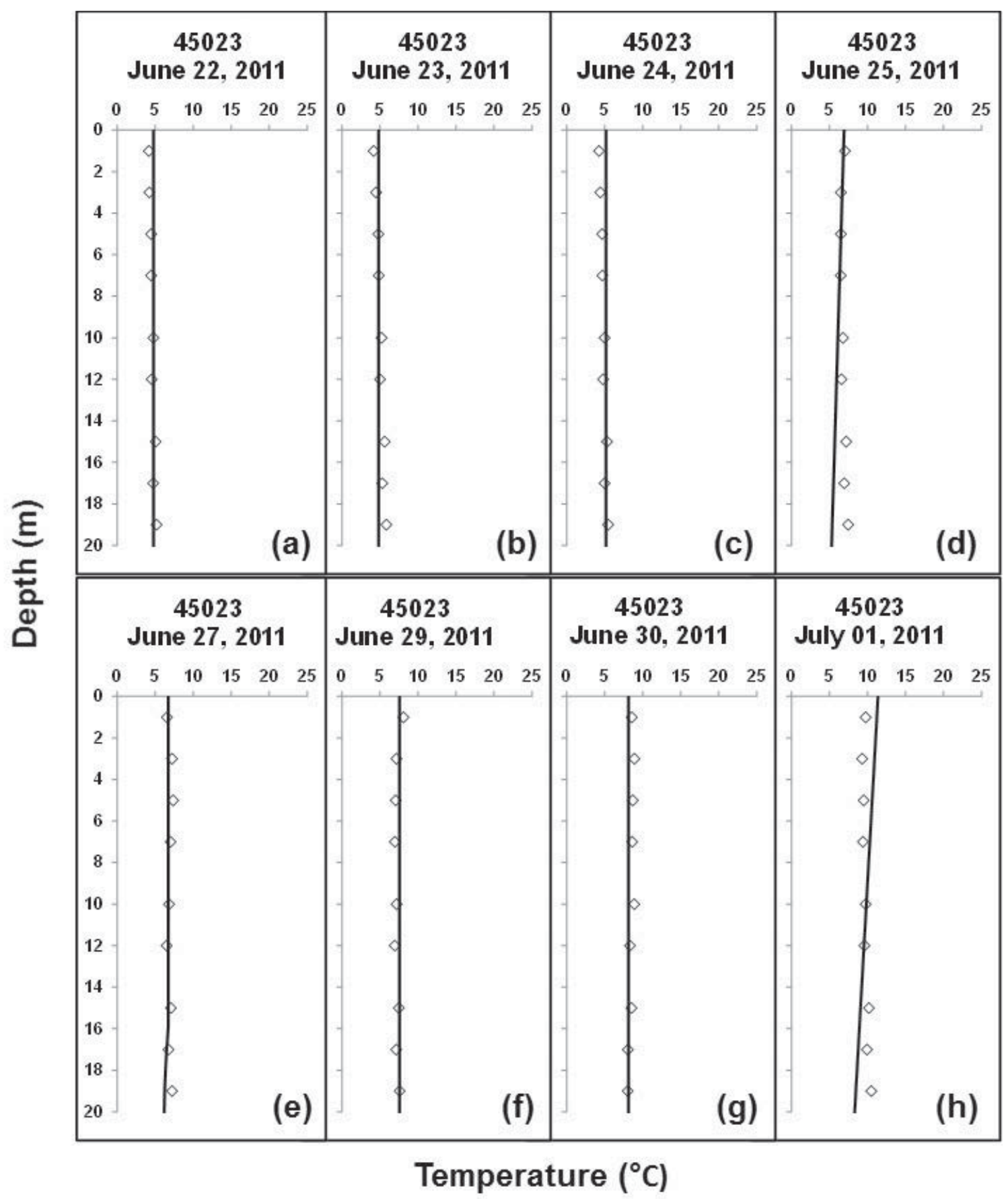

Figure 3.6. Comparison of the measured (open diamonds) and modeled (solid line) temperature profiles at Buoy 45023 for the $21^{\text {st }}$ June to $1^{\text {st }}$ July interval. 
temperatures showed a significant departure (ranging between $1.2^{\circ} \mathrm{C}$ to $16.4{ }^{\circ} \mathrm{C}$ ) from measured vertical profiles (Figure 3.7d-h), a limitation of this one-dimensional modeling study. However, this one-dimensional model helps isolate the impact of these threedimensional phenomena on vertical thermal structure and offers insights on mixing calculations and distribution of heat energy.

As with the HNO20 simulation, the model is re-initialized with a measured vertical profile (September $9^{\text {th }}$, Figure $3.8 a$ ) to appropriately incorporate the impact of this upwelling event on the thermal structure in the period following. As mentioned earlier, in this confirmation simulation the model coefficients do not change at re-initialization and are held fixed over the entire June - September period. Model performance continued to improve with better predictions of the rate of warming and the onset of fall turnover, yielding a good fit between modeled and measured temperature profiles (Figure 3.8b-j), supported by visual inspection and RMSE calculations.

RMSE values for this entire June to September simulation ranged between 0.3 ${ }^{\circ} \mathrm{C}$ to $1.6^{\circ} \mathrm{C}$, with an overall average of $0.9^{\circ} \mathrm{C}$. The model therefore performed well in simulating the vertical thermal structure using independent confirmation data from Buoy 45023. Having satisfactorily evaluated model performance through inspection of graphical reproductions and comparison of the RMSE values determined at the two independent study sites, this modeling tool was considered calibrated and confirmed for the nearshore region of Lake Superior.

\subsubsection{Offshore}

Next, salient features of the thermal stratification regime were identified using two comprehensive data sets in the offshore region of Lake Superior. The model is calibrated using temperature measurements at station HN260 and then confirmed with data from the EPA cruises at the three stations, SU12, SU14 and SU16. 


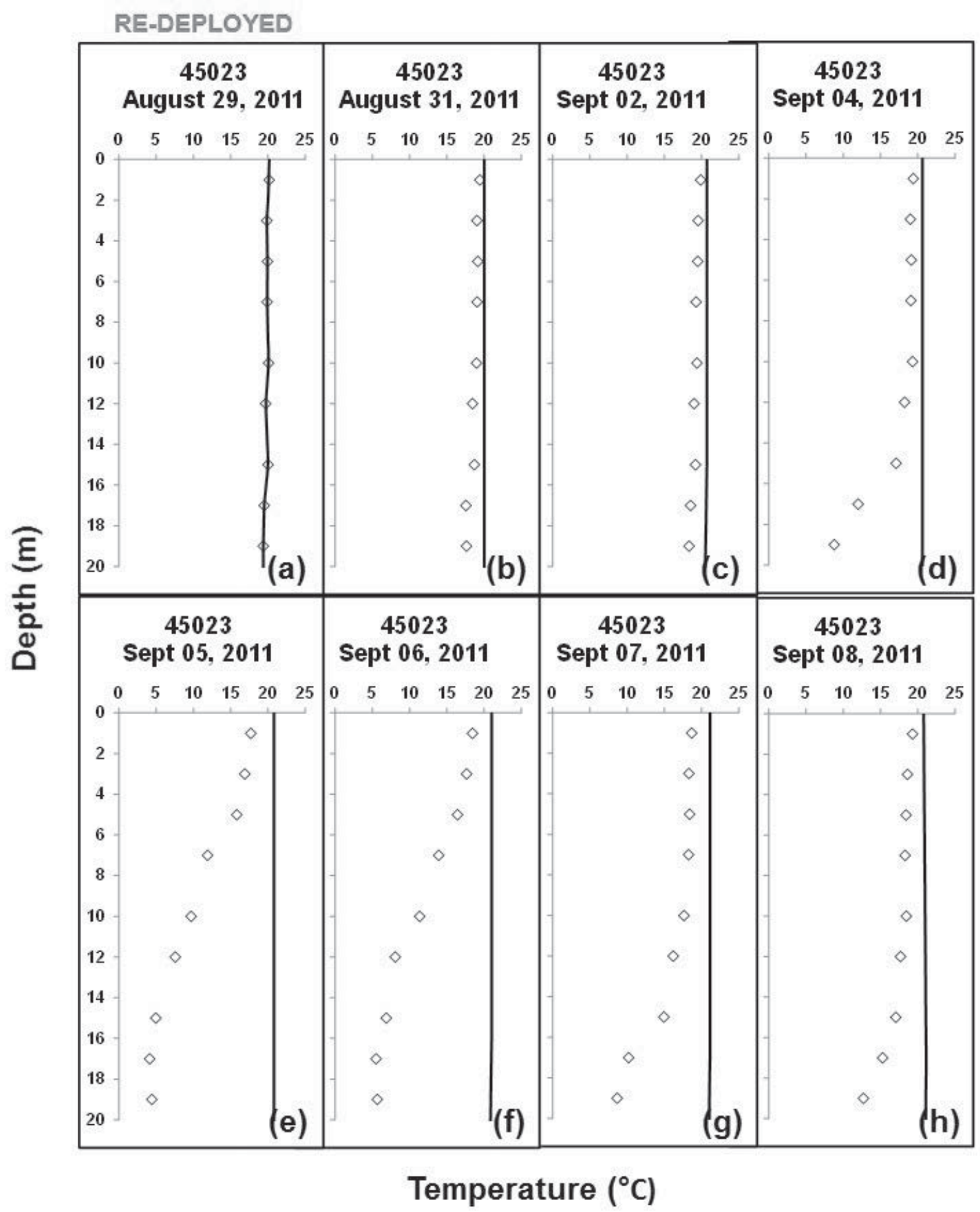

Figure 3.7. Comparison of the measured (open diamonds) and modeled (solid line) temperature profiles at Buoy 45023 for the $29^{\text {th }}$ August to $8^{\text {th }}$ September interval. The buoy was re-deployed on the $29^{\text {th }}$ of August as highlighted in (a). The profiles in the $4^{\text {th }}-$ $8^{\text {th }}$ September interval $(d-h)$ indicate an upwelling event at this location. 


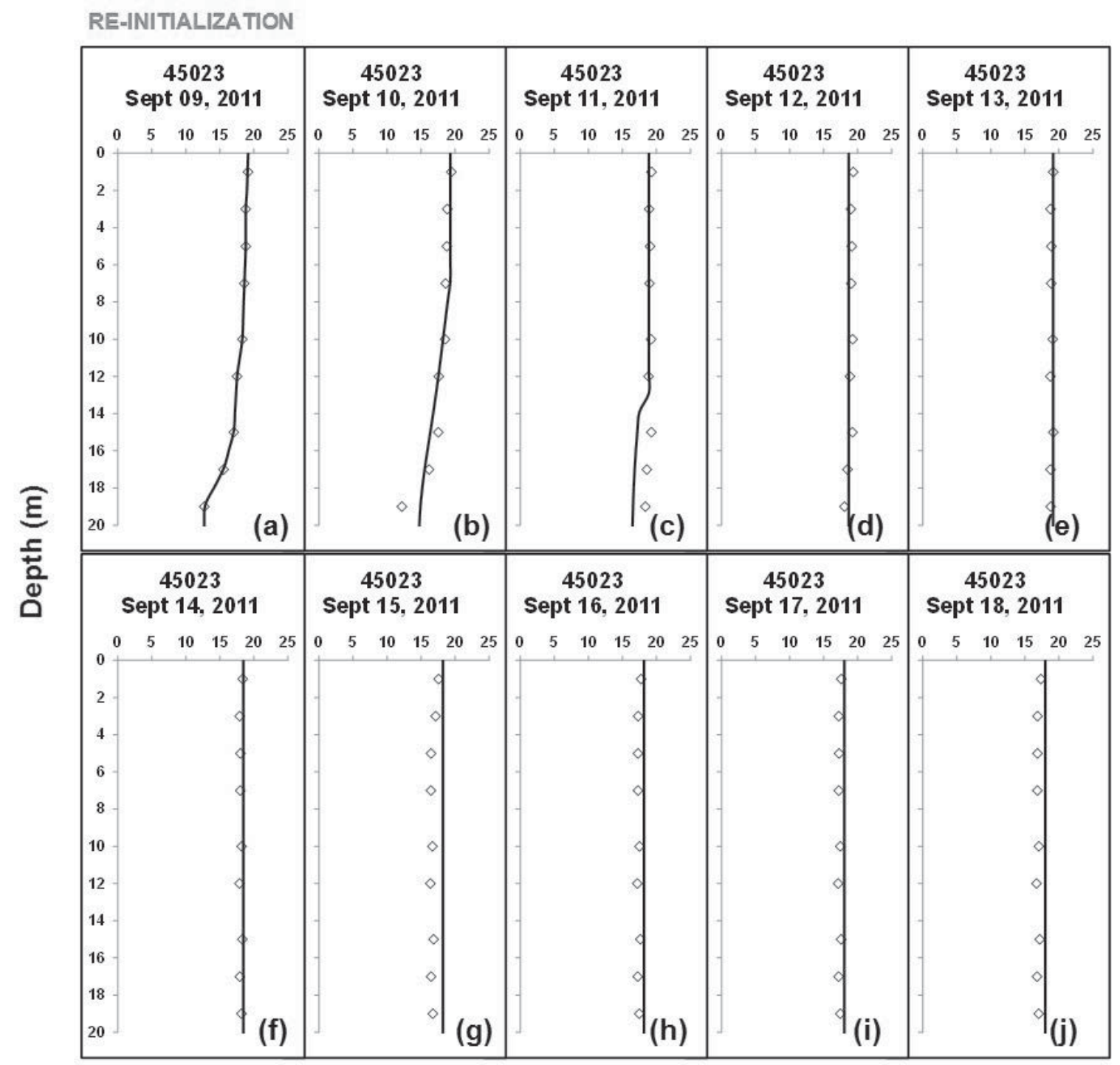

Temperature $\left({ }^{\circ} \mathrm{C}\right)$

Figure 3.8. Comparison of the measured (open diamonds) and modeled (solid line) temperature profiles at Buoy 45023 for the $9^{\text {th }}$ to $18^{\text {th }}$ September interval. The measured profile from September $9^{\text {th }}$ (a) serves as re-initialization for the model. 


\subsubsection{Station HN260}

For this simulation, the model is initialized with an observed, vertically isothermal temperature profile recorded at the offshore station, HN260 on April 25 $5^{\text {th }}, 2011$ (Figure 3.3c). Calibration coefficients, $\mathbf{b}$ and $\boldsymbol{\eta}$, are derived for the spring vertically mixed period, yielding values of 0.0013 and 1.8 (Table 3.2), respectively.

During spring turnover, the offshore waters progressively warm to a uniform $4{ }^{\circ} \mathrm{C}$ temperature through vertical distribution of heat energy. Density gradients between warmer, lighter surface waters and colder, denser bottom waters drive the downward transport of heat until the entire water column achieves vertical homogeneity at the temperature of maximum density $\left(3.98^{\circ} \mathrm{C}\right.$, Figure $\left.3.9 \mathrm{f}\right)$. The model is able to reproduce completely mixed thermal conditions resulting from surface-driven convective mixing, as observed in Figure 3.9a-f. The rate at which the water column is heating, an equally important feature of the thermal regime, is also well simulated by the model (Figure 3.9af).

As surface waters warm past $4{ }^{\circ} \mathrm{C}$ at this offshore station, initial stratification sets in and the model is re-initialized using the measured profile from July $12^{\text {th }}$, as indicated in Figure $3.9 \mathrm{~g}$. At this onset of stratification, the calibration coefficients are also adjusted to accurately describe characteristics of the stratified period (Table 3.2), yielding periodspecific coefficient values of 0.0006 and 1.88 for $\mathbf{b}$ and $\boldsymbol{\eta}$ respectively. In the summer period, surface water temperatures continue to rise. Transport of heat to subsurface waters slows and a thermocline is established between the warm epilimnion and cold hypolimnion. As determined through visual inspection of Figure 3.9h-l, model-simulated profiles successfully track the warming trend in the upper mixed layer and predict the slope and depth of the thermocline described by the measured temperature profiles. 


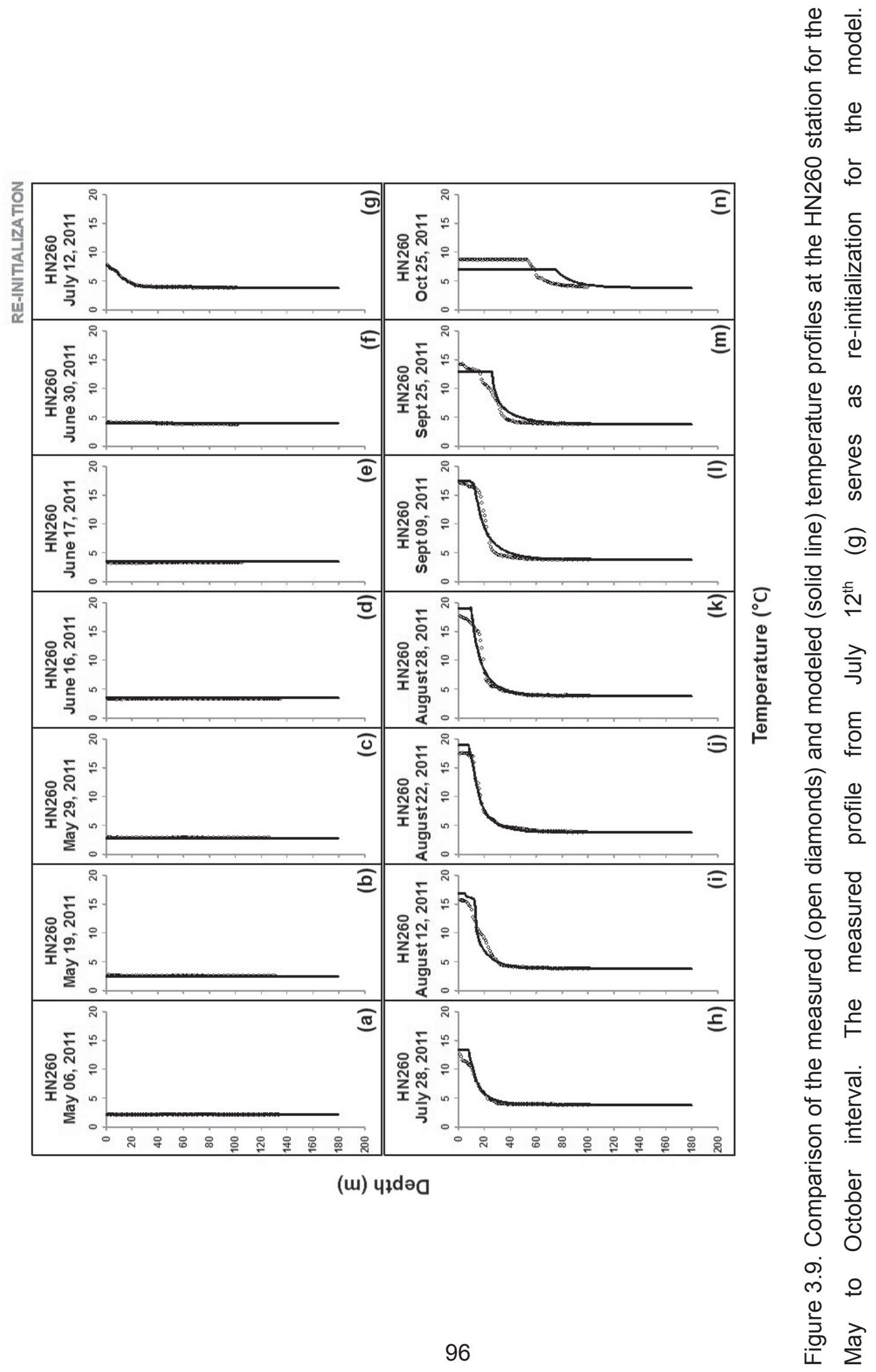


The depth of the thermocline stays relatively constant through the stratified period as offshore surface waters warm. As stratification begins to dissipate (i.e. as the water column progresses towards uniformly mixed conditions), however, surface temperatures decrease and the depth of the thermocline increases as a result of the enhanced vertical mixing characteristic of fall turnover. This phenomenon is evident in the deepening of the thermocline in the vertical profile measured on September $25^{\text {th }}$ (Figure $3.9 \mathrm{~m}$ ). The depth of the thermocline then increases at an accelerated rate and, by October $25^{\text {th }}$, fall turnover is well underway. The coefficients employed here, selected for their ability to simulate strongly stratified conditions, are less successful in reproducing conditions on October $25^{\text {th }}$ (Figure $3.9 n$ ), a date representative of autumnal cooling.

Evaluating model performance at station HN260 yielded RMSE values ranging between $0.01{ }^{\circ} \mathrm{C}$ and $1.6^{\circ} \mathrm{C}$ with an average error of $0.6^{\circ} \mathrm{C}$. These are well within the bounds established by the adopted RMSE criterion $\left(1.98{ }^{\circ} \mathrm{C}\right)$ for quantitatively evaluating model performance. In addition, the UFILS4 model performed well in simulating features of the thermal stratification regime and can therefore be considered to be calibrated for offshore conditions.

\subsubsection{EPA Stations: SU12, SU14 and SU16}

Vertical temperature profiles collected by the U.S. EPA at three stations in April

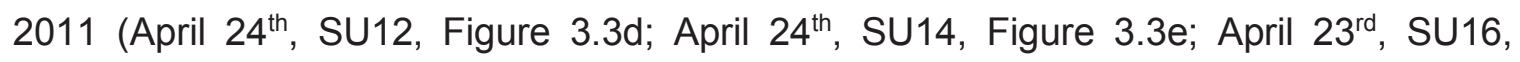
Figure 3.3f) are representative of early spring thermal dynamics in the offshore. At station SU12, the measured profile from April $24^{\text {th }}, 2011$ is applied as an initial condition for conducting the model simulation. The calibration coefficients, characterizing the unstratified period at the offshore station $\operatorname{HN} 260(\mathbf{b}=0.0013$ and $\boldsymbol{\eta}=1.8$; Table 3.2), are adopted and held constant over the April to mid-July interval in this confirmation 
exercise. In this simulation run, the model predicts the onset of stratification on July $17^{\text {th }}$, 2011 and the stratified period-specific set of coefficients (listed in Table 3.2) are applied at this point to better represent thermal dynamics in the stratification regime. In the absence of a measured temperature profile representing transitional mixing conditions, the model-predicted profile from July $17^{\text {th }}$ is used for re-initialization (Figure $3.10 \mathrm{a}$ ). This procedure is repeated at the other two U.S. EPA stations, SU14 and SU16, where model-predicted onset of stratification occurs on July $19^{\text {th }}$ (Figure $3.10 \mathrm{~b}$ ) and July $11^{\text {th }}$ (Figure 3.10c) respectively.

Model predicted vertical profiles, at each of the three stations, tracked the measurements well through the entire simulation period. Comparison of model predictions to measurements from the August sampling conducted by U.S. EPA yielded accurate reproduction of surface temperatures, the depth and slope of the thermocline and hypolimnetic temperatures in the simulated profiles (Figure 3.10d-f). To evaluate model performance, RMSE values of $2.3^{\circ} \mathrm{C}, 1.9{ }^{\circ} \mathrm{C}$ and $1.3^{\circ} \mathrm{C}$ were determined at stations SU12, SU14 and SU16 respectively. These RMSE values are comparable with those mentioned in the peer-reviewed literature (an average of $1.98{ }^{\circ} \mathrm{C}$ ) and according to the quantitative method, this model can be considered calibrated and confirmed for the offshore region of Lake Superior. 


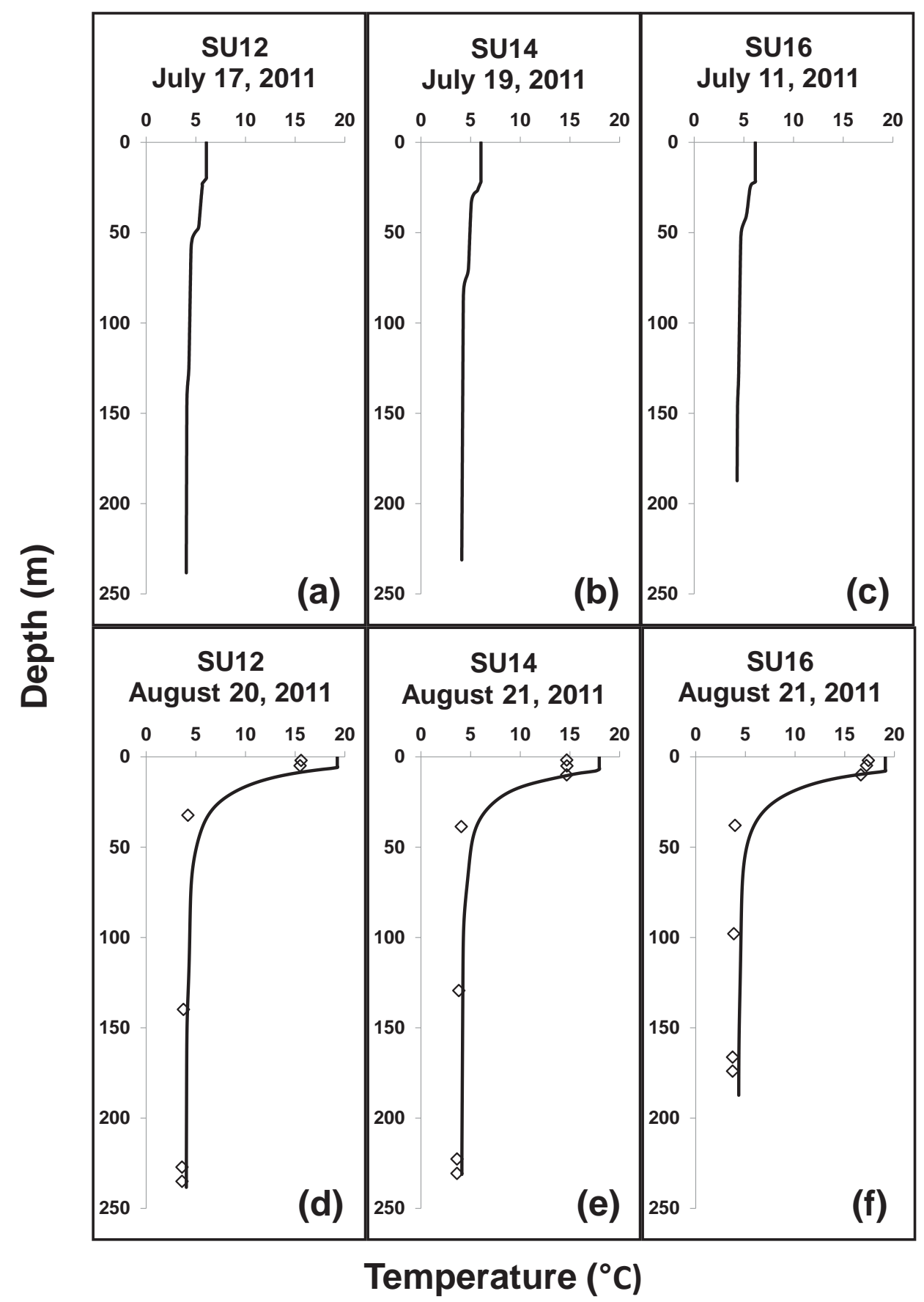

Figure 3.10. Vertical temperature profiles at the three U.S. EPA stations. Panels a-c represent a transitional water column used as re-initialization profiles at (a) SU12, (b) SU14 and (c) SU16 respectively. Panels $d-f$ describe the comparison of measured (open diamonds) and modeled (solid line) temperature profiles at (d) SU12 (e) SU14 (f) SU16 in August 2011. 


\subsection{Model Application}

\subsubsection{Comparing the predictive capacity of $1 \mathrm{D}$ and $3 \mathrm{D}$ models}

The one-dimensional UFILS4 model has been successfully calibrated and confirmed for the nearshore and offshore regions of Lake Superior using quantitative and qualitative criteria for evaluating model performance. In this large lake application, the efficiency (short time of execution), simplicity (improved resolution along the dimension of interest [vertical]) and applicability (parsimonious in required inputs) of theUFILS4 model provide a distinct advantage over the inherent complexities of threedimensional frameworks. This then leads to the question of whether the thermal structure predicted by this one-dimensional framework is comparable to the output generated by the complex model. Following calibration and confirmation, therefore, the predictive capability of this one-dimensional hydrodynamic model is compared to that of a three-dimensional framework to evaluate the quality of output generated by the two models of varying spatial resolution.

A three-dimensional hydrodynamics model, Environmental Fluids Dynamics Code (EFDC), applied to Lake Superior to quantify the characteristics of its thermal regime (Gawde et al. pending submission), is selected for this purpose. The model domain encompasses the entire north-south expanse of the lake extending from Duluth, Minnesota in the west to the tip of the Keweenaw Peninsula (Michigan) in the east. Accordingly, a model grid, consisting of 31 vertical layers with $\sim 4100$ active cells per layer, was established for the western basin of Lake Superior to define the spatial extent and vertical partitioning of the system. After finalizing the grid, meteorological forcing conditions (including solar radiation, cloud cover, wind speed and direction, air temperatures and relative humidity) and boundary conditions for the eastern open lake boundary (water temperatures and flow velocities), simulation runs were conducted for 
the April to September period of 2011 and 2012. Water temperature was used as a quantitative index of the transport of energy in the lake and the model was calibrated using a temperature database for 2011 and confirmed using measurements for the following year. Calibration and confirmation were conducted on both a spatial and temporal basis. On a spatial scale, model output satisfactorily matched vertical (depth profiles) and horizontal (longitudinal profiles, extending from nearshore to offshore) temperature structure defined using data collected along the HN transect for 2011 and 2012 (as described in Gawde et al., pending submission). A time series of model generated values was also compared against buoy measurements at the 45027 (western), 45006 (central) and 45023 (Michigan Tech, Keweenaw Waterway) buoys located in Lake Superior as retrieved from NOAA's National Data Buoy Center (NDBC) database. The quality of calibration and confirmation were determined using multiple criteria including a quantitative approach (Root Mean Square Error), a qualitative evaluation of the characteristics of the thermal regime and finally, an ecologicallymeaningful criterion (as described in Gawde et al., pending submission). For each criterion, the uncertainty calculated for the optimal fit was in agreement with established standards and this three-dimensional application of the EFDC model was said to be calibrated and confirmed.

In application here, vertical temperature profiles at the HN020 and HN260 stations were extracted from the calibrated and confirmed EFDC model and compared to corresponding profiles predicted by the UFILS4 model. At the nearshore HN020 station, both the one-dimensional and three-dimensional models perform well in capturing early spring isothermal conditions (Figure 3.11a-b), as indicated by their RMSE values (May $19^{\text {th }}$, EFDC $-0.4{ }^{\circ} \mathrm{C}$, UFILS4 $-0.2{ }^{\circ} \mathrm{C}$; June $17^{\text {th }}$ EFDC $-0.7^{\circ} \mathrm{C}$, UFILS4 $-1.5{ }^{\circ} \mathrm{C}$ [transient stratification]). On two dates in summer, however, (June $30^{\text {th }}$, Figure $11 \mathrm{c}$ and 
July $28^{\text {th }}$, Figure $3.11 \mathrm{~d}$ ) as determined through visual inspection, the EFDC model is better able to reproduce measurements then is the UFILS4 model (Figure 3.11c-d). These two measured profiles have been identified as reflecting the impact of an upwelling (i.e. nearshore-offshore transport as discussed in Section 3.4.1.1). The ability of the 3D EFDC model (Figure 3.11c) to simulate this multi-dimensional phenomenon points to a limitation of the one-dimensional model (Figure 3.11d). In the subsequent profiles recorded in August (Figure 3.11e-f), however, the rate of warming is more accurately captured by the one-dimensional model, thereby generating lower errors than those of the EFDC model (August $12^{\text {th }}$, EFDC $-1.6^{\circ} \mathrm{C}$, UFILS4 $-0.8^{\circ} \mathrm{C}$; August $28^{\text {th }}$, EFDC $-2.2^{\circ} \mathrm{C}$, UFILS $4-0.3^{\circ} \mathrm{C}$ ). Model predictions of the onset of autumnal cooling, represented by the September $9^{\text {th }}$ profile (Figure $3.11 \mathrm{~g}$ ), yield comparable RMSE values for the two frameworks (EFDC $-0.2{ }^{\circ} \mathrm{C}$, UFILS $\left.4-1.1^{\circ} \mathrm{C}\right)$.

This analysis was also extended to the offshore station. During the spring wellmixed period (May - June, Figure 3.12a-e), EFDC modeled temperatures were consistently warmer than both the measurements and UFILS4-predicted values resulting in higher RMSE values for the three-dimensional model (May 6 ${ }^{\text {th }}$, EFDC $-0.9{ }^{\circ} \mathrm{C}$, UFILS $4-0.01{ }^{\circ} \mathrm{C}$; May $19^{\text {th }}$, EFDC $-0.9^{\circ} \mathrm{C}$, UFILS $4-0.1^{\circ} \mathrm{C}$; May $29^{\text {th }}$, EFDC $-0.9^{\circ} \mathrm{C}$, UFILS $4-0.1^{\circ} \mathrm{C}$; June $17^{\text {th }}$, EFDC $-1.5^{\circ} \mathrm{C}$, UFILS $4-0.2^{\circ} \mathrm{C}$; June $30^{\text {th }}$, EFDC $-1.4^{\circ} \mathrm{C}$, UFILS4 $\left.-0.1^{\circ} \mathrm{C}\right)$. In June, especially, the EFDC model predicts transitional stratification, a projection not supported by measured profiles $\left(17^{\text {th }}\right.$ June, Figure $3.12 \mathrm{~d}$; $30^{\text {th }}$ June, Figure $3.12 \mathrm{e}$ ), indicating that the one-dimensional model is able to capture the rate of warming more accurately than the three-dimensional model.

Performance of the one-dimensional model continues to surpass that of the EFDC model through the stratified period. As observed in Figure 3.12f, the UFILS4 model faithfully tracks the depth and slope of the thermocline of the July $28^{\text {th }}$ measured 


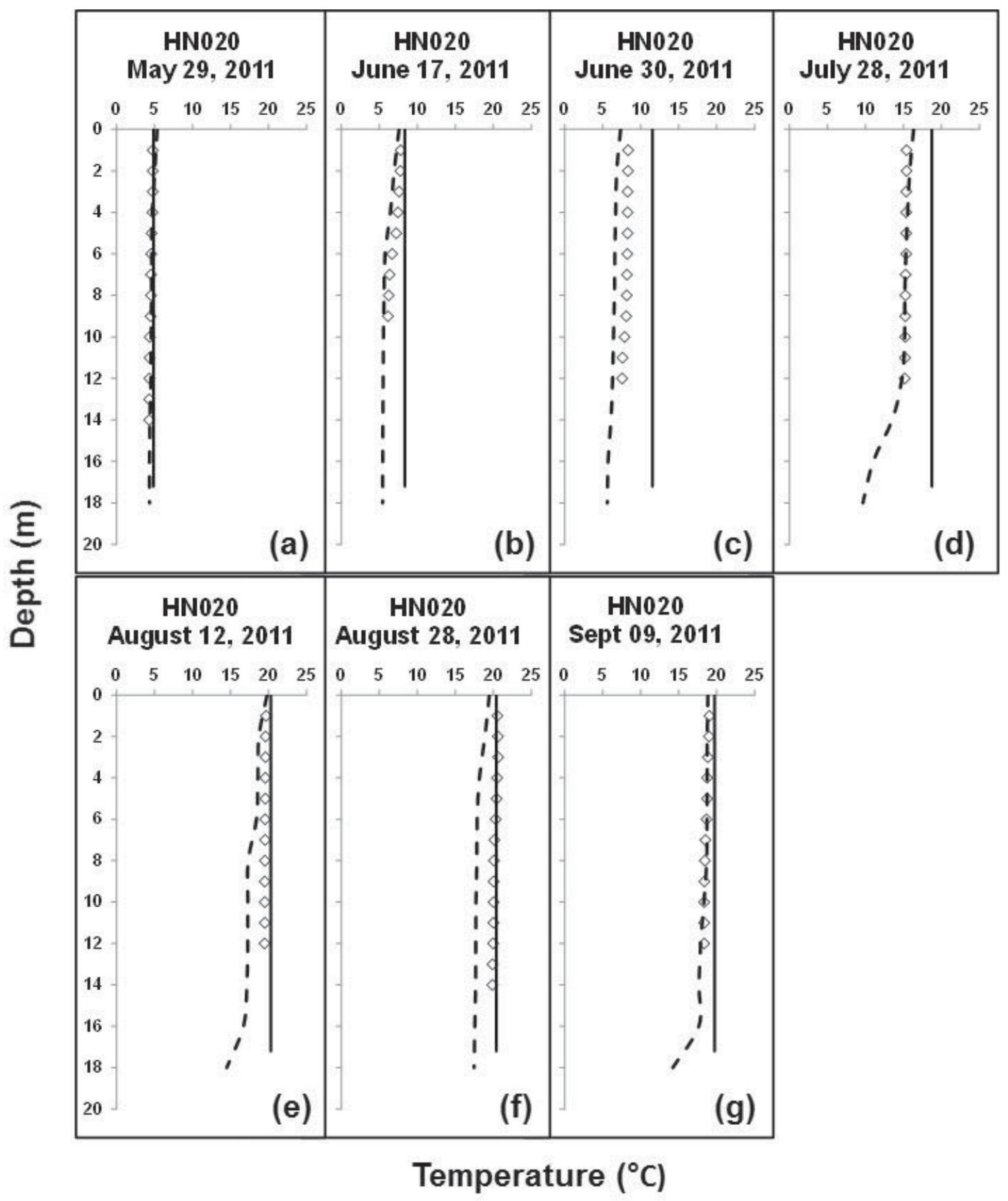

Figure 3.11. Comparison of the measured (open diamonds), UFILS4 predicted (solid line) and EFDC predicted (dashed line) temperature profiles at station HN020 for the May to September interval of 2011. 
profile. However, the fit is less satisfactory with the EFDC model predicted temperatures which yield a gentler-sloped and shallower thermocline. Inspecting all the profiles from the July to September interval (Figure 3.12f-i) shows that the depth and slope of the thermocline are accurately reproduced by the UFILS4 model while the EFDC predicted thermoclines were less well defined. Calculations of RMSE values for the two models (July $28^{\text {th }}$, EFDC $-1.3^{\circ} \mathrm{C}$, UFILS $4-0.6^{\circ} \mathrm{C}$; August $12^{\text {th }}$, EFDC $-1.1{ }^{\circ} \mathrm{C}$, UFILS4 -0.9 ${ }^{\circ} \mathrm{C}$; August $28^{\text {th }}$, EFDC $-1.3^{\circ} \mathrm{C}$, UFILS4 $-1.0{ }^{\circ} \mathrm{C}$; September $9^{\text {th }}$, EFDC $-2.5^{\circ} \mathrm{C}$, UFILS4 $-0.9^{\circ} \mathrm{C}$ ) support this observation.

In summary, nearshore dynamics were more convincingly captured by EFDC while the UFILS4 model provided a more accurate representation of the characteristics of the thermal regime in the offshore. Overall, accuracy of the one-dimensional model (UFILS4) in predicting features of the thermal regime was comparable to or better than that of the three-dimensional model (EFDC), with the exception of cases where measured profiles were influenced by multi-dimensional phenomena, e.g. upwellings.

\subsubsection{Modeling vertical mixing on a temporal scale}

The calibrated and confirmed UFILS4 model is then applied to simulate the inherent mixing patterns along the vertical dimension in the water column. For lakes in temperate latitudes, vertical mixing is instrumental in mediating transport of heat and nutrients in the water column. The resulting thermal structure and nutrient distribution in turn regulate biological processes and attendant food web dynamics in the lake. For example, White and Matsumoto (2012) identified the depth and magnitude of the phosphorus $(P)$ nutricline and the presence of thermal stratification as two of the three primary factors influencing the presence, position and magnitude of the deep chlorophyll maximum (DCM) in Lake Superior. Therefore, addressing concerns related to physical (heat), chemical (nutrients) and biological (food web interactions) phenomena requires a 


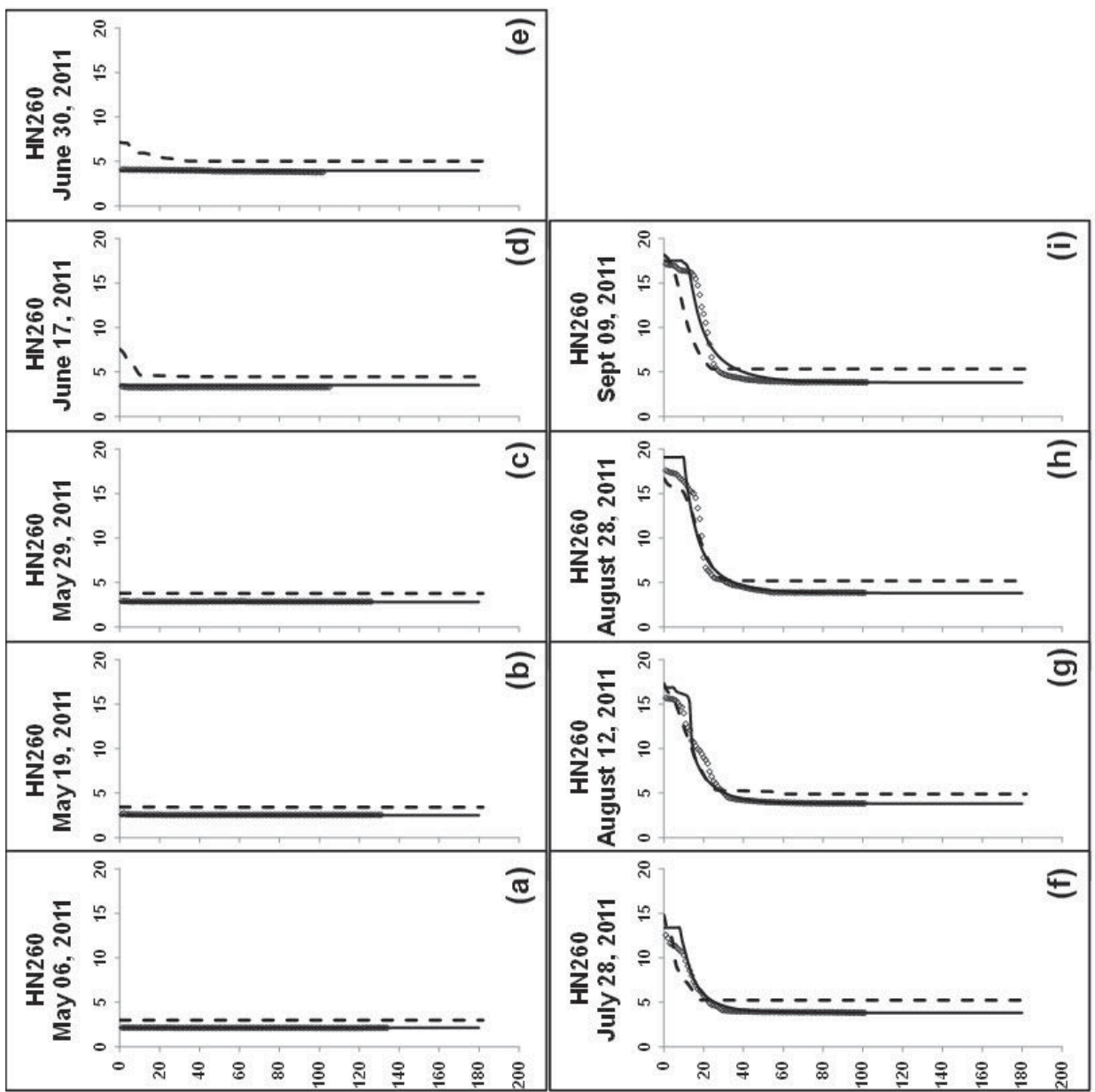

(ui) पวdəa

눈

듬

(1)

응

잉

인

远

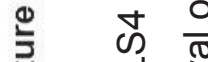

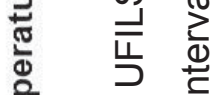

Е

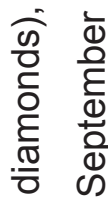

당ㅇ

을 त

ఏ ఖ

गे

๖

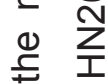

느음

유

त त

ठํ

ㄴ.

๓ं

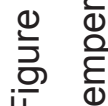


comprehensive understanding of the characteristics of vertical mixing in lake ecosystems. Here, the offshore station, HN260 is selected as an example for this application to track vertical mixing in the water column, driven primarily by the energy imparted by incident solar radiation and wind at the water surface.

The one-dimensional hydrodynamic model, UFILS4, generates vertical mixing coefficients at 1-m intervals (in every layer) at HN260 for the April to October interval of 2011. The minimum mixing coefficient, characterizing the limiting step in vertical mixing over the entire depth of the water column, is obtained for each day of the simulation period and averaged over seven-day (weekly) intervals. Graphical representation of these weekly-averaged mixing coefficients on a temporal scale exhibits a distinct trend: high rates of mixing in the spring, a decline in mixing coefficients with a seasonal minimum in August and gradual increase in the rate of mixing in fall (Figure 3.13). This seasonality in mixing coefficients mirrors the trend observed in the completely mixed isothermal temperature profiles observed in April and May (Figure 3.9a-f), onset and length of the stratification period from July through August (resulting from limited vertical mixing, Figure $3.9 \mathrm{~g}-\mathrm{k}$ ) and the dissipation of stratification in September (through enhanced mixing in the fall, Figure 3.9I-n) at HN260.

This application can be further extended to quantify transport of nutrients, especially flux of the limiting nutrient, phosphorus $\left(\mathbf{J}, \mathrm{mgP} \cdot \mathrm{m}^{-2} \cdot \mathrm{d}^{-1}\right)$ across the metalimnion during the stratified period (assuming that the mixing coefficients are equivalent to the mass transfer coefficient along the vertical dimension) using three variables; the minimum vertical mixing coefficient described here $\left(\mathbf{E}, \mathrm{m}^{2} \cdot \mathrm{d}^{-1}\right)$, thickness of the metalimnion $(\boldsymbol{D}, \mathrm{m})$ and the maximum concentration gradient (i.e. magnitude of the 


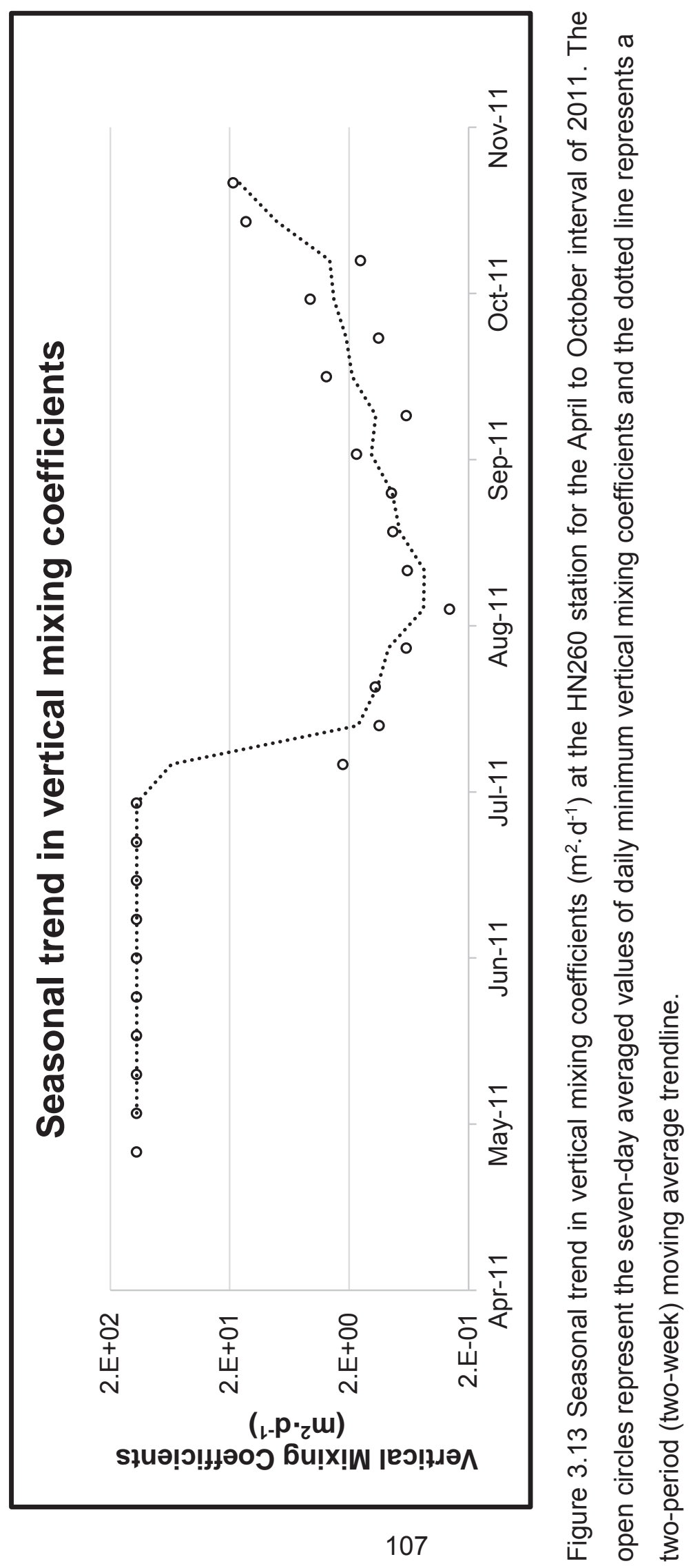


nutricline, $\left.\Delta \mathrm{C}, \mathrm{mg} \mathrm{P} \cdot \mathrm{m}^{-3}\right)$. Calculated as,

$$
J=\frac{E \cdot \Delta C}{D}
$$

this flux can be evaluated on temporal scales to determine seasonal and inter-annual variations in the magnitude and availability of phosphorus for primary production in the vicinity of the nutricline (metalimnion) and, ultimately, the epilimnion.

\subsection{Conclusions}

An n-layer, mechanistic, one-dimensional model, UFILS4, was introduced in this study to simulate thermal dynamics in a large lake ecosystem. Calibration and confirmation procedures for this modeling study were conducted in the nearshore and offshore region of Lake Superior using a data set of water temperature measurements collected through monitoring and retrieved from independent, external sources.

The first application of this study focused on comparing the output from this onedimensional framework and the three-dimensional framework described by Gawde et al. (pending submission) to evaluate the capability of these two modeling tools in simulating thermal characteristics of the lake. The performance of the simple one-dimensional UFILS4 model is comparable to that of the more complex three-dimensional EFDC model in predicting nearshore thermal dynamics. In the deep offshore region, the capability of the one-dimensional model in reproducing features of the stratified water column (including slope and depth of the thermocline) is greater than that of the threedimensional model. This predictive capacity of the UFILS4 framework, together with its efficient (reduced) computational time, provides a unique alternative for effective

parameterization of complex, there-dimensional ecosystem models using a test-bed approach outlined by McDonald et al. (2012). 
The second application of this study examined mixing characteristics over the water column, another parameter simulated by the one-dimensional UFILS4 model. Here, a temporal plot of the weekly-averaged minimum vertical mixing coefficients was evaluated at the offshore HN260 station. A seasonal trend was observed through visual inspection of this plot presenting higher rates of mixing in spring (April - June) and fall (September - October) separated by a reduced intensity of mixing in July and August. This application finds further utility in simulating transport of nutrients vertically in the water column over the stratified interval to identify seasonal and inter-annual differences in magnitude and distribution of the nutrients (and attendant phytoplankton productivity).

The one-dimensional UFILS4 model provides a predictive capacity comparable to (or better than) the more advanced (three-dimensional) frameworks in simulating the temperature response (and underlying mixing characteristics) to environmental forcing conditions for most cases. The model can, therefore, be integrated in a coupled onedimensional physical-ecological framework to test kinetic rate coefficients and ecosystem dynamics for further application to support development and parameterization of complex three-dimensional frameworks.

\subsection{References}

Atkinson, J. F., Edwards, W. J., and Feng, Y. (2012). "Physical measurements and nearshore nested hydrodynamic modeling for Lake Ontario nearshore nutrient study." Journal of Great Lakes Research, 38, 184-193.

Bai, X., Wang, J., Schwab, D. J., Yang, Y., Luo, L., Leshkevich, G. A., and Liu, S. (2013). "Modeling 1993-2008 climatology of seasonal general circulation and thermal structure in the Great Lakes using FVCOM." Ocean Modelling, 65, 40-63. 
Beletsky, D., Hawley, N., and Rao, Y. R. (2013). "Modeling summer circulation and thermal structure of Lake Erie." Journal of Geophysical Research: Oceans, 118(11), 6238-6252.

Beletsky, D., Mason, D. M., Schwab, D. J., Rutherford, E. S., Janssen, J., Clapp, D. F., and Dettmers, J. M. (2007). "Biophysical Model of Larval Yellow Perch Advection and Settlement in Lake Michigan." Journal of Great Lakes Research, 33(4), 842866.

Beletsky, D., and Schwab, D. J. (2001). "Modeling circulation and thermal structure in Lake Michigan: Annual cycle and interannual variability." Journal of Geophysical Research, 106(C9), 19-745.

Bennett, E. B. (1978). "Characteristics of the thermal regime of Lake Superior." Journal of Great Lakes Research, 4(3), 310-319.

Bennington, V., McKinley, G. A., Kimura, N., and Wu, C. H. (2010). "General circulation of Lake Superior: Mean, variability, and trends from 1979 to 2006." Journal of Geophysical Research, 115, C12015.

Bocaniov, S. A., Smith, R. E. H., Spillman, C. M., Hipsey, M. R., and Leon, L. F. (2014). "The nearshore shunt and the decline of the phytoplankton spring bloom in the Laurentian Great Lakes: insights from a three-dimensional lake model." Hydrobiologia, 731(1), 151-172.

Brooks, R. J., and Tobias, A. M. (1996). "Choosing the best model: Level of detail, complexity, and model performance." Mathematical and Computer Modelling, 24(4), $1-14$.

Chapra, S. C. (1997). Surface water-quality modeling. McGraw-Hill New York. 
Chen, C., Zhu, J., Ralph, E., Green, S. A., Budd, J. W., and Zhang, F. Y. (2001). "Prognostic modeling studies of the Keweenaw current in Lake Superior. Part I: Formation and evolution." Journal of Physical Oceanography, 31(2), 379-395.

Dijkstra, M.L., and Auer, M.T. "Spatio-temporal dynamics in environmental forcing conditions, standing crop and primary production of Lake Superior." Pending submission.

Gawde, R.G., Auer, M.T., and Dijkstra, M.L. "Calibration and confirmation of a threedimensional hydrodynamic framework for Lake Superior: evaluating model performance using an ecologically meaningful approach." Pending submission.

Huang, A., Rao, Y. R., and Lu, Y. (2010). "Evaluation of a 3-D hydrodynamic model and atmospheric forecast forcing using observations in Lake Ontario." Journal of Geophysical Research, 115(C2), C02004.

Ji, Z.G. (2008). Hydrodynamics and water quality: modeling rivers, lakes, and estuaries. John Wiley \& Sons.

Leon, L. F., Smith, R. E. H., Malkin, S. Y., Depew, D., Hipsey, M. R., Antenucci, J. P., Higgins, S. N., Hecky, R. E., and Rao, R. Y. (2012). "Nested 3D modeling of the spatial dynamics of nutrients and phytoplankton in a Lake Ontario nearshore zone." Journal of Great Lakes Research, 38, Supplement 4, 171-183.

McDonald, C. P., Bennington, V., Urban, N. R., and McKinley, G. A. (2012). "1-D testbed calibration of a 3-D Lake Superior biogeochemical model." Ecological Modelling, 225, 115-126.

Mesinger, F., DiMego, G., Kalnay, E., Mitchell, K., Shafran, P. C., Ebisuzaki, W., Jović, D., Woollen, J., Rogers, E., and Berbery, E. H., others. (2006). "North American regional reanalysis." Bulletin of the American Meteorological Society, 87(3). 
O'Donnell, S. M., O'Donnell, D. M., Owens, E. M., Effler, S. W., Prestigiacomo, A., and Baker, D. M. (2010). "Variations in the stratification regime of Onondaga Lake: patterns, modeling, and implications." Fundamental and Applied Limnology/Archiv für Hydrobiologie, 176(1), 11-27.

Owens, E. M. (1998). "Development and testing of one-dimensional hydrothermal models of Cannonsville Reservoir." Lake and Reservoir Management, 14(2-3), 172185.

Owens, E. M., and Effler, S. W. (1989). "Changes in stratification in Onondaga Lake, New York." JAWRA Journal of the American Water Resources Association, 25(3), $587-597$.

Owens, E. M., and Effler, S. W. (1996). "Modeling the impacts of a proposed hypolimnetic wastewater discharge on stratification and mixing in Onondaga Lake." Lake and Reservoir Management, 12(1), 195-206.

Rao, Y. R., Marvin, C. H., and Zhao, J. (2009). "Application of a numerical model for circulation, temperature and pollutant distribution in Hamilton Harbour." Journal of Great Lakes Research, 35(1), 61-73.

R. G. Wetzel. (2001). Limnology: lake and reservoir ecosystems. Academic Press, New York

Swinbank, W. C. (1963). "Long-wave radiation from clear skies." Quarterly Journal of the Royal Meteorological Society, 89(381), 339-348.

Ullman, D., Brown, J., Cornillon, P., and Mavor, T. (1998). "Surface Temperature Fronts in the Great Lakes." Journal of Great Lakes Research, 24(4), 753-775.

Wang, J., Hu, H., Schwab, D., Leshkevich, G., Beletsky, D., Hawley, N., and Clites, A. (2010). "Development of the Great Lakes Ice-circulation Model (GLIM): Application to Lake Erie in 2003-2004." Journal of Great Lakes Research, 36(3), 425-436. 
White, B., Austin, J., and Matsumoto, K. (2012). "A three-dimensional model of Lake Superior with ice and biogeochemistry." Journal of Great Lakes Research, 38, 6171.

White, B., and Matsumoto, K. (2012). "Causal mechanisms of the deep chlorophyll maximum in Lake Superior: A numerical modeling investigation." Journal of Great Lakes Research, 38(3), 504-513.

Zhao, J., Rao, Y. R., and Wassenaar, L. I. (2012). "Numerical modeling of hydrodynamics and tracer dispersion during ice-free period in Lake Winnipeg." Journal of Great Lakes Research, 38, Supplement 3(0), 147-157. 


\section{Chapter 4}

\section{Modeling the impact of climatic 'bookend' years on the thermal regime of Lake Superior}




\subsection{Introduction}

Climate change, considered a distant menace in the not-so-faraway past, has emerged as a major present-day global concern (IPCC Report 2007, Melillo et al. 2014). Observations of ever increasing air temperatures, reduced snow and ice extent and volume (over terrestrial, marine and freshwater surfaces), disproportionate increases in precipitation extremes and irregular wind patterns, compiled by a multitude of observing systems on global, regional and local scales, provide substantial evidence of changing climatic conditions (IPCC Report 2007; Melillo et al. 2014). Furthermore, the Intergovernmental Panel on Climate Change (IPCC) Report of 2007, supported by datasets from studies conducted around the globe, documents with a high level of confidence that physical characteristics and biological processes in natural systems are impacted by transitions in the above mentioned measures of climate, especially rising temperatures.

However, the extent to which these physical and biological systems are influenced varies regionally. In the Laurentian Great Lakes basin, discernible impacts of regional climatic change were manifested through reduced ice cover $(71 \%$ reduction between 1973-2010, Wang et al. 2012), rising water temperatures (McCormick and Fahnensteil 1999; Austin and Colman 2007; Dobiesz and Lester 2009) and longer periods of stratification (McCormick and Fahnensteil 1999). Researchers have developed modeling tools, primarily applications of General Circulation Models (GCMs) and hydrodynamic frameworks, forecasting the impacts of these variations in climatic forcings on the physical characteristics of the Great Lakes as a whole (Hill and Magnuson 1990; Smith 1991; Lehman 2002; Lofgren et al. 2002; Trumpickas et al. 2009) and individually (Lake Superior - Bennington et al. 2010, White et al. 2012; Lake

Michigan-Huron system - McCormick 1990, Beletsky and Schwab 2001, Angel and 
Kunkel 2010, Zhao et al. 2012; Lake Erie - Lam and Schertzer 1987, Blumberg and DiToro 1990, Leon et al. 2011; Lake Ontario - Huang et al. 2010, Leon et al. 2012). Others have examined long-term historical records of physical measures (e.g. water levels, Lenters 2001; water temperatures, Dobiesz and Lester 2009; and spatial and temporal extent of ice cover, Wang et al. 2012) and meteorological forcing conditions for the Great Lakes region to establish statistically-meaningful relationships between response and perturbation.

Predictive climate scenarios call for larger changes in Lake Superior's physical system, specifically the thermal regime, than for the other Great Lakes (Lehman 2002; Lofgren et al. 2002; Trumpickas et al. 2009). Observations of a $79 \%$ reduction in Lake Superior ice cover over the $1973-2010$ period (2.1\% $\mathrm{yr}^{-1}$, Wang et al. 2012), a warming trend of $0.035^{\circ} \mathrm{C} \cdot \mathrm{yr}^{-1}$ in lake surface temperatures $\left(3.5^{\circ} \mathrm{C}\right.$ over a century, Austin and Colman 2008) and a 25-day increase in the length of the summer stratification period over the $20^{\text {th }}$ century (from 145 to $170 \mathrm{~d}$, Austin and Colman 2008) strengthen the credibility of these projections.

Lake Superior has, in rapid succession, experienced two climatic 'bookend' years, the unusually warm 2012 season (here called 'Big Heat') and the extreme cold of 2014 (here called 'Big Chill'), following closely on a year (2011) where the thermal regime was representative of the decadal average. These 'bookend' years provide a unique opportunity to assess the impact of these climate anomalies on the thermal regime, thereby offering insights regarding the potential response of the lake to longterm climate change. Here, a comprehensive dataset of surface water temperature and vertical temperature profile measurements made during the April to October period of 2011, 2012 and 2014 is used to characterize the thermal regime of Lake Superior as driven by differences in annual meteorological forcing conditions. An n-layer, one- 
dimensional hydrodynamic model is then applied to characterize the thermal regime for each of the two years with anomalous meteorological forcing conditions (2012 and 2014) and compare that result with an average year (2011; Gawde et al., pending submission).

\subsection{Climatic Conditions and Monitoring}

\subsubsection{Climatic Conditions}

Climate change research has increasingly focused on the complex interactions between air and water temperatures on local, regional and global scales, (Hansen et al. 2006, IPCC 2007) yielding a strong positive agreement in long-term trends for the two variables, especially in tropical regions (O'Reilly et al. 2003, Verburg et al. 2003). While the correlation between atmospheric forcing and water temperature is not as strong in mid-latitude ecosystems such as the Laurentian Great Lakes (being attenuated or augmented by other meteorological forcing conditions), changes in air temperature do influence summer thermal dynamics (Austin and Colman 2007, Yu and Brutsaert 1968).

Ice cover on Lake Superior has decreased by $79 \%$ over the 38 -year period, 1973-2010 (Wang et al. 2012). Albedo at the lake surface increases with ice coverage, reducing the amount of shortwave solar radiation absorbed by the water and thereby influencing thermal dynamics (Austin and Colman 2007). Therefore, while the response of the thermal regime is significantly influenced by regional atmospheric temperatures (Stefan et al. 1998, Robertson and Ragotzkie 1990), the observed decline in ice cover on Lake Superior is also considered to be a factor contributing to the warming trend in summer temperatures (Austin and Colman 2007). 


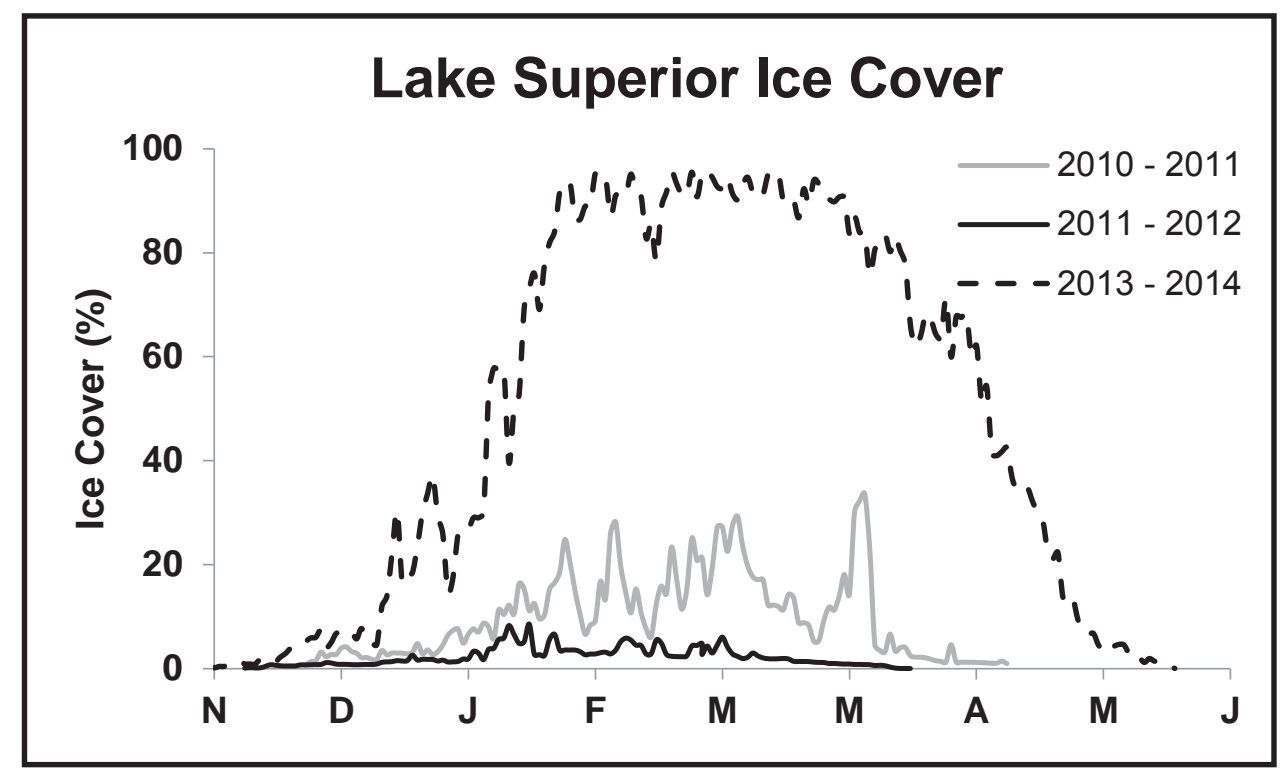

Figure 4.1 Ice cover on Lake Superior during the winter of 2011-2012 (solid black line) and 2013-2014 (dashed black line). The solid gray line represents ice cover on the lake for the winter period of the average year, 2011.

In the unusually warm winter of $2011-2012$, the maximum ice cover on the lake reached only $8.5 \%$ (solid black line, Figure 4.1; NOAA Great Lakes Surface Environmental Analysis [GLSEA]), representing a distinct departure from historical norms (maximum ice cover for the 1973-2014 long-term average - 48.4\%, for the average year, 2011 - 33.6\%; NOAA GLSEA; Table 4.1). This anomaly, and the antecedent conditions driving it, transpired over a period of months, extending from the late fall of 2011 through the winter of 2012. These mild winter conditions, accompanied by a low extent of ice cover, were followed by a second, shorter extreme event: an anomaly featuring elevated air temperatures and impacting a large area of the Midwest. Occurring on a time scale of weeks $\left(12^{\text {th }}-23^{\text {rd }}\right.$ March 2012), the anomaly resulted in a deviation of $\sim 15^{\circ} \mathrm{C}$ (Table 4.1) from the decadal (1981-2010) average air temperature at its focal point in the Great Lakes basin (Figure 4.2; Dole et al. 2014). 


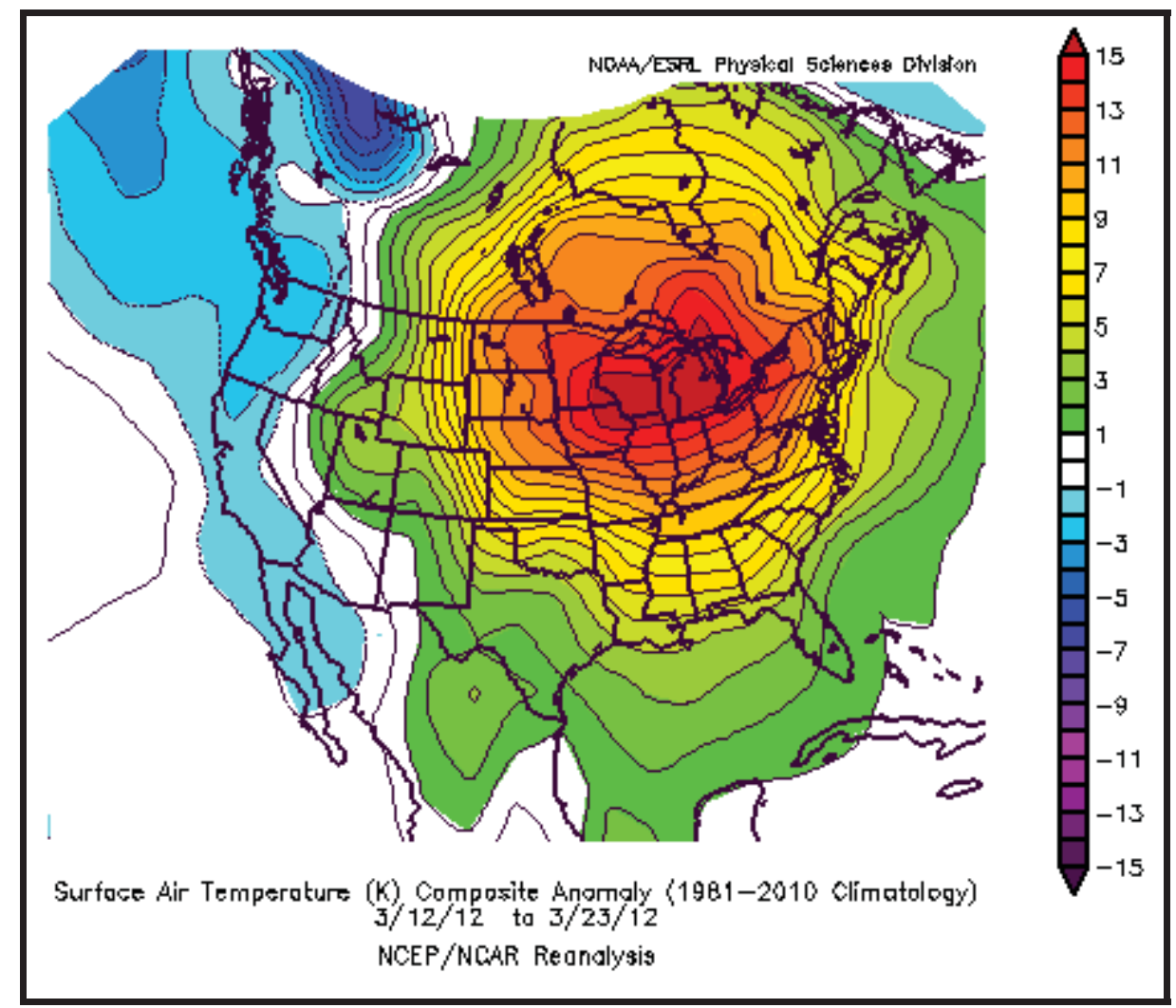

Figure 4.2 Air temperature anomaly of March 2012 (Figure 4a [left panel] from Dole, R. et al. (2014). "The making of an extreme event: putting the pieces together." Bulletin of the American Meteorological Society, 95(3), 427 - 440, @ American Meteorological Society. Used with permission).

In sharp contrast, the winter of 2013-2014 in the Great Lakes basin was classified as the coldest in the past 20 years (Midwestern Regional Climate Center Great Lakes Report of March 2014), featuring the lowest recorded air temperatures for the Lake Superior region (a departure of greater than $-5^{\circ} \mathrm{C}$ from the $1981-2010$ decadal average over the December to February interval, Figure 4.3). This anomalous interval of extremely cold water temperatures and near-record extent of ice cover on Lake Superior (dotted black line, Figure 4.1; NOAA GLSEA) extended until June $6^{\text {th }}$ (NOAA National Ice Center, Clites et al. 2014; Table 4.1), resulting in a spring characterized by icecovered waters and the latest ice-out on record (June $\left.6^{\text {th }}, 2014\right)$. 


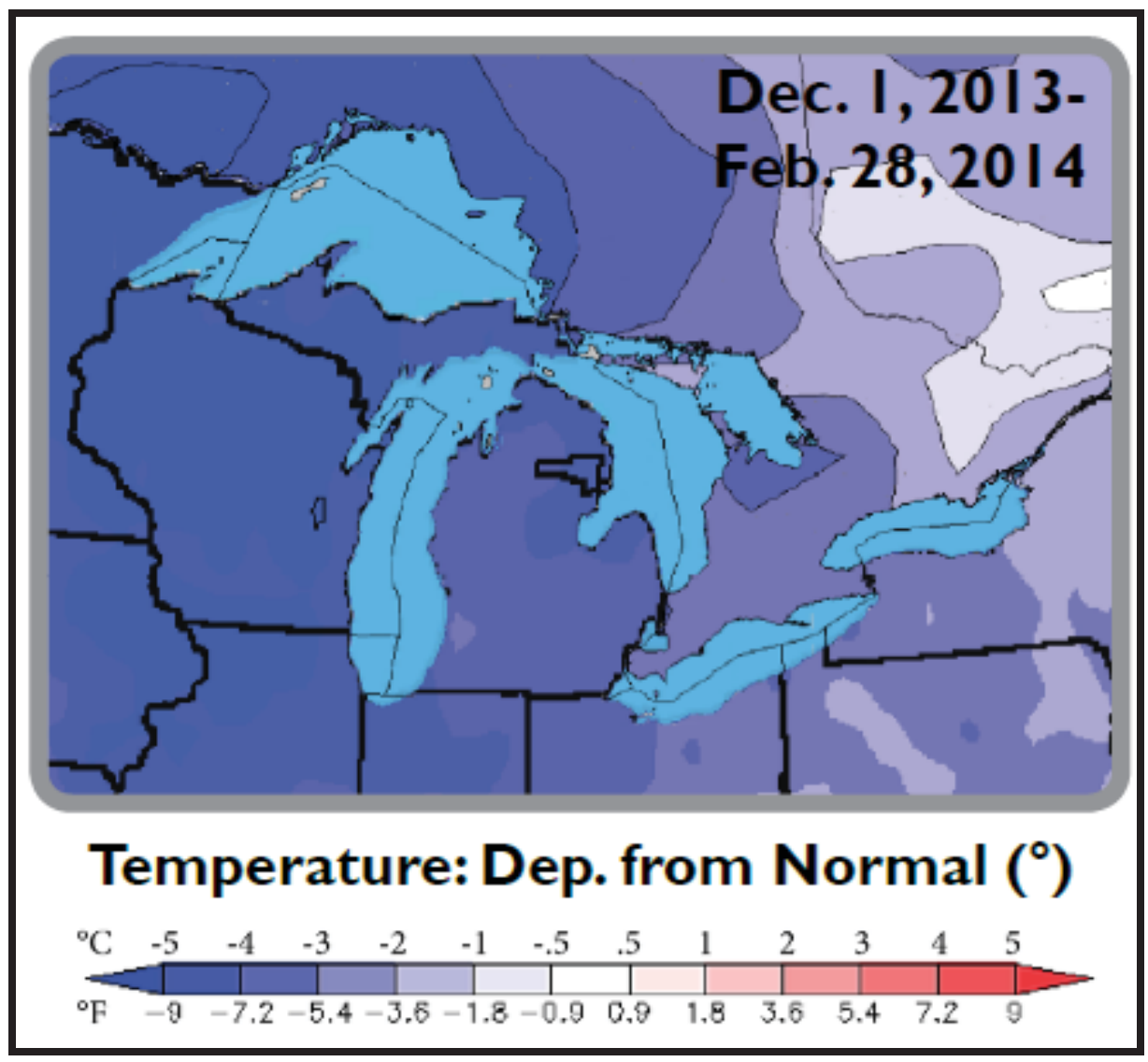

Figure 4.3 Deviation from decadal average in air temperature surrounding the Great Lakes basin over the December 2013 to February 2014 interval (NOAA Northeast Regional Climate Center at Cornell University and Environment Canada; From the Great Lakes Quarterly Climate Impacts and Outlook report [March 2014]). 
Table 4.1 Summary of the differing meteorological forcing conditions in the average year (2011) and the two 'bookend' years (2012 and 2014).

\begin{tabular}{|c|c|c|c|c|c|c|}
\hline Metric & Units & 2011 & 2012 & 2014 & $\begin{array}{l}\text { Decadal } \\
\text { Average }\end{array}$ & Notes \\
\hline $\begin{array}{c}\text { Maximum } \\
\text { fractional ice } \\
\text { cover }\end{array}$ & $\%$ & 33.6 & 8.5 & 95.7 & $48.4^{*}$ & $\begin{array}{c}\text { *Signifies the maximum ice } \\
\text { cover value from the long- } \\
\text { term average (1973-2014) } \\
\text { calculated for Lake } \\
\text { Superior }\end{array}$ \\
\hline $\begin{array}{l}\text { Last ice-off } \\
\text { date }\end{array}$ & - & April $30^{\text {th }}$ & April $9^{\text {th }}$ & June $6^{\mathrm{th} \mathrm{h}^{\star *}}$ & - & $\begin{array}{l}\text { Ice-off dates determined } \\
\text { from ice concentration data } \\
\text { obtained from NOAA } \\
\text { GLSEA } \\
{ }^{* *} \text { Referenced from Clites et } \\
\text { al. } 2014\end{array}$ \\
\hline $\begin{array}{l}\text { Deviation in } \\
\quad \text { air } \\
\text { temperature }\end{array}$ & ${ }^{\circ} \mathrm{C}$ & - & $\sim 15$ & -5 & - & $\begin{array}{c}\text { Both these deviations are } \\
\text { determined with respect to } \\
\text { the decadal average (1981- } \\
\text { 2010) air temperature } \\
\text { measurements over the } \\
\text { Great Lakes Basin }\end{array}$ \\
\hline $\begin{array}{c}\text { Duration of } \\
\text { deviation }\end{array}$ & week & - & $\sim 2$ & 12 & - & (2) \\
\hline
\end{tabular}

\subsubsection{Field Monitoring}

A field monitoring program was conducted at 11 stations along the Houghton North (HN) transect (adjacent to the North Entry of the Keweenaw Waterway, Figure 4.4) over the summers of 2012 and 2014 aboard Michigan Technological University's $R / V$ Agassiz. The HN transect, one of several established as part of the NSF-funded Keweenaw Interdisciplinary Transport Experiment in Superior (KITES) project (Auer and Kahn 2004, Urban et al. 2004), was sampled with biweekly frequency at stations 1, 2, 3, $4,5,7,9,13,17,21$ and $26 \mathrm{~km}$ offshore from the western shore of the Keweenaw Peninsula. A Seabird Electronics Conductivity/Temperature/Depth profiler (SBE-25 CTD) was used to conduct vertical profiling of temperature, conductivity and concentrations of chlorophyll-a. Water samples from the surface and at depth were collected periodically through the April to September intervals of the two years to 
develop a database of water chemistry and lower food web (phytoplankton and zooplankton) parameters.

From this database, information for two stations, HN020 (depth $18 \mathrm{~m}$ ) and HN260 (depth $183 \mathrm{~m}$ ), was selected to represent the shallow nearshore and deep offshore thermal characteristics of the lake (Figure 4.4) for the anomalous years. These results are compared with field data and simulation results for 2011 (Sections 4.4.1.1 and 4.4.2.1), a year of average meteorological conditions and thermal regime (Gawde et al., pending submission).

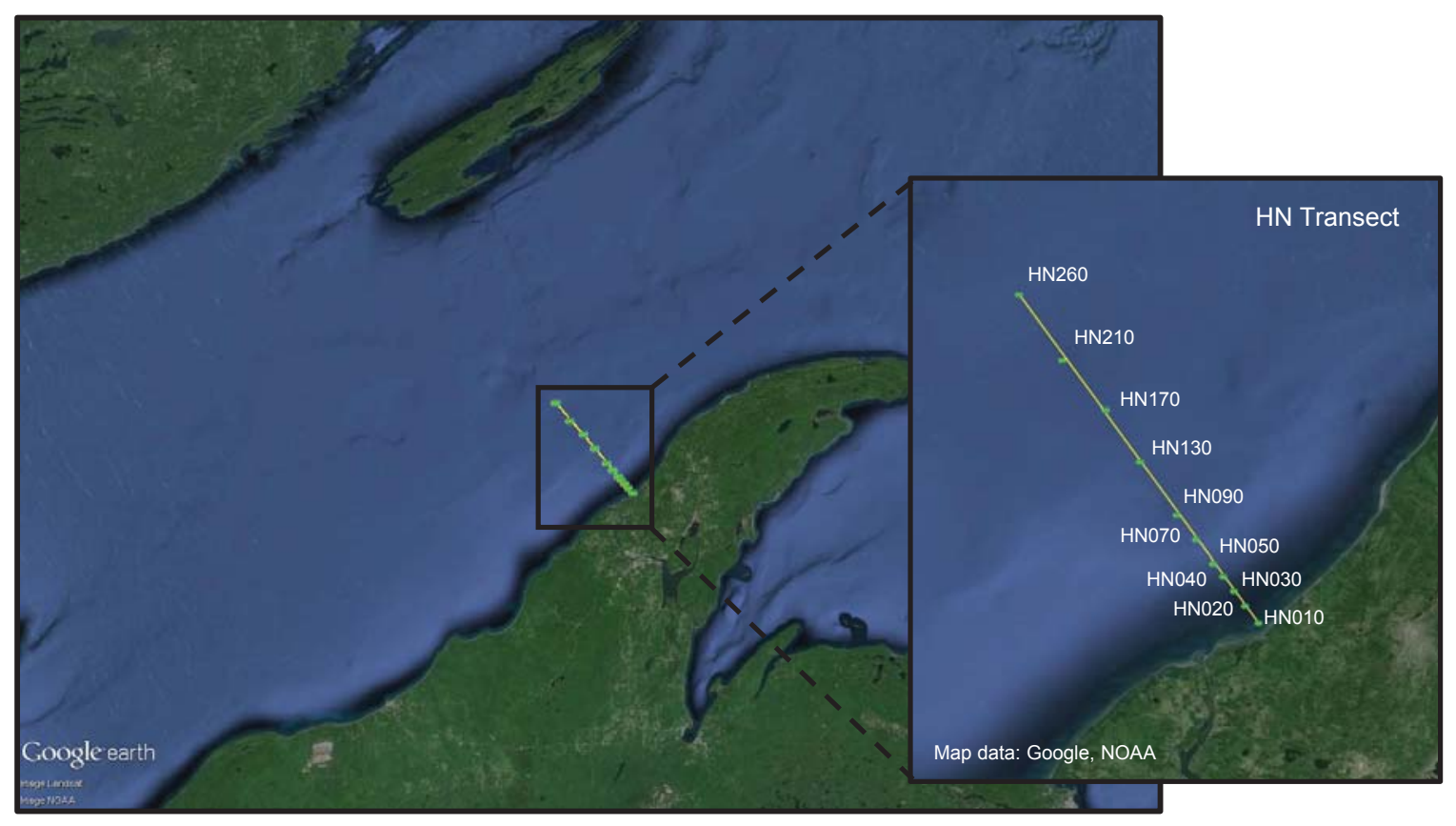

Figure 4.4 The Keweenaw Peninsula with an inset identifying the 11 sampling stations along the Houghton North (HN) transect. Map data: Google, NOAA, USGS/NASA Landsat Program. (C) 2015 Google Inc, used with permission. Google and the Google logo are registered trademarks of Google Inc. 


\subsection{Model Description, Inputs and Specifications}

\subsubsection{Description}

The mechanistic, one-dimensional UFILS4 model is applied here to explore the response of the thermal regime of Lake Superior to differences in annual meteorological forcing conditions for the two anomaly years, 2012 and 2014 and comparing that response to conditions for the average year (2011; Gawde et al., pending submission). Derived from the CE-THERM-R1 model (Environmental Laboratory 1982), UFILS4 has found wide application in simulating thermal stratification and water-quality concerns in a number of lakes and reservoirs (O’Donnell et al. 2010, Owens 1998, Owens and Effler 1996, Owens and Effler 1989). It has also been successfully evaluated for simulating thermal dynamics in the nearshore and offshore regions of Lake Superior (Gawde et al., pending submission), introducing application to large lake ecosystems.

The model calculates vertical transport and distribution of heat and water mass, assuming a uniform cross-sectional area of the water column $\left(1 \mathrm{~m}^{2}\right)$ and zero exchange in the horizontal dimensions. A detailed description of the equations characterizing heat budget and mixing calculations has been presented in Gawde et al. (pending submission) but a few salient features are addressed here. The UFILS4 model incorporates net (defined as the difference between incident and reflected) solar radiation with the atmospheric, back longwave, evaporative and conductive components of heat transfer to determine heat flux at the water surface (Owens and Effler 1996). At depth, the model applies an extinction coefficient $\mathbf{k}_{\mathbf{D}}$ to attenuate the net solar radiation (in accordance to Beer's Law) prior to calculating the heat flux. The model adopts a mixed layer approach, using a conservation equation for turbulent kinetic energy to calculate the depth of the epilimnion while vertical diffusivity in the hypolimnion is determined using an empirical relationship that accommodates its dependence on 
surface wind shear and the density gradients in the water column (Owens and Effler 1996).

\subsubsection{Inputs and specifications}

Independent, isolated one-dimensional model grids, segmented vertically into discrete layers of $1-\mathrm{m}$ thickness with a cross-sectional area of $1 \mathrm{~m}^{2}$ per layer, were established at the nearshore (HN020, 18 layers) and offshore (HN260, 183 layers) stations. Each model grid was forced with meteorological inputs (incident solar radiation, cloud cover, atmospheric pressure, wind speed, air and dew point temperatures) using a daily time resolution. As described in Gawde et al. (pending submission), inputs of incident solar radiation, cloud cover and atmospheric pressure were accessed from the National Centers for Environmental Prediction (NCEP) National American Regional Reanalysis (NARR) database (Mesinger et al. 2006) over the April October interval of 2012 and 2014 for the western basin of Lake Superior and horizontal homogeneity was assumed over the spatial extent of the study area (between the HN020 and HN260 stations). Spatial variability in the other meteorological variables (wind speed, air and dew point temperatures) was accommodated by obtaining sitespecific data for the two anomalous years at HN020 and HN260 stations using the Point Query Tool from the NOAA Great Lakes Coastal Forecasting System (GLCFS).

Vertical temperature profiles, measured at the start of the sampling period in 2012 and 2014, were used to initialize the model at HN020 (April 23 ${ }^{\text {rd }}, 2012$, Figure 4.5a; May $23^{\text {rd }}, 2014$, Figure 4.5b) and HN260 (April 5 $5^{\text {th }}, 2012$, Figure 4.5c; May $23^{\text {rd }}, 2014$, Figure 4.5d). As detailed in Gawde et al. (pending submission), the shallow nearshore and deep offshore exhibit vastly different mixing and heat transfer characteristics which are accommodated in the model by assigning a specific set of calibration coefficients (the evaporation multiplier, $\mathbf{b}$ and the wind mixing coefficient, $\boldsymbol{\eta}$ ) to each region. 
Additionally, the isothermal water column in the nearshore progressively warms over the April to October interval, but with two distinctive rates: a rapid warming in spring and a relatively slower one in summer. In a similar fashion, the offshore region experiences a period of 'unstratified' isothermal conditions before stratification sets in. Therefore, two sets of period-specific coefficients, determined through calibration (2011 dataset; Gawde et al., pending submission), were applied to each of the regions to support the spring and summer rates of warming in the nearshore and the unstratified and stratified intervals in the offshore. These model coefficients and the two defined simulation periods (in the nearshore and offshore; Table 3.2) were held constant for the 2012 and 2014 simulations.

\subsection{Results and Discussion}

With the advent of climate change, extreme events relating to regional meteorological drivers, e.g. solar radiation, air temperature, wind speed and direction and the extent of ice cover, have occurred with increasing intensity and frequency (IPCC Report 2007, Meillo et al 2014). Two such deviations from long-term average forcing conditions occurred in 2012 and 2014: one associated with unusually warm climatic conditions and the other with severe cold meteorological drivers. These climatic anomalies then cascade through the seasons impacting the thermal regime and, potentially, ecosystem function in the lake. 


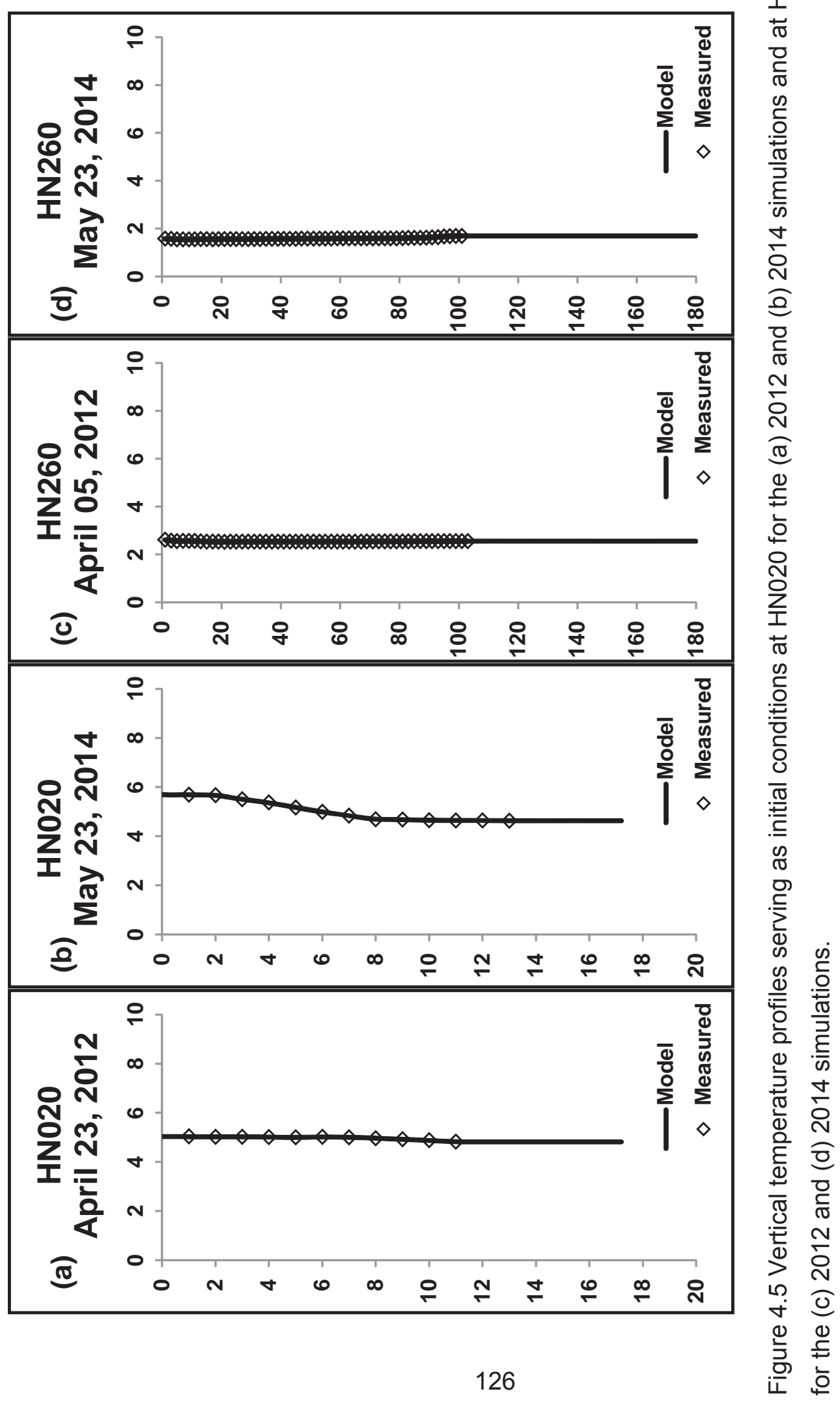




\subsubsection{Nearshore}

In the shallow, (nearly) isothermal nearshore, two characteristics, surface water temperatures and rate of warming, were used to evaluate differences in the response of the thermal regime to the two climatic 'bookend' years. Thermal characteristics observed during the May to October period of 2011 (Gawde et al., pending submission) are also summarized to represent nearshore dynamics in an average year.

\subsubsection{Characteristics of the thermal regime in 2011 (average year)}

Visual inspection of plots of surface water temperatures and the rate of warming over the April to October interval in 2011 (Figure 4.6a) provide a means for characterizing the response of the thermal regime to average meteorological conditions in the nearshore.

At the HN020 station (18 m deep), surface waters warmed from temperatures of $3.4{ }^{\circ} \mathrm{C}$ (May $19^{\text {th }}$ ) to $8.3^{\circ} \mathrm{C}$ (June $30^{\text {th }}$ ) at a rate of $0.9^{\circ} \mathrm{C} \cdot \mathrm{d}^{-1}$ over the spring period of 2011 (Figure 4.6a). Warming of the surface waters continued at a slightly reduced rate $\left(0.2^{\circ} \mathrm{C} \cdot \mathrm{d}^{-1}\right)$ through the summer interval yielding a maximum temperature of $20.5^{\circ} \mathrm{C}$ on August $28^{\text {th }}$ (Figure 4.6a). The UFILS4 model, applied to simulate the thermal regime of 2011 in Gawde et al. (pending submission), is able to reproduce the temporal pattern in surface temperatures (solid line, Figure 4.6a) with the exception of one upwelling event on June $30^{\text {th }}$ (open circle, Figure 4.6a). This one-dimensional framework is limited by its spatial resolution in capturing the impacts of this three-dimensional phenomenon (upwelling) on thermal structure in the nearshore (Gawde et al. pending submission).

\subsubsection{Surface water temperatures and rate of warming in 2012 and 2014}

Seasonal trends in 2012 and 2014 surface water temperatures were evaluated for identifying the impacts of the two climatic anomalies in the nearshore region of the lake. 
In spring (Figures $4.6 \mathrm{~b}$ and $\mathrm{c}$ ), the surface water temperature was $\sim 6{ }^{\circ} \mathrm{C}$ warmer in $2012\left(12.3^{\circ} \mathrm{C}\right.$ on June $\left.4^{\text {th }}\right)$ than in $2014\left(6.2{ }^{\circ} \mathrm{C}\right.$ on June $\left.5^{\text {th }}\right)$. In addition, surface waters warmed at a faster rate $\left(1.2^{\circ} \mathrm{C} \cdot \mathrm{d}^{-1}\right)$ in the spring of 2012 than in the spring of $2014\left(0.9^{\circ} \mathrm{C} \cdot \mathrm{d}^{-1}\right)$, as is indicated by the steeper slope of the dashed line in 2012 (Figure 4.6b) with respect to 2014 (Figure 4.6c). While surface water temperatures peaked in early September in both years (September $5^{\text {th }}, 2012$ and September $8^{\text {th }}, 2014$ ), the maximum value recorded in 2012 was $\sim 3^{\circ} \mathrm{C}$ warmer than that in $2014\left(20.6{ }^{\circ} \mathrm{C}\right.$ in 2012 , $17.6{ }^{\circ} \mathrm{C}$ in 2014 , Figures $4.6 \mathrm{~b}$ and $\mathrm{c}$ ). While a clear trend in warmer surface water temperatures is noted in 2012, the difference between the two years is subdued compared with those observed in the offshore.

The model satisfactorily predicts the spring warming, summer maximum and autumnal cooling patterns in surface water temperatures in 2012 and 2014 (Figures 4.6b and c). However, limited by its one-dimensional capability, the model is not able to reproduce the three-dimensional upwelling events which influence water column temperatures (Gawde et al., pending submission), e.g. July 31 ${ }^{\text {st }}, 2012$ (open circles, Figure 4.6b), June $21^{\text {st }}, 2014$ and August 22 ${ }^{\text {nd }}, 2014$ (open circles, Figures 4.6c). Both measurements and model simulations point to the occurrence of higher surface water temperatures in 2012 than in the 2014 values consistent with their respective and markedly differing climatic conditions.

\subsubsection{Offshore}

The water column in the deep offshore regions of Lake Superior undergoes thermal stratification twice annually in summer and winter, separated by spring and fall turnovers. Differences in the stratification regime in the offshore for the 'bookend' years are explored by examining surface water temperatures and the rate of warming, as for the nearshore and, additionally, the onset and duration of stratification and the position 

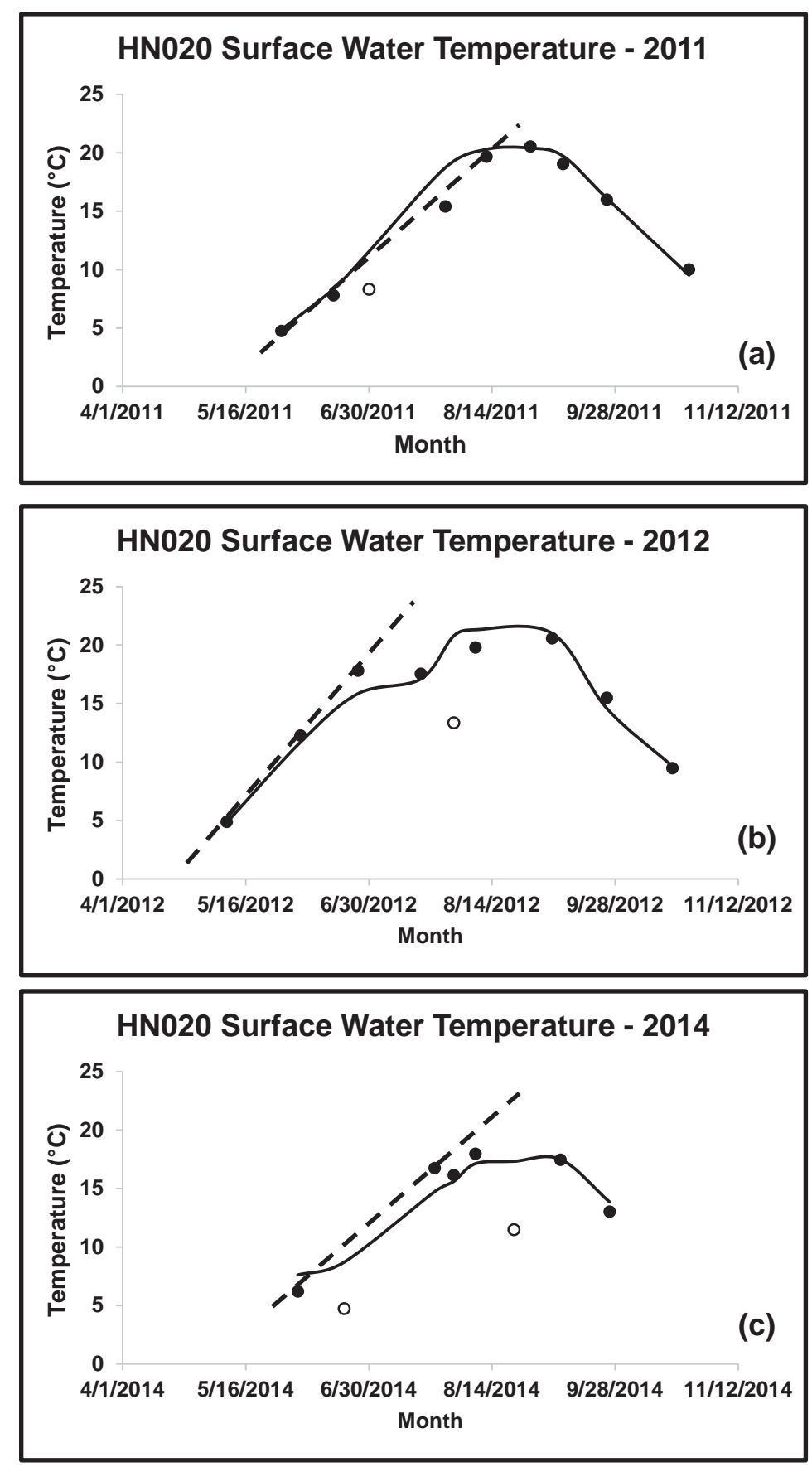

Figure 4.6 Surface water temperatures at the HN020 station in Lake Superior. Panels (a), (b) and (c) represent a comparison between measured (filled circles) and modeled (solid line) temperatures for the April to October period of 2011, 2012 and 2014 respectively. The open circles represent reduced temperatures resulting from upwelling events. The dashed line in the three panels represents the rate of warming observed in the surface water temperatures. 
of the thermocline. As in the nearshore, the thermal response of the offshore region (HN260 station) is also described for the May to October period of 2011 (Gawde et al., pending submission) for comparison to characteristics of the stratification regime for average meteorological forcing conditions.

\subsubsection{Characteristics of the thermal regime in 2011 (average year)}

In dimictic systems, completely mixed conditions during spring turnover are preceded by a relatively weak winter stratified period and followed by the more stably developed summer stratification interval. Temporally, the stratification regime in summer can be defined to include a transitional period featuring partially-stratified vertical temperature profiles, stable conditions characterized by a strongly stratified water column with a well-defined thermocline and a dissipation interval distinguished by deepening of the thermocline prior to isothermal conditions during fall turnover. Development of vertical temperature gradients during the transitional period marks the onset of stratification. The water column continues to stratify and attains spatial and thermal stability (a sharp thermocline and a well-established metalimnion) before it dissipates as a result of autumnal cooling. Dissipation of the stratified thermal structure leads into fall turnover, marking the end of the stratified period and allowing calculation of the duration of stratification.

In the offshore HN260 station, surface layer temperature measurements made in the spring of 2011 document a gradual increase from $2.2{ }^{\circ} \mathrm{C}$ on May $6^{\text {th }}$ (Figure $4.7 \mathrm{a}$ ) to values approaching the temperature of maximum density $\left(3.98{ }^{\circ} \mathrm{C}\right)$ towards the end of June $\left(4.1^{\circ} \mathrm{C}\right.$ on June $30^{\text {th }}$, Figure $\left.4.7 \mathrm{a}\right)$. Warming was accompanied by development of a vertical thermal gradient on July $12^{\text {th }}$ (filled arrow, Figure $4.8 a$ ) signaling the onset of stratification. Warming of the surface waters continued through the stratified period (at a rate of $\left.1.17{ }^{\circ} \mathrm{C} \cdot \mathrm{d}^{-1}\right)$ culminating in a maximum temperature of $17.6{ }^{\circ} \mathrm{C}$ on August $28^{\text {th }}$ 
(Figure 4.7a). At the onset of stratification, the thermocline at this offshore station was 9 $\mathrm{m}$ deep (July $12^{\text {th }}$ ) but reached $17 \mathrm{~m}$ on September $25^{\text {th }}$ as stratification began to dissipate (dashed lines, Figure 4.8a). Vertical stratification (dissipation phase) is evident as late as October $25^{\text {th }}$ (open arrow, Figure $4.8 \mathrm{a}$ ), the last day of the sampling season, resulting in a stratified period of $>106$ days.

As depicted in Figures 4.7a and 4.8a, the UFILS4 model is able to satisfactorily reproduce all of the characteristics of the thermal regime in the offshore including the rate of warming, the maximum surface water temperature, the onset of stratification, depth of the thermocline and the duration of stratification during the May to October period of 2011.

\subsubsection{Surface water temperature and rate of warming in 2012 and 2014}

Surface water temperatures were strikingly warmer in the ice-free period of 2012 than in 2014. Spring temperatures in 2012 (April and May) ranged between $3.1{ }^{\circ} \mathrm{C}$ and $3.7^{\circ} \mathrm{C}$ (Figure $4.7 \mathrm{~b}$ ) whereas the persistence of ice cover until mid-May in 2014 resulted in lower spring surface temperatures $\left(1.6{ }^{\circ} \mathrm{C}\right.$ on $23^{\text {rd }}$ May; Figure $\left.4.5 \mathrm{~d}\right)$. This marked difference in surface water conditions continued into summer with the offshore temperature in 2012 reaching a seasonal maximum of $19.6{ }^{\circ} \mathrm{C}$ (Figure $4.7 \mathrm{~b}$ ), $5.5^{\circ} \mathrm{C}$ greater than the maximum recorded in $2014\left(14.1{ }^{\circ} \mathrm{C}\right.$; Figure $\left.4.7 \mathrm{c}\right)$. While the summer maximum temperatures were substantially different for the two 'bookend' years, the rate of warming did not vary significantly $\left(1.15^{\circ} \mathrm{C} \cdot \mathrm{d}^{-1}\right.$ in 2012 and $1.10^{\circ} \mathrm{C} \cdot \mathrm{d}^{-1}$ in 2014 ; slope of the dashed lines in Figures $4.7 \mathrm{~b}$ and $\mathrm{c}$ ). The time lag in reaching the summer maximum temperature (31 July in 2012 and 22 August in 2014), a delay of $\sim 3$ weeks, may be ascribed to persistent cold surface water temperatures in 2014 , the year of extensive ice cover. This delay combined with a constant rate of warming, kept surface water temperatures an average of $4-6^{\circ} \mathrm{C}$ colder over the entire summer season in 2014 . 

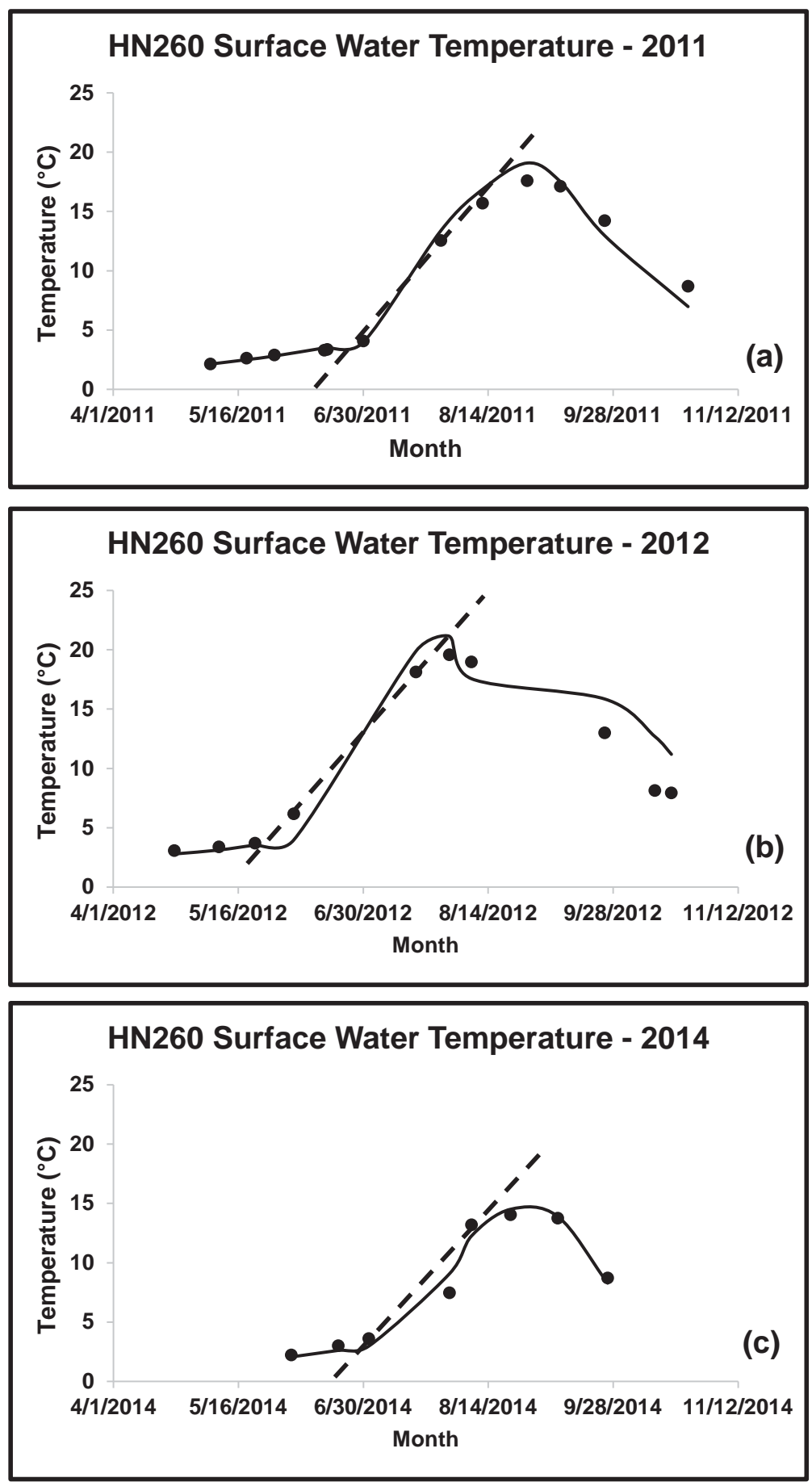

Figure 4.7 Surface water temperatures at the HN260 station in Lake Superior. Panels (a), (b) and (c) represent a comparison between measured (filled circles) and modeled (solid line) temperatures for the April to October period of 2011, 2012 and 2014 respectively. The dashed line in the three panels represents the rate of warming observed in the surface water temperatures. 
Model simulations successfully predicted the timing and magnitude of summer maximum temperature in both years.

\subsubsection{Thermal characteristics during the stratified period in 2012 and 2014}

The timing of the onset of stratification, determined from sequential vertical temperature profiles recorded at HN260, varied dramatically between the two years. Stratification was well developed by June $26^{\text {th }}, 2012$ (filled arrow, Figure 4.8b), while conditions remained isothermal $\left(\sim 2.3^{\circ} \mathrm{C}\right)$ on that date in 2014 (Figure 4.8c). In 2014, the system was stratified by July $24^{\text {th }}, 4$ weeks later than in 2012 (filled arrow, Figure 4.8c). In 2012, the thermocline was positioned at $9 \mathrm{~m}$ on July $31^{\text {st }}$, deepening to $32 \mathrm{~m}$ by September $25^{\text {th }}$ (dashed lines, Figure $4.8 b$ ). The thermocline was slightly shallower in the short stratified period of 2014 , located at a depth of $5 \mathrm{~m}$ and $28 \mathrm{~m}$ on July $31^{\text {st }}$ and September $26^{\text {th }}$, respectively (dashed lines, Figure $4.8 \mathrm{c}$ ). The water column remained strongly stratified until the end of the field monitoring season (open arrow, Figures $4.8 \mathrm{~b}$ and c) in both 2012 (October 19 (1) $^{\text {}}$ ) and 2014 (September 26 ${ }^{\text {th }}$ ). Stratification extended over a longer period in 2012 (>136 days) than in 2014 ( 64 days). The model serves well in predicting the impact of differing meteorological forcing conditions on the rate of warming (no effect), the onset of stratification (4 weeks earlier in 2012), the position of the thermocline (deeper in 2012), and the duration of stratification (>8 weeks longer in 2012).

\subsection{Mixing and the thermal regime in an ecological context}

It is well known that the thermal regime of lakes plays an important role in mediating ecological processes. It has been demonstrated here that variability in the thermal regime may be expected to accompany climate anomalies and long-term changes in meteorological conditions. While the potential effects of changes in the 
thermal regime are manifold, consideration here is limited to seasonality in vertical mixing as it may impact nutrient transport and redistribution in the water column. Two processes relating to phosphorus and vertical mixing provide the desired context. First of these is the potential for zooplankton excretion to meet the daily phosphorus demand of phytoplankton in the poorly-mixed waters that host the deep chlorophyll layer during summer stratification (Oliver et al. 2014). The simple presence of that layer as well as the opportunity for phosphorus concentrations to become elevated requires an interval of low vertical mixing. Second is the dispersal of the contents of the benthic nepheloid layer, enriched with particles having an elevated phosphorus content, into the larger volume of overlying water as the thermocline erodes in fall (Urban et al. 2004). Here, a high degree of mixing is required to redistribute nutrients lost to deeper water during thermal stratification. These two processes, one favored by low rates of mixing, the other by high rates, provide the ecological context for consideration of seasonality in vertical mixing and its variability across the spectrum of thermal regime characteristics represented by the climate anomalies examined here.

In UFILS4, vertical mixing is characterized by the coefficient $\mathbf{E}\left(\mathrm{m}^{2} \cdot \mathrm{d}^{-1}\right)$, values of which are generated as a time series of model output (introduced briefly by Gawde et al. pending submission). At HN260, the minimum mixing coefficient (i.e. that limiting vertical transport) is calculated over the water column (segmented in discrete 1-m layers) for every day of the April to October interval of 2011 (Gawde et al. pending submission), 2012 and 2014. Weekly (seven-day) averages of these daily (vertically) minimum values are plotted against time to reflect seasonality in mixing characteristics for the three years. A general trend of higher rates of mixing in spring and fall separated by a period of reduced mixing in mid-summer is observed for all years (Figure 4.9). 


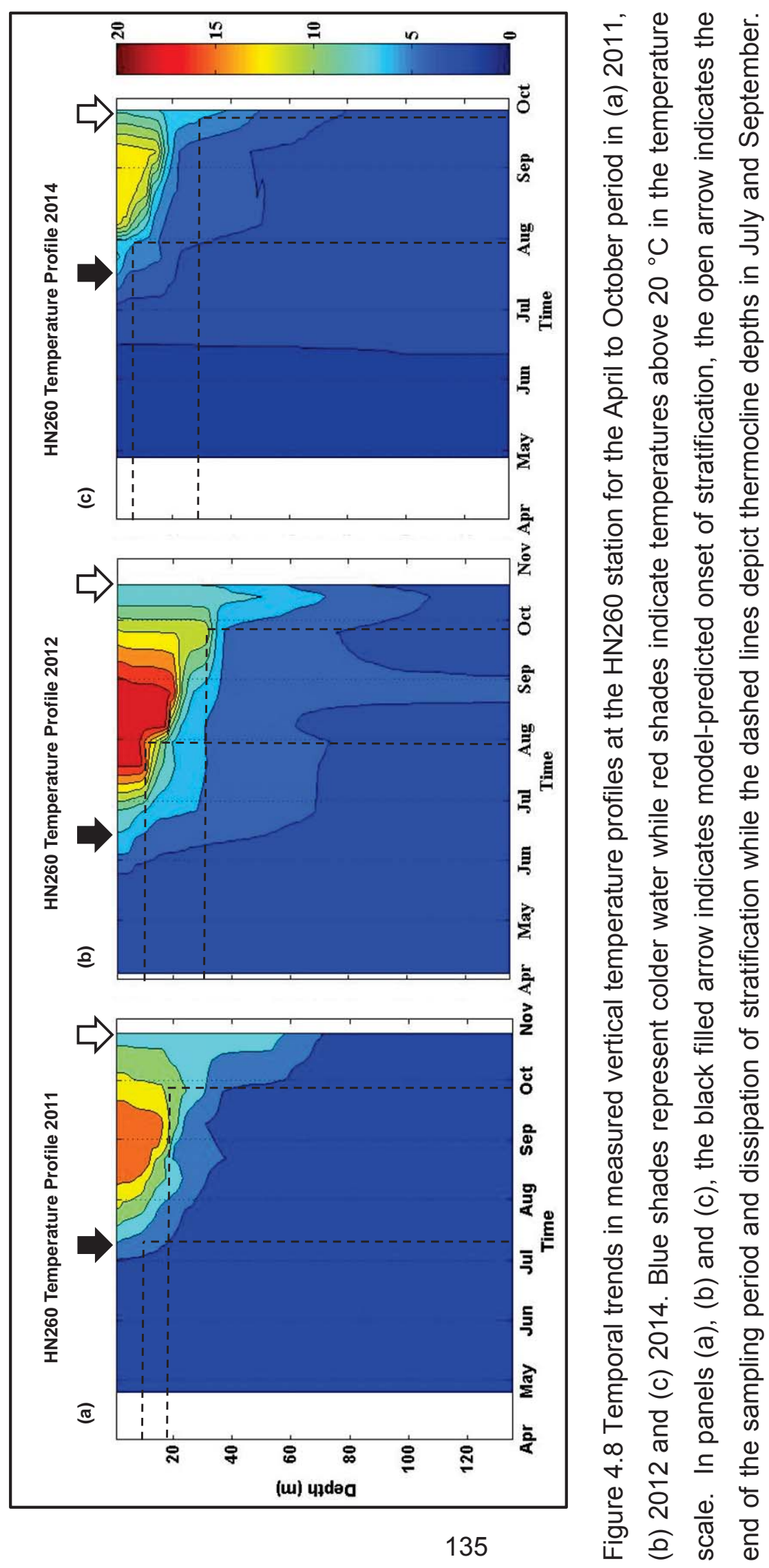


However, extensive inter-annual variability can be observed in the timing and duration of each set of mixing conditions (Figure 4.9).

Spring - strong mixing, characteristic of the spring season, was observed for a period of 2 months (from the end of April through June) in the average year (2011, Figure 4.9a). For the two anomalous years, there was a shift in the timing of the spring mixing interval. In 2012, high mixing rates developed early in April ( 3 weeks earlier than in 2011) and continued until the middle of June (Figure 4.9b). In the cold year, the onset of spring mixing was delayed by $\sim 3$ weeks (with respect to the timing in 2011 , Figure 4.9c), developing in mid-May of 2014 and extending until the middle of July. While the onset and duration of the spring mixing interval was staggered in the three years, no significant inter-annual variation in its duration (approximately two months, Figures 4.9a, b and c) was noted.

During this spring mixing period, heat and nutrients are distributed uniformly throughout the water column. This period follows the dissipation of the (relatively weak) winter thermal stratification observed in this dimictic system. The high mixing rates during this interval have the potential to introduce and re-distribute nutrients accumulating in the hypolimnion during winter stratification. Early development of the spring mixing period in 2012, therefore, accelerates warming (Figure 4.8b) and the potential for nutrient enrichment of the upper water column as compared to conditions prevailing in the average year. In contrast, the water column at HN260 is slow to warm in 2014 (Figure 4.8c) and persisting winter conditions delay spring mixing and nutrient resupply.

Summer - the spring season is followed by a period of reduced rates of vertical mixing during summer. In the average year, limnological summer starts in early July and extends over a period of 12 weeks until the end of September (when the rate of mixing 
starts to increase), with the lowest rate of mixing (most stable stratification) occurring in early August (Figure 4.9a). In the warm year, the water column at HN260 transitions to reduced rates of mixing relatively early (mid-June, Figure 4.9b) and the summer period extends until the end of September, resulting in a lengthier duration ( 14 weeks) compared to 2011. In contrast, the summer period in 2014 extended for a very short duration ( 6 weeks, Figure $4.9 \mathrm{c})$, starting late towards the end of July and dissipating early towards the end of September. Therefore, while lower mixing rates associated with the summer period were manifested in 2011, 2012 and 2014, a significant variation was observed in both the timing and duration of this interval (Figures 4.9a, b and c).

The summer, thermally-stratified period is characterized by limited vertical transfer of heat and nutrients in the water column. The reduced intensity of mixing inhibits transfer of matter across the metalimnion by diffusion and thus nutrients lost from the epilimnion through settling cannot be fully replenished from sources deeper in the water column. As the summer period progresses, the epilimnion becomes increasingly nutrient depleted, potentially impacting the rate and magnitude of primary production (the summer desert; see Dijkstra and Auer, pending submission). In 2012, the early onset and longer duration of the summer mixing period would translate to a longer period of severe nutrient depletion (an extended summer desert) as compared to the average year. On the other hand, the cold year, marked by the delayed development and shorter length of summer mixing conditions, would result in a shorter summer desert period with a lesser degree of nutrient limitation.

Fall - the vertical mixing rate increases gradually towards the end of the summer and remains high over the fall interval. The entire duration of the fall mixing period was not included in the simulation period (sampling constraints) and, therefore, inter-annual variability was evaluated based on the timing (onset) of this interval. In 2012, fall mixing 


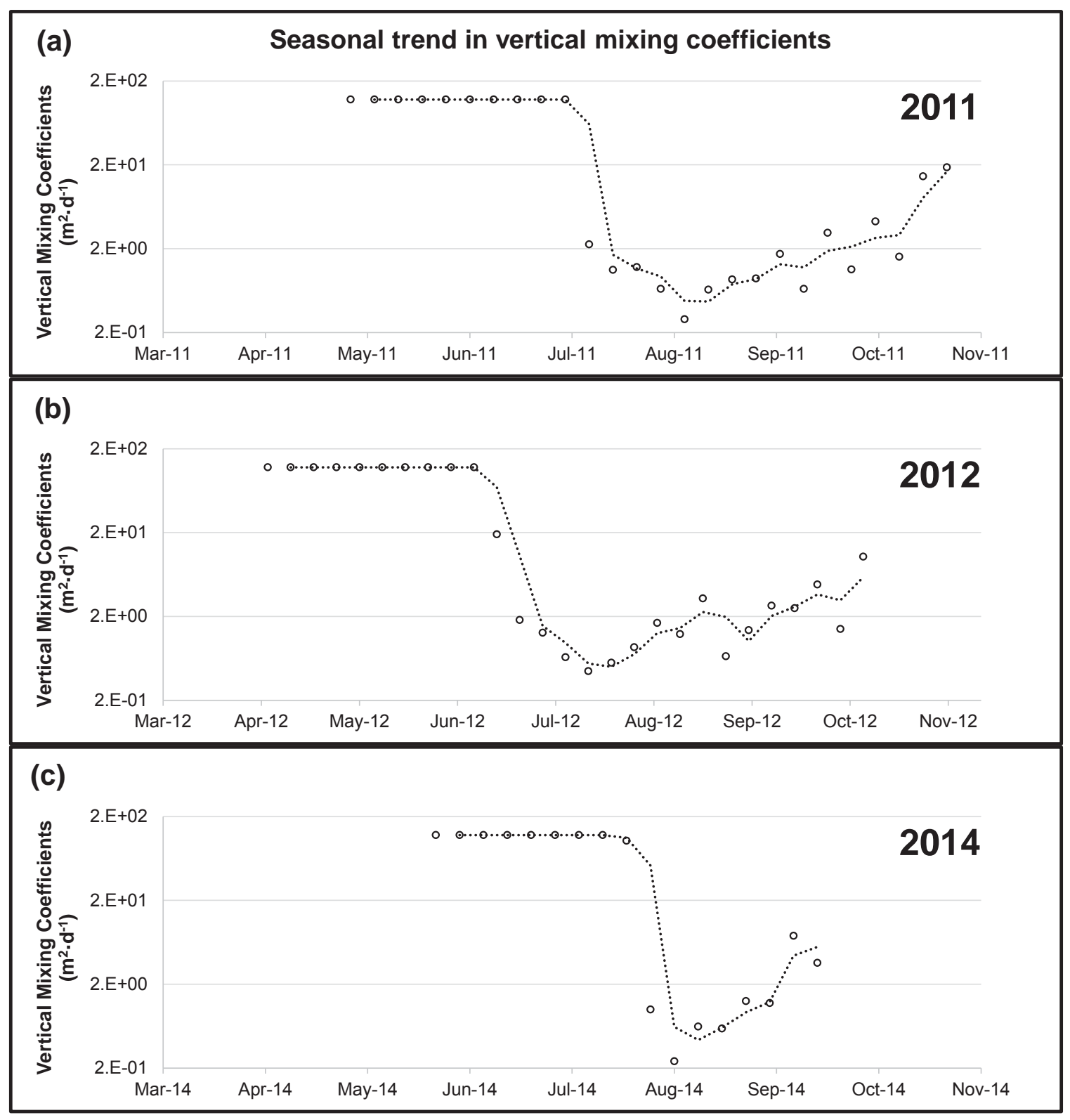

Figure 4.9 Seasonal trend in vertical mixing coefficients $\left(\mathrm{m}^{2} \cdot \mathrm{d}^{-1}\right)$ at the HN260 station in Lake Superior for (a) 2011, (b) 2012 and (c) 2014. The open circles represent the sevenday averaged values of daily minimum vertical mixing coefficients and the dotted line represents a two-period (two-week) moving average trendline. 
characteristics developed in early October (Figure 4.9b) coinciding with the timing for the average year (beginning of October 2011, Figure 4.9a). In 2014, there was a shift in the timing of this period as enhanced mixing associated with fall developed early in the middle of September (Figure 4.9c), perhaps because thermal stratification was not as well developed in this cold year.

The fall interval, characterized by improved vertical transfer of heat and nutrients, corresponds to the period of dissipation of thermal stratification. Vertical temperature profiles in this interval are marked by deepening of the thermocline due to enhanced mixing in the water column. This period also allows for increased transfer across the weakening thermal gradient in the metalimnion and supports the enrichment of the now nutrient-limited epilimnion. In 2011 and 2012, the weakly stratified water column approaches isothermal conditions (Figures 4.8a and b) and homogeneity in nutrient distribution following the onset of fall mixing characteristics in early October. In 2014, however, the earlier onset of fall mixing in September would support an earlier transition to vertically uniform temperature (Figure 4.8c) and nutrient conditions in the water column as the fall period progresses.

\subsection{Conclusions}

Impacts of the two 'bookend' years, the unusually warm 2012 season (the Big Heat) and the extreme cold of 2014 (the Big Chill), on the thermal regime of Lake Superior were observed and characterized based on temperature measurements and application of a one-dimensional hydrodynamic model, UFILS4, offering insights regarding the potential response of the lake's ecosystem to long-term climate change.

The response of the thermal regime to the two climatic anomalies was more subdued in the shallow nearshore but with both the measurements and model 
predictions supporting a warmer trend in surface water temperatures in 2012 as compared to 2014. In the offshore, the higher heat flux resulting from the 2012 climatic anomaly was manifested through higher basin-wide surface temperatures, earlier onset of stratification, a longer period of stratification and a deeper thermocline. During the short summer of 2014, the response of Lake Superior's thermal regime yielded reduced basin-wide surface temperatures, a delayed onset of stratification, a shorter stratified season and shallower thermoclines.

In the offshore, seasonal and inter-annual variability in the timing and duration of spring, summer and fall mixing characteristics, resulting from the impacts of the two divergent meteorological forcing conditions, have also been analyzed and compared to those determined for an average year (2011). The warm season of 2012 was characterized by an early onset of spring mixing conditions (high rates), a longer duration of summer conditions (lower rates) and a similar duration of fall mixing, when compared to the temporal pattern evident in 2011 . The cold year of 2014 , on the other hand, experienced a delayed development of the spring period, a short interval of reduced mixing in summer and an early onset of fall mixing characteristics in comparison to the seasonality noted in 2011 .

The understanding derived from this inter-annual variability in mixing characteristics and thermal regime was further applied to identify and interpret the potential impact of these two climatic 'bookend' years on nutrient dynamics in the offshore. Seasonal patterns of temperature and mixing in 2012 supported a longer period of limited vertical mass transfer, potentially enhancing the accumulation of nutrients in the poorly-mixed metalimnion and resulting in an extended nutrient desert in the epilimnion. This information, together with the early onset of stratification (and spring mixing conditions), suggests a potential shift in the timing and magnitude of primary 
production in 2012. The short duration of the stratified period and lower rates of summer mixing in 2014 offers a brief interval of temperature and nutrient conditions suitable for supporting primary production in the epilimnion. This would imply that the epilimnetic layer would be subjected to a lesser degree of nutrient depletion in the cold year of 2014. The one-dimensional UFILS4 model, therefore, offers guidance on identifying and evaluating the impacts of the two climatic anomalies on the thermal and ecosystem dynamics in the offshore region of the lake.

\subsection{References}

Angel, J. R., and Kunkel, K. E. (2010). "The response of Great Lakes water levels to future climate scenarios with an emphasis on Lake Michigan-Huron." Journal of Great Lakes Research, 36, 51-58.

Auer, N. A., and Kahn, J. E. (2004). "Abundance and distribution of benthic invertebrates, with emphasis on Diporeia, along the Keweenaw Peninsula, Lake Superior." Journal of Great Lakes Research, 30, 340-359.

Austin, J. A., and Colman, S. M. (2007). "Lake Superior summer water temperatures are increasing more rapidly than regional air temperatures: A positive ice-albedo feedback." Geophysical Research Letters, 34(6), L06604.

Austin, J., and Colman, S. (2008). "A century of temperature variability in Lake Superior." Limnology and Oceanography, 2724-2730.

Beletsky, D., and Schwab, D. J. (2001). "Modeling circulation and thermal structure in Lake Michigan: Annual cycle and interannual variability." Journal of Geophysical Research, 106(C9), 19-745. 
Bennington, V., McKinley, G. A., Kimura, N., and Wu, C. H. (2010). "General circulation of Lake Superior: Mean, variability, and trends from 1979 to 2006." Journal of Geophysical Research, 115, C12015.

Blumberg, A. F., and Di Toro, D. M. (1990). "Effects of climate warming on dissolved oxygen concentrations in Lake Erie." Transactions of the American Fisheries Society, 119(2), 210-223.

Clites, A. H., Wang, J., Campbell, K. B., Gronewold, A. D., Assel, R. A., Bai, X., and Leshkevich, G. A. (2014). "Cold water and high ice cover on Great Lakes in spring 2014." Eos, Transactions American Geophysical Union, 95(34), 305-306.

Dijkstra, M.L., and Auer, M.T. "Spatio-temporal dynamics in environmental forcing conditions, standing crop and primary production of Lake Superior." Pending submission.

Dobiesz, N. E., and Lester, N. P. (2009). "Changes in mid-summer water temperature and clarity across the Great Lakes between 1968 and 2002." Journal of Great Lakes Research, 35(3), 371-384.

Dole, R., Hoerling, M., Kumar, A., Eischeid, J., Perlwitz, J., Quan, X.-W., Kiladis, G., Webb, R., Murray, D., Chen, M., and others. (2014). "The making of an extreme event: putting the pieces together." Bulletin of the American Meteorological Society, 95(3), 427-440.

Environmental Laboratory. (1982). CE-QUAL-R1: A Numerical One-Dimensional Model of Reservoir Water Quality: User's Manual. Instruction Report, US Army Engineer Waterways Experiment Station, Vicksburg, MS.

Gawde, R.G., Owens, E.M., and Auer, M.T. "Introducing a mechanistic, one-dimensional n-layer hydrodynamic model with application to Lake Superior." Pending submission. 
Hansen, J., Sato, M., Ruedy, R., Lo, K., Lea, D. W., and Medina-Elizade, M. (2006). "Global temperature change." Proceedings of the National Academy of Sciences, 103(39), 14288-14293.

Hill, D. K., and Magnuson, J. J. (1990). "Potential effects of global climate warming on the growth and prey consumption of Great Lakes fish." Transactions of the American Fisheries Society, 119(2), 265-275.

Huang, A., Rao, Y. R., and Lu, Y. (2010). "Evaluation of a 3-D hydrodynamic model and atmospheric forecast forcing using observations in Lake Ontario." Journal of Geophysical Research, 115(C2), C02004.

IPCC, 2007: Climate Change 2007: Synthesis Report. Contribution of Working Groups I, II and III to the Fourth Assessment Report of the Intergovernmental Panel on Climate Change. [Core Writing Team, Pachauri, R.K and Reisinger, A. (eds.)]. IPCC, Geneva, Switzerland, 104 p.

Lam, D. C. L., and Schertzer, W. M. (1987). "Lake Erie thermocline model results: comparison with 1967-1982 data and relation to anoxic occurrences." Journal of Great Lakes Research, 13(4), 757-769.

Lehman, J. T. (2002). "Mixing patterns and plankton biomass of the St. Lawrence Great Lakes under climate change scenarios." Journal of Great Lakes Research, 28(4), 583-596.

Lenters, J. D. (2001). "Long-term trends in the seasonal cycle of Great Lakes water levels." Journal of Great Lakes Research, 27(3), 342-353.

Leon, L. F., Smith, R. E. ., Hipsey, M. R., Bocaniov, S. A., Higgins, S. N., Hecky, R. E., Antenucci, J. P., Imberger, J. A., and Guildford, S. J. (2011). "Application of a 3D hydrodynamic-biological model for seasonal and spatial dynamics of water quality and phytoplankton in Lake Erie." Journal of Great Lakes Research. 
Leon, L. F., Smith, R. E. H., Malkin, S. Y., Depew, D., Hipsey, M. R., Antenucci, J. P., Higgins, S. N., Hecky, R. E., and Rao, R. Y. (2012). "Nested 3D modeling of the spatial dynamics of nutrients and phytoplankton in a Lake Ontario nearshore zone." Journal of Great Lakes Research, 38, Supplement 4, 171-183.

Lofgren, B. M., Quinn, F. H., Clites, A. H., Assel, R. A., Eberhardt, A. J., and Luukkonen, C. L. (2002). "Evaluation of potential impacts on Great Lakes water resources based on climate scenarios of two GCMs." Journal of Great Lakes Research, 28(4), $537-554$.

McCormick, M. J. (1990). "Potential changes in thermal structure and cycle of Lake Michigan due to global warming." Transactions of the American Fisheries Society, 119(2), 183-194.

McCormick, M. J., and Fahnenstiel, G. L. (1999). "Recent climatic trends in nearshore water temperatures in the St. Lawrence Great Lakes." Limnology and Oceanography, 44(3), 530-540.

Melillo, Jerry M., Terese (T.C.) Richmond, and Gary W. Yohe, Eds., 2014: Climate Change Impacts in the United States: The Third National Climate Assessment. U.S. Global Change Research Program, 841 pp. doi:10.7930/J0Z31WJ2.

Mesinger, F., DiMego, G., Kalnay, E., Mitchell, K., Shafran, P. C., Ebisuzaki, W., Jović, D., Woollen, J., Rogers, E., and Berbery, E. H., others. (2006). "North American regional reanalysis." Bulletin of the American Meteorological Society, 87(3).

Midwestern Regional Climate Center. (March 2014). Great Lakes Region: Quarterly Climate Impacts and Outlook. Retrieved from http://mrcc.isws.illinois.edu/pubs/docs/GL-201403Winter FINAL.pdf.

O’Donnell, S. M., O’Donnell, D. M., Owens, E. M., Effler, S. W., Prestigiacomo, A., and Baker, D. M. (2010). "Variations in the stratification regime of Onondaga Lake: 
patterns, modeling, and implications." Fundamental and Applied Limnology/Archiv für Hydrobiologie, 176(1), 11-27.

Oliver, S. K., Branstrator, D. K., Hrabik, T. R., Guildford, S. J., Hecky, R. E., and Smith, R. (2014). "Nutrient excretion by crustacean zooplankton in the deep chlorophyll layer of Lake Superior." Canadian Journal of Fisheries and Aquatic Sciences, 72(3), 390-399.

O'Reilly, C. M., Alin, S. R., Plisnier, P. D., Cohen, A. S., McKee, B. A., and others. (2003). "Climate change decreases aquatic ecosystem productivity of Lake Tanganyika, Africa." Nature, 424(6950), 766-768.

Owens, E. M. (1998). "Development and testing of one-dimensional hydrothermal models of Cannonsville Reservoir." Lake and Reservoir Management, 14(2-3), 172185.

Owens, E. M., and Effler, S. W. (1989). "Changes in stratification in Onondaga Lake, New York." JAWRA Journal of the American Water Resources Association, 25(3), $587-597$.

Owens, E. M., and Effler, S. W. (1996). "Modeling the impacts of a proposed hypolimnetic wastewater discharge on stratification and mixing in Onondaga Lake." Lake and Reservoir Management, 12(1), 195-206.

Robertson, D. M., and Ragotzkie, R. A. (1990). "Changes in the thermal structure of moderate to large sized lakes in response to changes in air temperature." Aquatic Sciences, 52(4), 360-380.

Smith, J. B. (1991). "The potential impacts of climate change on the Great Lakes." Bulletin of the American Meteorological Society, 72(1), 21-28. 
Stefan, H. G., Fang, X., and Hondzo, M. (1998). "Simulated climate change effects on year-round water temperatures in temperate zone lakes." Climatic Change, 40(3-4), $547-576$.

Trumpickas, J., Shuter, B. J., and Minns, C. K. (2009). "Forecasting impacts of climate change on Great Lakes surface water temperatures." Journal of Great Lakes Research, 35(3), 454-463.

Urban, N. R., Jeong, J., and Chai, Y. (2004). "The Benthic Nepheloid Layer (BNL) north of the Keweenaw Peninsula in Lake Superior: composition, dynamics, and role in sediment transport." Journal of Great Lakes Research, Exploring Superior, 30, Supplement 1, 133-146.

Verburg, P., Hecky, R. E., and Kling, H. (2003). "Ecological consequences of a century of warming in Lake Tanganyika." Science, 301(5632), 505-507.

Wang, J., Bai, X., Hu, H., Clites, A., Colton, M., and Lofgren, B. (2012). "Temporal and spatial variability of Great Lakes ice cover, 1973-2010**." Journal of Climate, 25(4), $1318-1329$.

White, B., Austin, J., and Matsumoto, K. (2012). "A three-dimensional model of Lake Superior with ice and biogeochemistry." Journal of Great Lakes Research, 38, 6171.

Yu, S. L., and Brutsaert, W. (1968). "Estimation of near-surface water temperatures of Lake Ontario." Proceedings of the Eleventh Conference on Great Lakes Research, $12-523$.

Zhao, J., Rao, Y. R., and Wassenaar, L. I. (2012). "Numerical modeling of hydrodynamics and tracer dispersion during ice-free period in Lake Winnipeg." Journal of Great Lakes Research, 38, Supplement 3(0), 147-157. 


\section{Chapter 5}

Summary and future work 
This chapter is divided in two sections, the first provides a summary of this dissertation and discusses contributions made to the field of science while the second describes recommendations for future research.

\subsection{Summary}

This dissertation focuses on applying hydrodynamic models of varying spatial sophistication to evaluate the response of the thermal regime of Lake Superior to environmental forcing conditions. Two models, a three-dimensional system, Environmental Fluid Dynamics Code (EFDC) and a one-dimensional framework, UFILS4, were adopted for this doctoral research.

Chapter 2 of this dissertation introduced an ecologically-meaningful criterion to evaluate model performance of hydrodynamic components integrated in coupled physical-biological frameworks from an application (ecosystem) perspective. The threedimensional EFDC model was calibrated and confirmed for the western basin of Lake Superior for 2011 and 2012 using a multi-criteria approach, including a quantitative approach, qualitative evaluation of the characteristics of the lake's thermal regime and the ecologically-meaningful criterion. This work, therefore, offers guidance to other modelers seeking a goodness-of-fit metric that translates the error in hydrodynamic model output to a corresponding uncertainty in ecosystem dynamics.

Chapter 3 of this dissertation describes the calibration, confirmation and application of a mechanistic, vertically segmented one-dimensional hydrodynamic model, UFILS4, to the nearshore and offshore regions of Lake Superior. The simple, computationally-efficient UFILS4 model provides a means of overcoming the impenetrable, resource intensive nature of complex three-dimensional hydrodynamic 
frameworks while retaining a comparable predictive capability in simulating the thermal response (and mixing characteristics) of the lake. Applied in conjunction with a onedimensional ecological framework, UFILS4 can find greater utility in the field of waterquality modeling to support the testing and parameterization of complex threedimensional kinetic models.

Chapter 4 of this dissertation examines the response of the thermal regime of Lake Superior to two climatic anomalies: the warm 2012 season and the cold 2014 season through analysis of temperature measurements and model simulations conducted in the nearshore and offshore regions of the lake. This detailed investigation and characterization of the thermal regime for the climatic 'bookend' years seeks to offer insights regarding the potential impact of long-term climate change on temperature and nutrient dynamics in the lake.

\subsection{Future work}

While this dissertation has described the utility and application of onedimensional and three-dimensional hydrodynamic models in simulating the thermal characteristics of Lake Superior, many more opportunities remain to advance the field of water-quality modeling and enhance our understanding of ecosystem dynamics.

In recent years, many hydrodynamic models have been applied in the Great Lakes region to study the response of the lake ecosystem to long-term meteorological forcings. The calibrated and confirmed EFDC framework established for Lake Superior in this study is one of these widely applied, open-source, public domain threedimensional models. Here, future research could conduct a comparison of the EFDC model with a second three-dimensional hydrodynamic framework (such as Finite Volume 
Coastal Ocean Model [FVCOM]) to evaluate their predictive capability in reproducing the spatial and temporal variability in physical characteristics of Lake Superior.

It would also be interesting to simulate the 500-year flood event that occurred in Lake Superior during June of 2012. Runoff from this storm discharged massive sediment and phosphorus loads to the nearshore regions of the lake. This extreme wet weather event provides a unique opportunity for testing the impact of environmental perturbation on Lake Superior. A coupled three-dimensional hydrodynamic-water quality modeling framework can be applied to quantify the delivery of phosphorus (limiting nutrient) to the environmentally sensitive regions of Lake Superior and to simulate the impact of the storm on food web dynamics. Here, the parameterization and testing of this three-dimensional water-quality model would be guided by means of a test-bed approach introduced by McDonald et al. (2012) using a one-dimensional coupled hydrodynamic - ecological modeling framework, where the UFILS4 model represents the physical component of this tool.

\subsection{References}

McDonald, C. P., Bennington, V., Urban, N. R., and McKinley, G. A. (2012). "1-D testbed calibration of a 3-D Lake Superior biogeochemical model." Ecological Modelling, 225, 115-126. 


\section{Appendix: Copyright Permission Documentation}

\section{Permission for Figures 2.2, 3.1 and 4.4}

Figures 2.2, 3.1 and 4.4 included in Chapters 2, 3 and 4 of this dissertation respectively, have been generated using the Google Earth ${ }^{\mathrm{TM}}$ tool. These three figures have the correct attribution text (automatically generated or customized) as specified by the following website: http://www.google.com/permissions/geoguidelines/attr-guide.html and the title below each screenshot includes the tagline "ऽ 2015 Google Inc, used with permission. Google and the Google logo are registered trademarks of Google Inc." as described in the following website: http://www.google.com/permissions/trademark/ourtrademarks.html. The relevant documentation for permissions from Google Earth ${ }^{\mathrm{TM}}$ and the two data providers, NOAA and Landsat, has been included below.

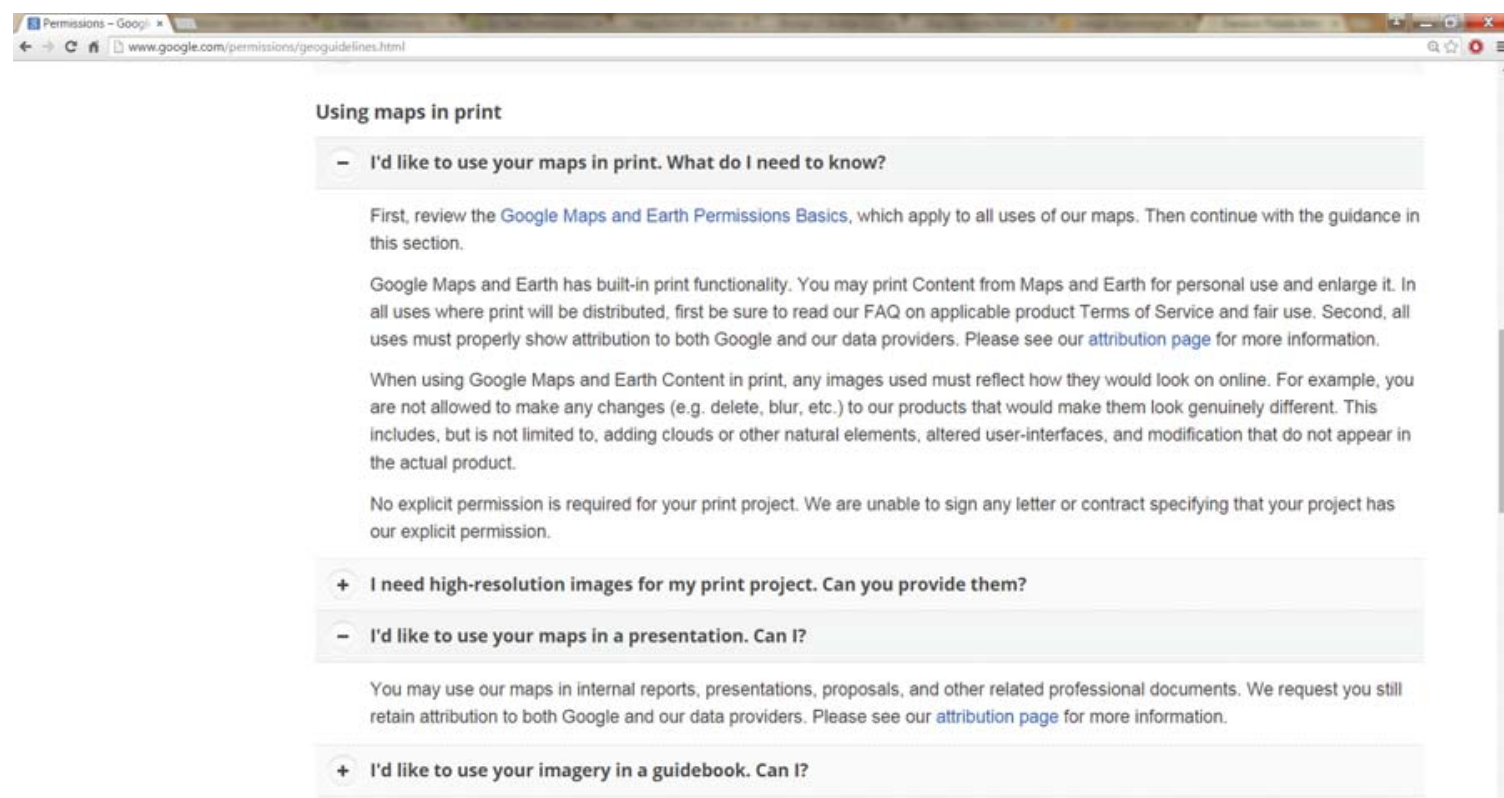




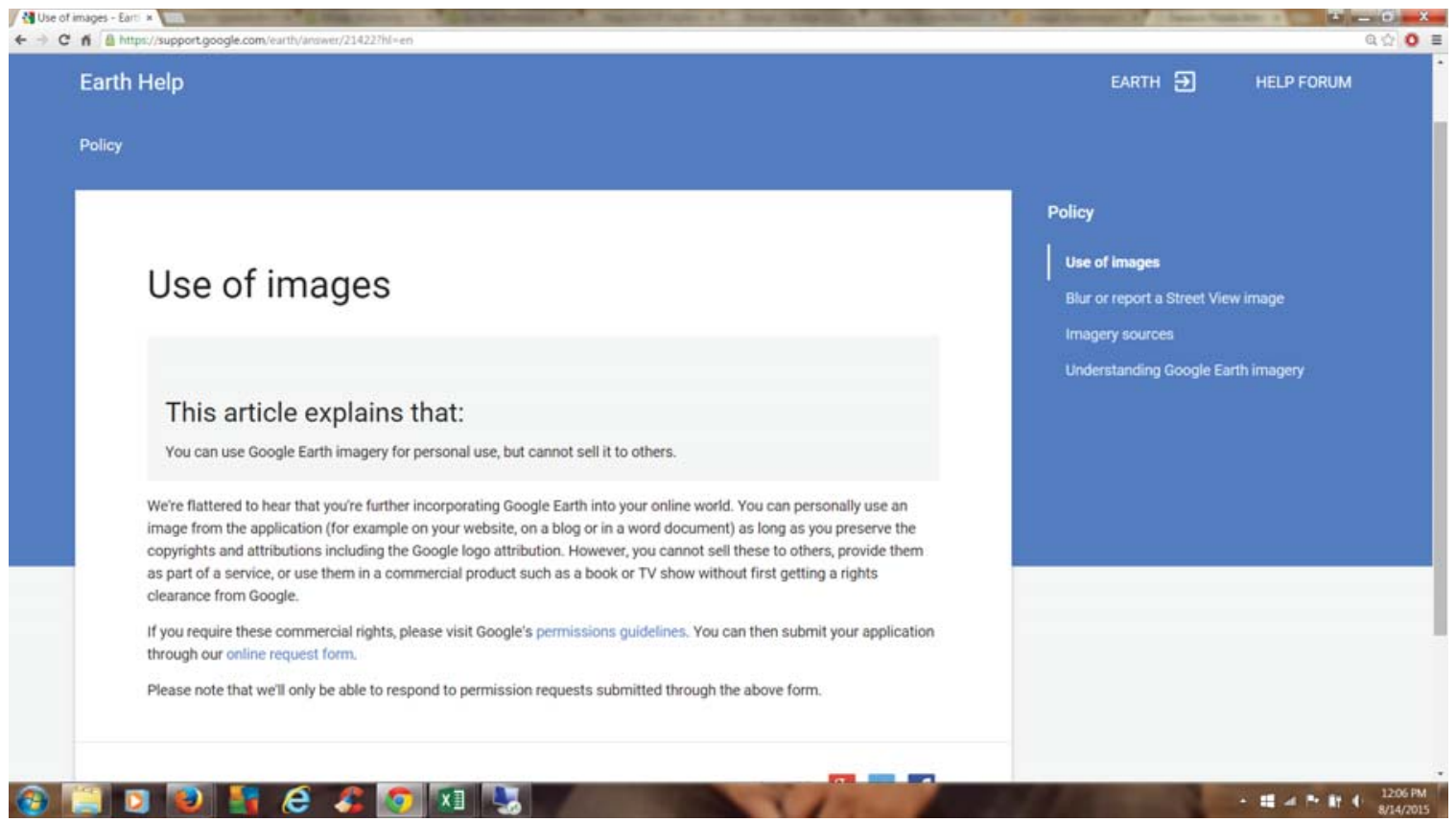

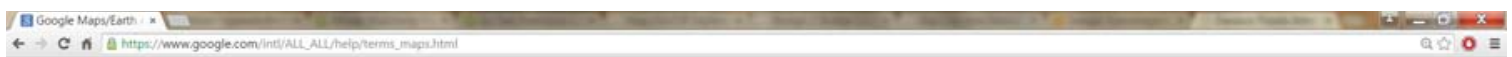

Google

Google Maps

Google Maps/Earth Additional Terms of Service

Help Center

Last Modified: March 1, 2012

Geo Permissions

By downloading, installing, or using the Google Earth software, accessing or using the Google Maps service (together, the "Products" or "Services"), or accessing or using any of the content available within the Products, you agree to be bound by the following: (1) the Google Terms of Service (the "Universal Terms"); (2) the terms found on our Legal Notices page (the "Legal Notices"); and (3) the additional terms

Terms of Service and conditions set forth below (the "Additional Terms"). Before you continue, you should read each of these three documents, as together

Legal Notices they form a binding agreement between you and Google regarding your use of the Products. Collectively, the Universal Terms, the Legal Notices, and the Additional Terms are referred to as the "Terms"

Photos and Videos Policy

As a condition of downloading, accessing, or using the Products, you also agree to the terms of the Google Privacy Policy.

1. Use of the Products. Google grants you a non-exclusive, non-transferable license to access the Google Maps service, to download and use the Google Earth software and service, and to access the Content (as defined below) within the Products and according to the Terms.

Legal Notices for Business Listings

2. Restrictions on Use. Unless you have received prior written authorization from Google (or, as applicable, from the provider of particular Content), you must not: (a) copy, translate, modify, or make derivative works of the Content or any part thereof; (b) redistribute, sublicense, rent, publish, sell, assign, lease, market, transfer, or otherwise make the Products or Content available to third parties; (c) reverse engineer, decompile or othenwise attempt to extract the source code of the Service or any part thereof, unless this is expressly permitted or required by applicable law, (d) use the Products in a manner that gives you or any other person access to mass downloads or bulk feeds of any Content, including but not limited to numerical latitude or longitude coordinates, imagery, and visible map data; (e) delete, obscure, or in any manner alter any warning or link that appears in the Products or the Content, or (f) use the Service or Content with any products, systems, or applications for or in connection with (i) real time navigation or route guidance, including but not limited to turn-by-turn route guidance that is 
applications for or in connection with (i) real time navigation or route guidance, including but not limited to turn-by-turn route guidance that is synchronized to the position of a user's sensor-enabled device; or (ii) any systems or functions for automatic or autonomous control of vehicle behavior; $(g)$ use the Products to create a database of places or other local listings information.

3. Appropriate Conduct; Compliance with Law and Google Policies. You agree that you are responsible for your own conduct and content while using the Products, and for any consequences thereof. You agree to use the Products only for purposes that are proper and in accordance with the Terms and any applicable policies or guidelines Google may make available. By way of example, and not as a limitation, you agree that when using the Products or the Content, you will not: (a) defame, abuse, harass, stalk, threaten or otherwise violate the legal rights (such as rights of privacy and publicity) of others; (b) upload, post, email, transmit or otherwise make available any inappropriate, defamatory, obscene, or unlawful content: (c) upload, post, transmit or otherwise make available any content that infringes any patent, trademark, copyright, trade secret or other proprietary right of any party, unless you are the owner of the rights, or have the permission of the owner or other legal justification to use such content; (d) upload, post, email, transmit or otherwise make available messages that promote pyramid schemes, chain letters, or disruptive commercial messages or advertisements; (e) upload, post, email. transmit or otherwise make available any other content, message, or communication prohibited by applicable law, the Terms or any applicable Product policies or guidelines: (f) download any file posted by another that you know, or reasonably should know, cannot be legally distributed in such manner, $(g)$ impersonate another person or entity, or falsify or delete any author attributions or proprietary designations or labels of the origin or source of Content, software or other material; (h) restrict or inhibit any other user from using and enjoying the Products or Google services; (i) use any robot, spider, site search/retrieval application, or other device to retrieve or index any portion of the Google services or Content, or collect information about users for any unauthorized purpose: (0) submit content that falsely expresses or implies that such content is sponsored or endorsed by Google; ( $k$ create user accounts by automated means or under false or fraudulent pretenses; (l) promote or provide instructional information about illegal activities: $(\mathrm{m})$ promote physical harm or injury against any group or individual; or (n) transmit any viruses, worms, defects. Trojan horses, or any items of a destructive nature.

4. Content in the Products. Google Maps and Google Earth allow you to access and view a variety of content, including but not limited to photographic imagery, map and terrain data, business listings, reviews, traffic, and other related information provided by Google, its licensors, and its users (the "Content"). Additionally, you may choose to access other third party content made available in the Products through Google services such as Google Gadgets. You understand and agree to the following: (a) Map data, traffic, directions, and related Content are provided for planning purposes only. You may find that weather conditions, construction projects, closures, or other events may

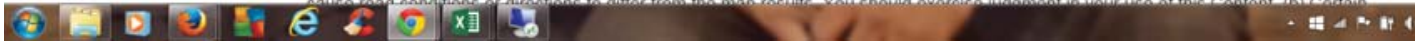
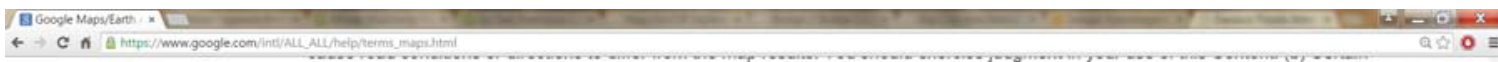

Content is provided under license from third parties, including but not limited to TomTom Global Content BV ("TomTom"), and is subject to copyright and other intellectual property rights owned by or licensed to TomTom and/or such third parties. You may be held liable for any unauthorized copying or disclosure of this Content. Your use of TomTom Content, including but not limited to printing or use in marketing or promotional materials, is subject to additional restrictions located in the Legal Notices page.

5. Additional Terms for Google Earth. The Google Earth software is subject to United States export controls. By using the Google Earth software, you agree to use the software only for purposes that are legal, proper and in accordance with these Terms. Specifically, you agree to comply with all applicable export and reexport control laws and regulations, including the Export Administration Regulations ("EAR") maintained by the U.S. Department of Commerce, and trade and economic sanctions maintained by the Treasury Department's Office of Foreign Assets Control.

6. DISCLAIMER OF WARRANTIES AND LIMITATIONS ON LIABILITY (a) GOOGLE AND ITS LICENSORS (INCLUDING BUT NOT LIMITED TO TOMTOM AND ITS SUPPLIERS) MAKE NO REPRESENTATIONS OR WARRANTIES REGARDING THE ACCURACY OR COMPLETENESS OF ANY CONTENT OR THE PRODUCTS. (b) SUBJECT TO THE "OUR WARRANTIES AND DISCLAIMERS" SECTION OF THE GOOGLE UNIVERSAL TERMS, GOOGLE AND ITS LICENSORS (INCLUDING BUT NOT LIMITED TO TOMTOM AND ITS SUPPLIERS) DISCLAIM ALL WARRANTIES IN CONNECTION WITH THE CONTENT AND THE PRODUCTS. AND WILL NOT BE LIABLE FOR ANY DAMAGE OR LOSS RESULTING FROM YOUR USE OF THE CONTENT OR THE PRODUCTS.

7. U.S. Government Restricted Rights. If the Products are being used or accessed by or on behalf of the United States government, such use is subject to additional terms located in the "Government End Users" section of our Legal Notices page.

Google - About Google : Privacy 8 Ternis 

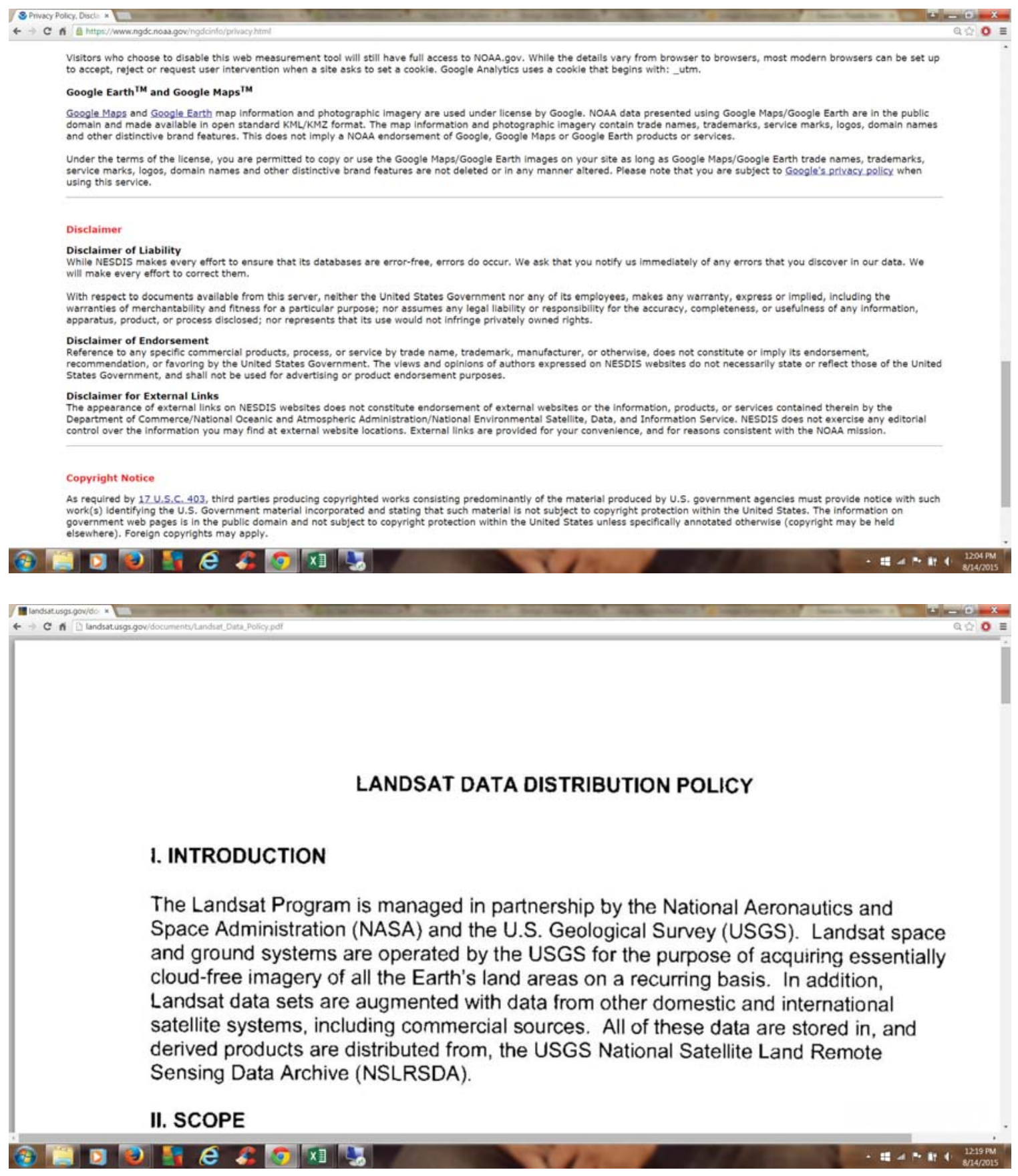


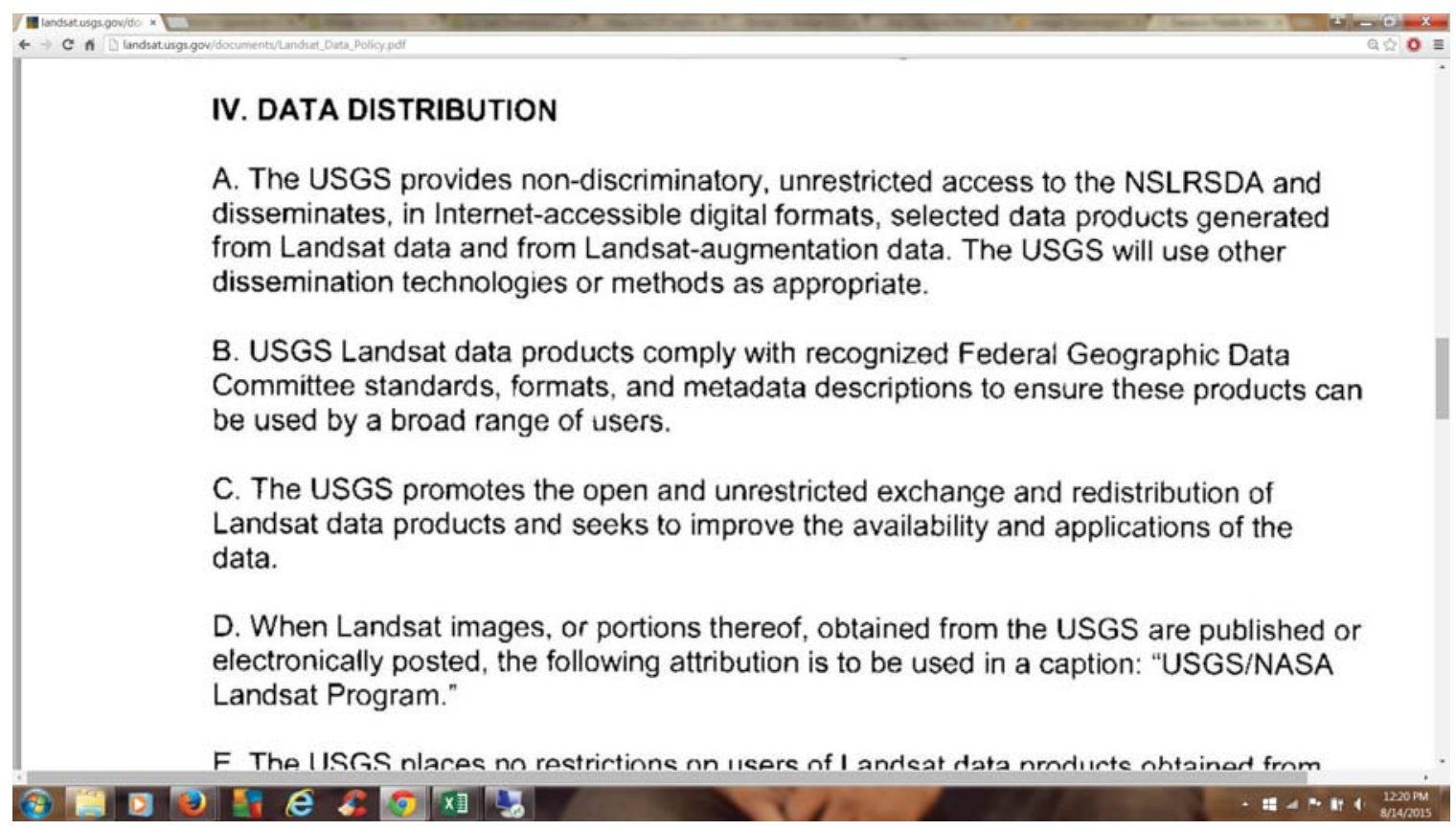

E. Ihe USGS places no restrictions on users of Landsat data products obtained from
the USGS or on users who create and sell or otherwise distribute products derived from
Landsat products originally distributed by the USGS. However, such products are not to
be licensed or placed under copyright unless the original Landsat data are digitally
merged with other data or are otherwise altered significantly.
F. The USGS, in coordination with the Department of State, establishes agreements
with foreign governments for the USGS to provide Landsat data via direct downlink or
other direct-delivery means to the international Landsat data user community. Landsat
images acquired by International Cooperators are, in return, made available to
NSLRSDA to help the Landsat Program fulfill its mission to provide global observations.
Direct-downlink or other direct-delivery arrangements can also be made with U.S.
commercial entities.
G. The USGS establishes agreements for acquiring Landsat-augmentation data from
domestic and foreign government or commercial providers for the purpose of
distributing such data to the Landsat user community from the NSLRSDA.
H. The USGS, in accordance with U.S. Government rights and obligations, reserves the
right to control, distribute, or use any Landsat data for any purpose deemed a function
of Federal, State, local, or tribal government in the United States. 


\section{Permission for Figure 4.2}

Figure 4.2 included in Chapter 4 of this dissertation has been published in the Bulletin of the American Meteorological Society journal (Volume 95, Issue 3, March 2014) by Dole et al. (2014) @ American Meteorological Society and has been used here with permission. The relevant email correspondence has been detailed below.

Dear Dr. Gawde-

My name is Jinny Nathans and I'm the Permissions Officer at AMS. Your question was referred to me. This signed message constitutes permission to use the material requested in your email below.

You may use the figure in your dissertation with the following conditions:

+ please include the complete bibliographic citation of the original source, and + please include the following statement with that citation: CAmerican Meteorological Society. Used with permission.

Thanks very much for your request and if you need any further information, please get in touch with me. My contact information is below.

Regards,

Jinny Nathans

Permissions Officer

American Meteorological Society

jnathans@ametsoc.org

$\underline{617226-3905}$

On Mon, Aug 3, 2015 at 5:35 PM, Rasika Gawde <rgawde@mtu.edu> wrote:

Department of copyright permissions:

I am writing to request permission to use an image from the "The making of an extreme event: Putting the pieces together" journal article for which I believe you hold the copyrights for. I contacted the corresponding author, Dr. Martin Hoerling, to request permission (reply attached) and he recommended contacting you to request copyright permission.

I would like to include the image in the left of panel (a) of Figure 4 (surface temperature anomaly from 12-23 March, 2012) published in Volume 95, Issue 3 (March 2014) of the Bulletin of the American Meteorological Society (http://journals.ametsoc.org/doi/abs/10.1175/BAMS-D-12-00069.1) in my dissertation to be submitted to Graduate School at Michigan Technological University in August 2015. 
The relevant image will be applied to support an educational purpose, with a maximum of 5 copies printed and distributed. In addition, the dissertation will be submitted to ProQuest and will be available for public access.

Thank you, Rasika Gawde

"We do not inherit the Earth from our ancestors... We borrow it from our children."

- A Native American proverb

Dr. Rasika Gawde

Great Lakes Research Center

Department of Civil and Environmental Engineering

Michigan Technological University

Graduate Student Govt. - Civil \& Environmental Engg. Rep. 2013-14

Board of Directors - Friends of Van Pelt Library 2013-14

Forwarded message

From: Martin Hoerling <martin.hoerling@noaa.gov>

Date: Mon, Aug 3, 2015 at 3:42 PM

Subject: Re: Requesting copyright permission

To: Rasika Gawde <rgawde@mtu.edu>

Hi Rasika

You are most welcome to use the graphic. However, I believe the proper contact for permission is the American Meteorological Society.

For more details and contact information, check:

https://www2.ametsoc.org/ams/index.cfm/publications/authors/journal-and-bamsauthors/author-resources/copyright-information/copyright-policy/

kind regards,

marty

On 8/3/15 12:22 PM, Rasika Gawde wrote:

Dr. Martin Hoerling,

I am writing to request permission to use an image from the "Meteorological March Madness 2012" report by the Earth System Research Laboratory Physical Sciences Division for which I believe you are cited as the contact person. 
I would like to include the top image (US surface temperature anomaly) listed under Figure 3 of the "Meteorology" section in the Meteorological March Madness 2012 report

(http://www.esrl.noaa.gov/psd/csi/events/2012/marchheatwave/meteorology.html) in my dissertation to be submitted to Graduate School at Michigan Technological University in August 2015.

The relevant image will be applied to support an educational purpose, with a maximum of 5 copies printed and distributed. In addition, the dissertation will be submitted to ProQuest and will be available for public access.

If you do not control the copyright, I would appreciate any information you can provide about others whom I should contact.

Thank you,

Rasika Gawde

"We do not inherit the Earth from our ancestors... We borrow it from our children."

- A Native American proverb

Rasika Gawde

Doctoral Candidate - Great Lakes Research Center

Department of Civil and Environmental Engineering

Michigan Technological University

$-$

Marty Hoerling

NOAA/ESRL Physical Sciences Division

R/E/PSD1 325 Broadway

Boulder CO 80303-3328

Martin.Hoerling@noaa.gov

ph: (303)497-6165 


\section{Permission for Figure 4.3}

Figure 4.3 included in Chapter 4 of this dissertation has been published in the March 2014 Great Lakes Quarterly Climate Impacts and Outlook report published by the Midwestern Regional Climate Center and has been used here with permission. Details of the relevant email correspondence have been described below.

\section{Good afternoon,}

You may use the graphics from the report as long as you give the following credit to these agencies. Thank you.

NOAA Northeast Regional Climate Center at Cornell University and Environment Canada

From the Great Lakes Quarterly Climate Impacts and Outlook report (March 2014)

Bryan Peake

Service Climatologist

Midwestern Regional Climate Center

Illinois State Water Survey

2204 Griffith Drive

Champaign, Illinois 61820-7495

Phone (217) 244-8226

Fax: (217) 244-0220

From: Rasika Gawde [mailto:rgawde@mtu.edu]

Sent: Tuesday, July 21, 2015 8:27 AM

To: ISWS MRCC Requests <ISWS-mrcc@mx.uillinois.edu>

Subject: Requesting copyright permission

Department of copyright permissions:

I am writing to request permission to use an image from the "Quarterly Climate Impacts and Outlook" reports for the Great Lakes Region for which I believe you hold the copyrights for.

I would like to include the image listed under the "Temperature" section in the March 2014 report (http://mrcc.isws.illinois.edu/pubs/docs/GL-201403Winter FINAL.pdf) in my 
dissertation to be submitted to Graduate School at Michigan Technological University in August 2015.

The relevant image will be applied to support an educational purpose, with a maximum of 5 copies printed and distributed. In addition, the dissertation will be submitted to ProQuest and will be available for public access.

If you do not control the copyright, I would appreciate any information you can provide about others whom I should contact.

Thank you,

Rasika Gawde

Rasika Gawde

Doctoral Candidate - Great Lakes Research Center

Department of Civil and Environmental Engineering

Michigan Technological University

\section{References}

Dole, R., Hoerling, M., Kumar, A., Eischeid, J., Perlwitz, J., Quan, X.-W., Kiladis, G., Webb, R., Murray, D., Chen, M., and others. (2014). "The making of an extreme event: putting the pieces together." Bulletin of the American Meteorological Society, 95(3), 427-440.

Midwestern Regional Climate Center. (March 2014). Great Lakes Region: Quarterly $\begin{array}{llll}\text { Climate Impacts and Outlook } & \text { Retrieved }\end{array}$ http://mrcc.isws.illinois.edu/pubs/docs/GL-201403Winter FINAL.pdf. 